\title{
Some nematodes from freshwater fishes in central Africa
}

\author{
František Moravec and Miloslav Jirků
}

\author{
Institute of Parasitology, Biology Centre of the Czech Academy of Sciences, České Budějovice, Czech Republic
}

\begin{abstract}
Twenty species (sixteen adult and four larval) of parasitic nematodes belonging to the Ascaridoidea, Camallanoidea, Cosmocercoidea, Dioctophymatoidea, Habronematoidea, Oxyuroidea, Seuratoidea, and Thelazioidea were collected from freshwater fishes of the Congo River basin in the Democratic Republic of the Congo and the Central African Republic in 2008 and 2012, respectively. Based on light and scanning electron microscopical examination, many species are redescribed in detail. This material also contained four previously unknown species, Labeonema longispiculatum sp. n. from Synodontis acanthomias Boulenger, Gendria longispiculata sp. n. from Schilbe grenfelli (Boulenger), G. sanghaensis sp. n. from Schilbe marmoratus Boulenger, and Cucullanus congolensis sp. n. from Auchenoglanis occidentalis (Valenciennes). The new species L. longispiculatum is mainly characterised by conspicuously long $(210-228 \mu \mathrm{m})$ spicules, approximately twice as long as those in other congeners, the length $(45-48 \mu \mathrm{m})$ of the gubernaculum and the host family (Mochokidae), whereas G. longispiculata by very long $(1.2 \mathrm{~mm}$ ) spicules, the shape of the oesophagus and cephalic vesicle, distribution of postanal papillae and the host family (Schilbeidae). Main characteristic features of G. sanghaensis are the presence of a hexagonal oral aperture surrounded by lip-like structures, the posterior portion of the oesophagus moderately expanded, spicules and the gubernaculum 414-438 $\mu \mathrm{m}$ and 54-57 $\mu \mathrm{m}$ long, respectively, deirids located at the level of the posterior end of the oesophagus and the absence of cervical alae. Cucullanus congolensis differs from congeneric species parasitising African freshwater and brackish-water fishes mainly in the absence of a ventral precloacal sucker and lateral preanal papillae, the presence of a large median precloacal papilla-like formation, spicules 480-489 $\mu \mathrm{m}$ long and the location of the excretory pore in the region of the oesophago-intestinal junction. Chabaudus Inglis et Ogden, 1965 is considered a junior synonym of Gendria Baylis, 1930 and, consequently, species listed in the former genus are transferred to the latter as G. alaini (Alfonso-Roque, 1981) comb. n., G. chabaudi (Inglis et Ogden, 1965) comb. n., G. dehradunensis (Rizvi, Bursey et Maity, 2016) comb. n., G. thysi (Puylaert, 1970) comb. n. and G. williamsi (Puylaert, 1970) comb. $\mathrm{n}$. The findings represent many new host and geographical records.
\end{abstract}

Keywords: helminth parasites, taxonomy, new taxa, Osteichthyes, Congo River basin

The present knowledge of nematodes parasitising freshwater fishes in Africa is still very incomplete (Moravec and Scholz 2017). Particularly regarding the parasite fauna in the Congo River basin, from where some papers describing mostly a single nematode species have been published (e.g. Taylor 1925, Baylis 1928, Rodhain and Vuylsteke 1934, Schuurmans Stekhoven 1937, Puylaert 1970a,b), but the number of studies currently is incipient. The most important study at the referred region was the comprehensive survey of Campana-Rouget (1961) on fish nematodes collected in 1952-1954 from three of the African Great Lakes, namely Kivu (Congo River basin), Edward and Albert (both upper Nile basin), now belonging to the Democratic Republic of the Congo. This survey included descriptions of several new species of these parasites.

During 2008 and 2012, several samples of parasitic nematodes were recovered from short-term parasitological studies on fishes in the Lower Congo River, Democratic Republic of the Congo, and in the Sangha River watershed Congo basin, belonging to the Dzanga-Sangha Protected
Areas (DSPA), Central African Republic. Partial results based on this material, dealing with species of Dujardinascaris Baylis, 1947, Procamallanus Baylis, 1923 and Rhabdochona Railliet, 1916, have already been published in the papers by Moravec and Jirků (2014a,b, 2015). Results of the systematic evaluation of other nematodes are presented herein. The purpose of this study is to extend knowledge of the hitherto little-known nematodes parasitising fish in the Congo ichthyological province of central Africa.

\section{MATERIALS AND METHODS}

Fish were collected by the junior author (M.J.) from several localities in the Democratic Republic of the Congo and the Central African Republic in 2008 and 2012, respectively. The nematodes recovered were washed in physiological saline and then fixed in hot $4 \%$ formalin; few specimens were also fixed in $99 \%$ ethanol for future DNA analysis. For light microscopical examination, the nematodes were cleared with glycerine. Drawings were made with the aid of a Zeiss drawing attachment. Specimens used for scanning electron microscopy (SEM) were postfixed in 1\% osmi- 
um tetroxide (in phosphate buffer), dehydrated through a graded acetone series, critical-point-dried and sputter-coated with gold; they were examined using a JEOL JSM-7401F scanning electron microscope at an accelerating voltage of $4 \mathrm{kV}$ (GB low mode). All measurements are in micrometres unless otherwise indicated. The higher nematode classification used is that of Keys to the Nematode Parasites of Vertebrates (Anderson et al. 2009). The names of fishes follow FishBase (Froese and Pauly 2017). Type and voucher nematode specimens are deposited in the Helminthological Collection of the Institute of Parasitology, Biology Centre of the Czech Academy of Sciences, České Budějovice, Czech Republic (IPCAS).

\section{RESULTS}

Cosmocercoidea Railliet, 1916

Atractidae Railliet, 1917

Labeonema longispiculatum sp. n.

Figs. 1, 2

ZooBank number for species:

urn:lsid:zoobank.org:act:A0737268-7694-4C0E-A65C-0649843FCCA4

Description. Small whitish nematodes with finely transversely striated cuticle; markedly narrow lateral alae arise short distance posterior to anterior extremity, extending posteriorly to about level of anus in both sexes (Fig. 2A,C). Mouth triangular, with 3 lips, each provided with cuticular flap overhanging oral aperture; 3 small elongate, slightly sclerotised structures present at inner bases of lips. Four submedian double cephalic papillae ( 2 on dorsal lip and 1 on each ventrolateral lip) present; pair of large lateral amphids situated near oral aperture on ventrolateral lips (Figs. 1C, 2A,B). Oesophagus consists of short pharyngeal portion, long corpus, isthmus and bulb; bulb provided with sclerotised valves (Fig. 1A,B,E). Intestine straight. Nerve ring encircles oesophagus approximately at mid-level of corpus. Conspicuous excretory pore situated near posterior end of corpus. Tail of both sexes conical, ending in sharp point (Figs. 1F-H, 2D-G).

Male (5 specimens; measurements of holotype in parentheses). Length of body $2.0-2.5 \mathrm{~mm}(2.5 \mathrm{~mm})$, maximum width 82-109 (109). Length of entire oesophagus 363-471 (468); length of pharynx 21-33 (33), width 15-18 (15); length of corpus 300-351 (345), maximum width 24 (24); isthmus 30-45 (30) long, 12-18 (12) wide; bulb 54-60 (60) long, 48-60 (57) wide. Nerve ring and excretory pore 156-195 (180) and 270-330 (330), respectively, from anterior extremity. Tail curved ventrally. Caudal alae absent. Caudal papillae rather variable in number and arrangement, sometimes distributed asymmetrically. Preanal papillae: 5-6 pairs of subventral papillae and 1-3 more lateral papillae situated anterior to paired papillae on either side of body; in addition, 3 pairs of minute ventral papillae and 1 unpaired median papilla present on anterior lip of cloaca. Adanal papillae: 1 subventral pair. Postanal papillae: 5-6 pairs, including 3-4 subventral and 2 lateral; pair of small lateral phasmids located slightly anterior to first pair of lateral postanal papillae (Figs. 1F,G, 2D-G). Two well sclerotised, equally long spicules present, 210-228 (228), curved ventrally in lateral view; proximal ends obtuse, markedly narrow, distal ends pointed (Figs. 1F, 2D,F). Gubernaculum well sclerotised, 45-48 (45) long (Fig. 1F). Length ratio of gubernaculum and spicules $1: 4.38-5.07$ (1 : 5.07). Length of tail 108-138 (138).

Female (5 ovigerous specimens; measurements of allotype in parentheses). Length of body $2.8-2.9 \mathrm{~mm}(2.9 \mathrm{~mm})$, maximum width 150-163 (150). Length of entire oesophagus 501-519 (519); length of pharynx 27-30 (27), width 15-18 (18); of corpus 366-384 (384), width 27 (27); of isthmus 45 (45), width 18-21 (21), of bulb 60-63 (63), width 60 (60). Nerve ring and excretory pore 204 (204) and 360-363 (363), respectively, from anterior extremity. Vulva in posterior half of body, $2.0 \mathrm{~mm}(2.0 \mathrm{~mm})$ from anterior extremity [at 69-73\% (69\%) of body length], with conspicuously elevated posterior lip (Fig. 1A,D). Vagina narrow, directed posteriorly from vulva. Ovary near anterior end of uterus (Fig. 1A). Uterus didelphic, with posterior branch transformed into sac without ovary and oviduct and extending posteriorly somewhat posterior to level of vulva. Uterus containing 5-6 (6) oval, thin-walled eggs at different stages of development, 153-186 × 111-165 (153-177 $\times$ 111-165); no hatched larvae present (Fig. 1A). Length of tail 218-245 (245).

Type host: Synodontis acanthomias Boulenger (Siluriformes: Mochokidae).

Site of infection: Intestine (distal part).

Type locality: Lower Congo River, right bank near Bulu, Democratic Republic of the Congo, $05^{\circ} 01^{\prime} 30^{\prime \prime} \mathrm{N} ; 1^{\circ} 00^{\prime} 25^{\prime \prime} \mathrm{E}$ (collected 11 July 2008).

Prevalence and intensity: 3 fish infected/4 fish examined; approximately 950 and 1,000 nematodes (specimens from one of the infected fish not sampled).

Deposition of type specimens: IPCAS N-1140 (holotype, allotype and many paratypes).

Etymology: The name longispiculatum relates to a characteristic feature of this nematode species, i.e. the presence of very long spicules as compared with congeners.

Remarks. To date, the following five species of Labeonema Puylaert, 1970 have been described from freshwater fishes in Africa: L. africanum Moravec et Van As, 2004, L. bainae Baker, 1982, L. bakeri Van Waerebeke, Chabaud, Bain et Georges, 1988, L. intermedium Puylaert, 1970 and L. synodontisi (Vassiliadès, 1973) (see Moravec and Van As 2004, Koubková et al. 2008). Although the body measurements of all these species are similar to those of L. longispiculatum sp. n., their spicules are much shorter; the longest spicules $(105-120 \mu \mathrm{m})$ are found in L. africanum, whereas those of other species are shorter than $100 \mu \mathrm{m}$. On the other hand, the spicules of the new species are 210-228 $\mu \mathrm{m}$, i.e. approximately twice as long as those in L. africanum, a parasite of Synodontis nigromaculatus Boulenger in Botswana (Moravec and Van As 2004). Both species also differ in the length of the gubernaculum (45-48 $\mu \mathrm{m}$ in L. longispiculatum vs 30-36 $\mu \mathrm{m}$ in L. africanum), in the gubernaculum/spicules length ra- 

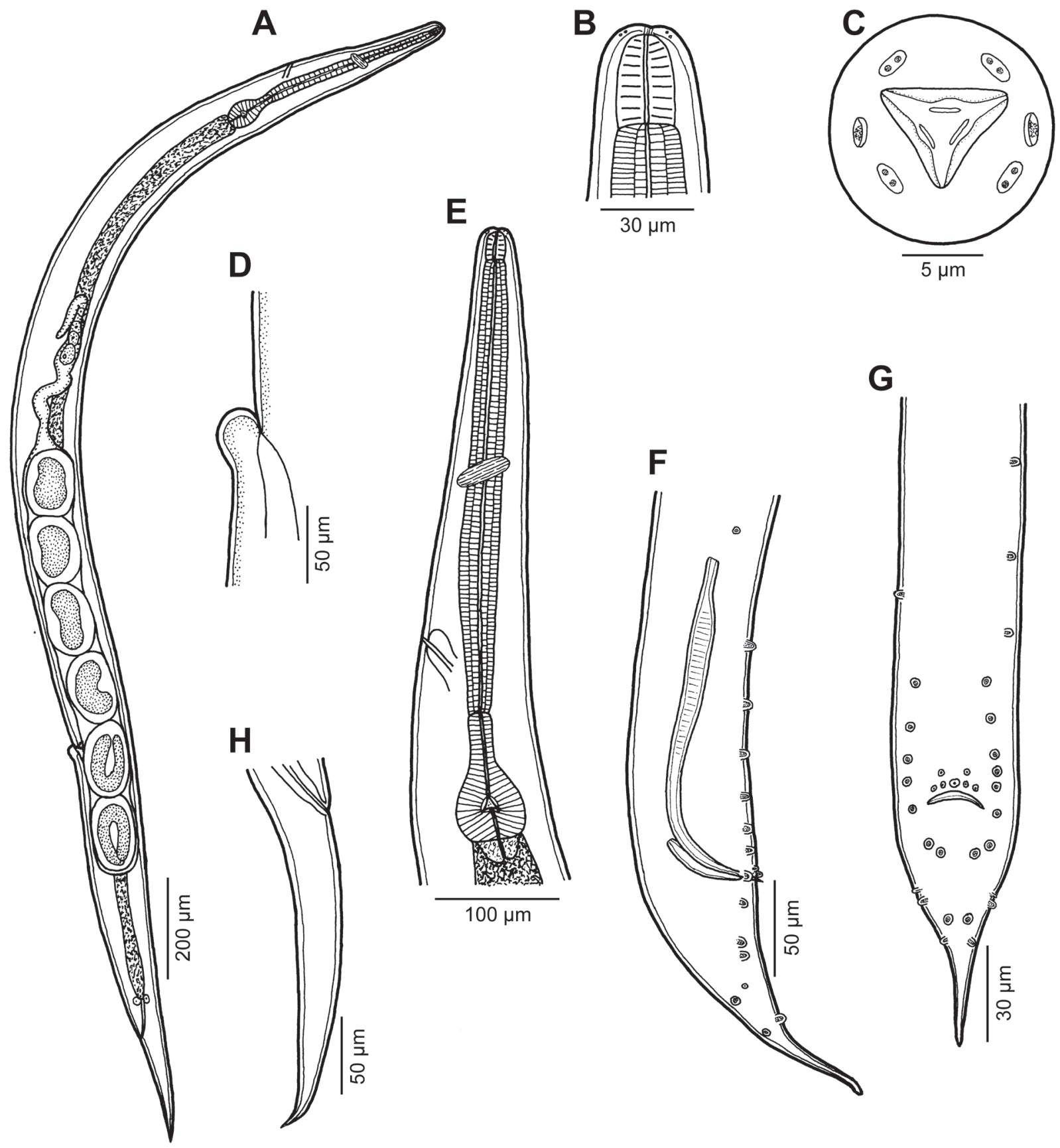

Fig. 1. Labeonema longispiculatum sp. n. from Synodontis acanthomias Boulenger. A - general view of female, lateral view; B, C - cephalic end, lateral and apical views, respectively; D - vulva, lateral view; $\mathbf{E}$ - anterior end of female, lateral view; F, G-posterior end of male, lateral and ventral views, respectively; $\mathbf{H}$ - tail of female, lateral view.

tio $(1: 4.4-5.1$ vs $1: 3.2-3.7)$ and in the number and distribution of genital papillae; in contrast to L. africanum, the proximal ends of spicules in L. longispiculatum are conspicuously narrowed. Interspecific differences are also found in the structure of the cephalic end.

Besides L. longispiculatum and L. africanum, there is an additional congeneric species, L. synodontisi (syn. Raillietnema synodontisi Vassiliadès, 1973), reported from several species of mochokid catfishes (Synodontis spp.) in Chad, Senegal and South Africa, and from aquarium-reared S. eupterus Boulenger in Europe (Czech Republic) originally imported from Africa (Vassiliadès 1973, 1976, Vassiliadès and Troncy 1974, Moravec and Řehulka 1987,
Boomker, 1994, Koubková et al. 2008). This species can be easily distinguished from $L$. longispiculatum by much shorter spicules (75-94 $\mu \mathrm{m} v s$ 210-228 $\mu \mathrm{m})$. Other congeneric species (L. bainae, L. bakeri and L. intermedium) are parasites of hosts belonging to other fish families (Schilbeidae, Distichodontidae and Cyprinidae, respectively).

Atractidae gen. sp. fourth-stage larva

Fig. 3

Description (1 female larva). Small whitish nematode $2.2 \mathrm{~mm}$ long, 111 wide, with smooth cuticle; very narrow lateral alae extend along body. Cephalic end rounded, 24 wide, bearing 4 small cephalic papillae. Oesophagus 468 


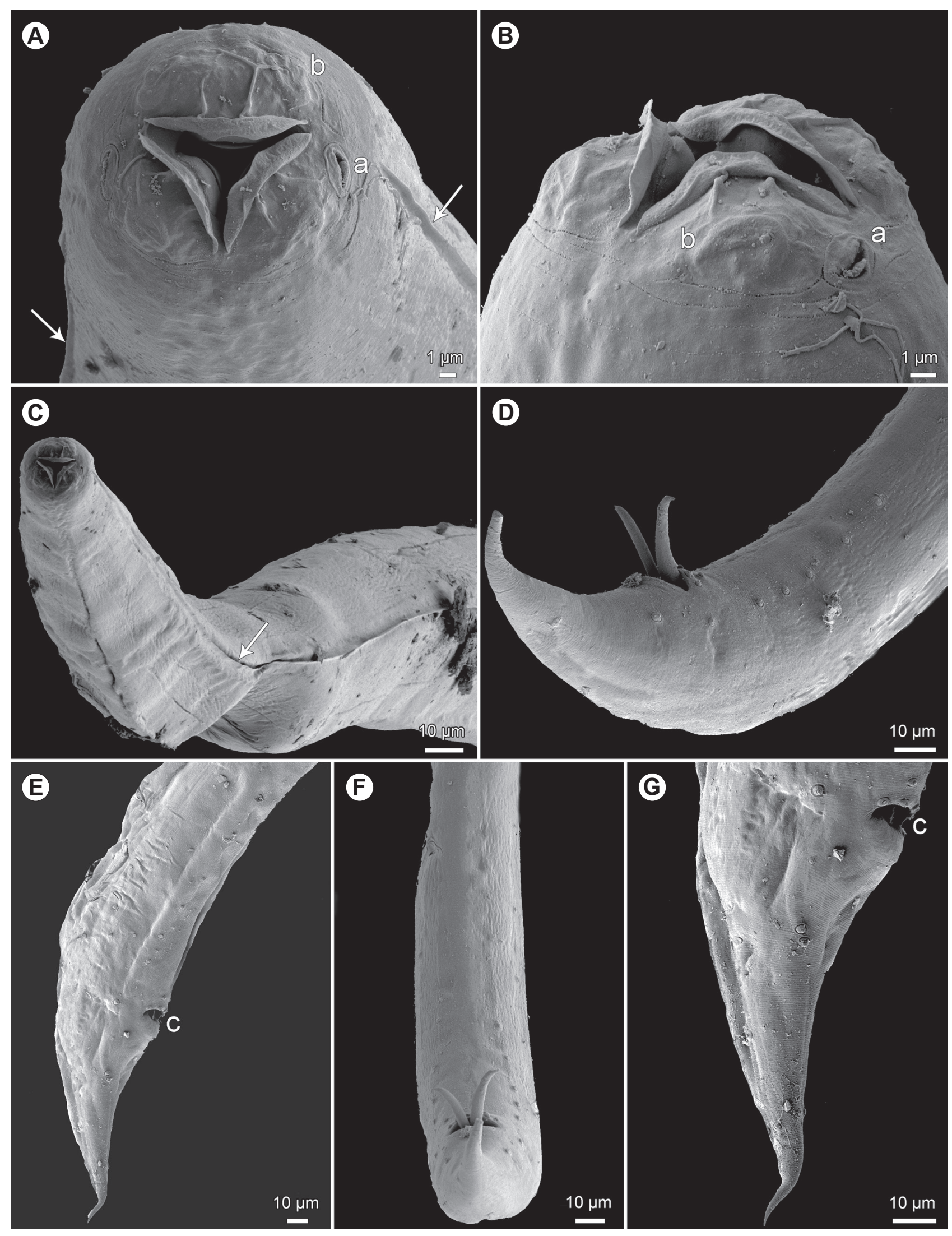

Fig. 2. Labeonema longispiculatum sp. n. from Synodontis acanthomias Boulenger, scanning electron micrographs of male. A - cephalic end, apical view (arrows indicate lateral alae); B - cephalic end, sublateral view; $\mathbf{C}$ - anterior end of body, sublateral view (arrow indicates lateral ala); D - posterior end, sublateral view; $\mathbf{E}$ - posterior end, lateral view (another specimen); $\mathbf{F}$ - posterior end with distinct preanal papillae arranged in two rows, ventral view; $\mathbf{G}$ - tail, lateral view. Abbreviations: a - amphid; b - cephalic papilla; $\mathrm{c}$ - cloaca. 


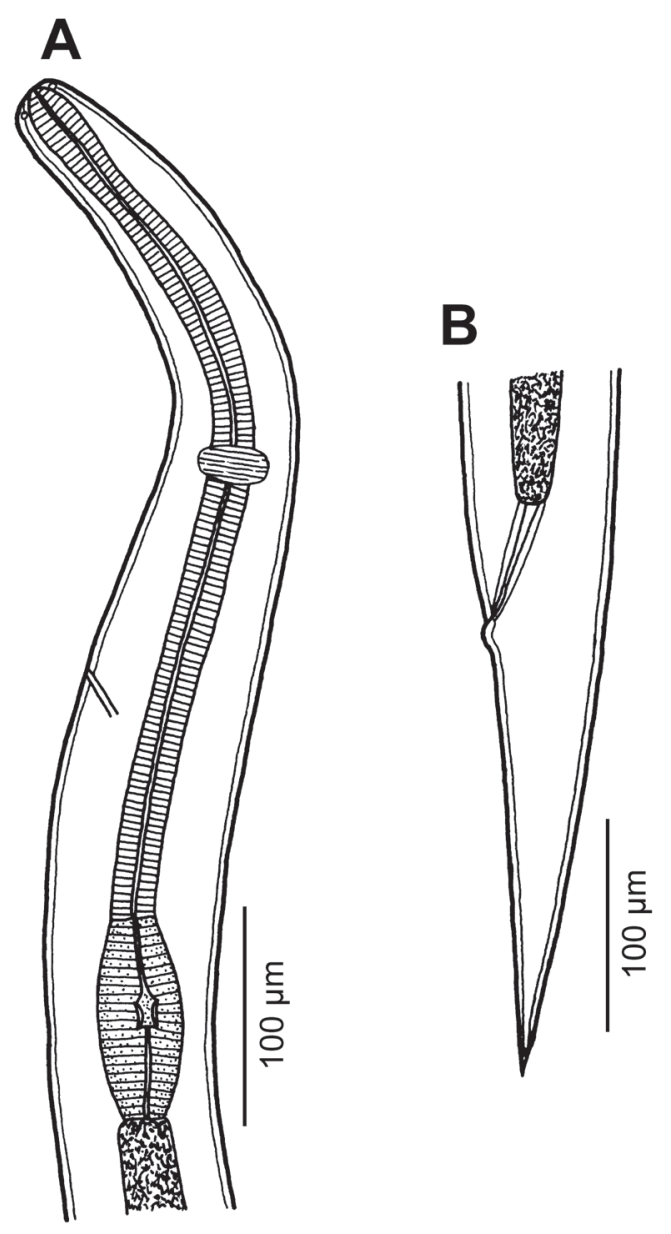

Fig. 3. A, B - Atractidae gen. sp. larva from Clarias gariepinus (Burchell) (anterior and posterior body ends, lateral views).

long; its anterior portion long, narrow, 15-18 wide; short posterior portion somewhat broader, longitudinally oval, 75 long and 33 wide, provided inside with small sclerotised apparatus (Fig. 3A). Intestine narrow, straight. Nerve ring and excretory pore 186 and 291, respectively, from anterior extremity. Developing vulva postequatorial, $1.5 \mathrm{~mm}$ from anterior end of body (at 70\% of body length). Tail conical, 202 long (Fig. 3B).

Host: North African catfish Clarias gariepinus (Burchell) (Siluriformes: Clariidae).

Site of infection: Intestine (distal part).

Locality: Lower Congo River, Democratic Republic of the Congo - unspecified locality in Bas Congo (Congo basin, collected 10 July 2008).

Prevalence and intensity: 1 fish infected/2 fish examined; 1 nematode.

Deposition of voucher specimen: IPCAS N-1137.

Remarks. The general morphology of this female larva, especially the presence of a distinct sclerotised apparatus inside the bulbous posterior portion of the oesophagus, indicates that it belongs to the Atractidae. Recently Moravec and Van As (2015a) reported a nongravid female designated as Atractidae gen. sp. from the intestine of the catfish Schilbe intermedius Rüppel (Schilbeidae) in Bot- swana, which, however, differs from the present specimen in a larger body, a distinct pharyngeal portion of the oesophagus and isthmus and in the location of the vulva in the anterior part of the body.

Kathlaniidae Lane, 1915

Falcaustra piscicola (von Linstow, 1907) CampanaRouget, 1961

Figs. 4, 5

Syns.: Nematoxys piscicola von Linstow, 1907; Spironoura congolense Taylor, 1925

Description. Medium-sized, fusiform, whitish nematodes. Cuticle finely transversely striated. Lateral alae absent. Deirids well developed, rounded, situated at about mid-level of oesophagus (Fig. 4A,B,J). Oral aperture large, triangular, surrounded by 3 small lips, each bearing 2 cephalic papillae; pair of lateral amphids present (Figs. 4D, 5A,B,D). Buccal cavity supported by flat cuticularised ring (Fig. 4A,B). Oesophagus consists of short, muscular pharyngeal portion, long corpus, inflated isthmus forming prebulb, and bulb (Fig. 4A-C). Nerve ring encircling oesophageal corpus at about $1 / 4$ of way along its length, excretory pore near level of junction of corpus and pre-bulb. Anterior end of intestine expanded. Tail of both sexes conical, sharply pointed (Figs. 4E,G-I, 5C,F).

Male (5 specimens). Length of body $13.8-18.7 \mathrm{~mm}$, maximum width 762-1,061. Lips 54-68 long; width of cephalic end at level of lips 177-190. Length of entire oesophagus $2.0-2.5 \mathrm{~mm}$; length of pharynx 82-95, of corpus $1.5-1.8 \mathrm{~mm}$, of pre-bulb 204-258, of bulb 258-313; width of pharynx, corpus, pre-bulb and bulb 95-109, 136-150, 150-190 and 313-367, respectively. Nerve ring 422-449, excretory pore $1.4-1.9 \mathrm{~mm}$ and deirids $1.0-1.5 \mathrm{~mm}$ from anterior extremity. Posterior end of body curved ventrally. Caudal alae absent. Ventral precloacal sucker absent; ventral precloacal region of body with $\mathrm{ca} 40$ pairs of oblique muscle bands (Fig. 4G). Nine pairs of genital papillae present, of which 3 subventral pairs are preanal, there is 1 adanal pair and 5 pairs ( 3 subventral and 2 lateral) are postanal; 1 additional unpaired median papilla present anterior to cloaca; phasmids situated anterior to level of last but one subventral pair of postanals (Figs. 4E,G,I, 5C,E,F). Spicules equal, alate, slightly curved, 594-780 long (Fig. 4E,G). Gubernaculum well developed, 180-204 long. Tail 120-558 long.

Female (5 gravid specimens). Length of body 17.8$22.2 \mathrm{~mm}$, maximum width 1.0-1.3 mm. Lips 54-68 long; width of cephalic end at level of lips 190-218. Length of entire oesophagus $2.5 \mathrm{~mm}$; length of pharynx 95-109, of corpus 1.8-1.9 mm, of pre-bulb 231-245, of bulb 313-326; width of pharynx, corpus, pre-bulb and bulb 122, 136-150, 163-204 and 340-394, respectively. Nerve ring 490-544, excretory pore $1.7-1.9 \mathrm{~mm}$ and deirids $1.3-1.5 \mathrm{~mm}$ from anterior extremity. Vulva postequatorial, situated 10.5$13.2 \mathrm{~mm}$ from anterior extremity (at 59-60\% of body length); vagina muscular, narrow, directed anteriorly from 


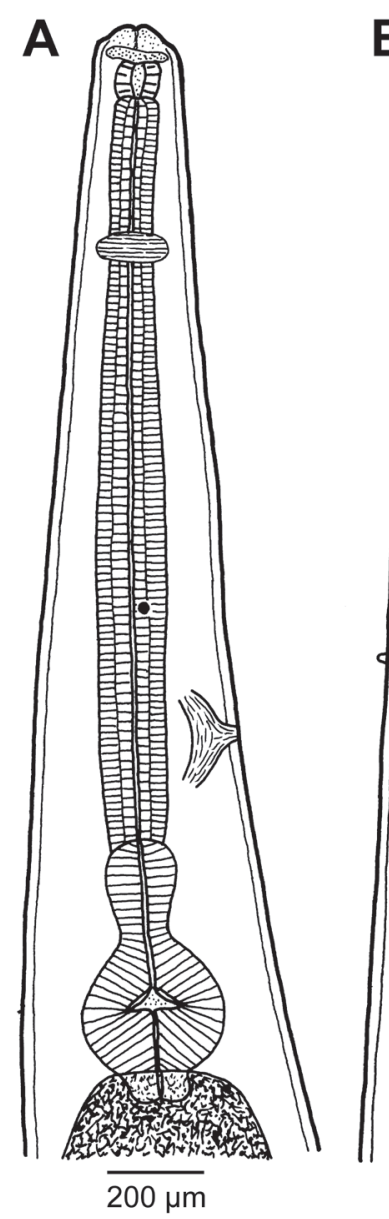

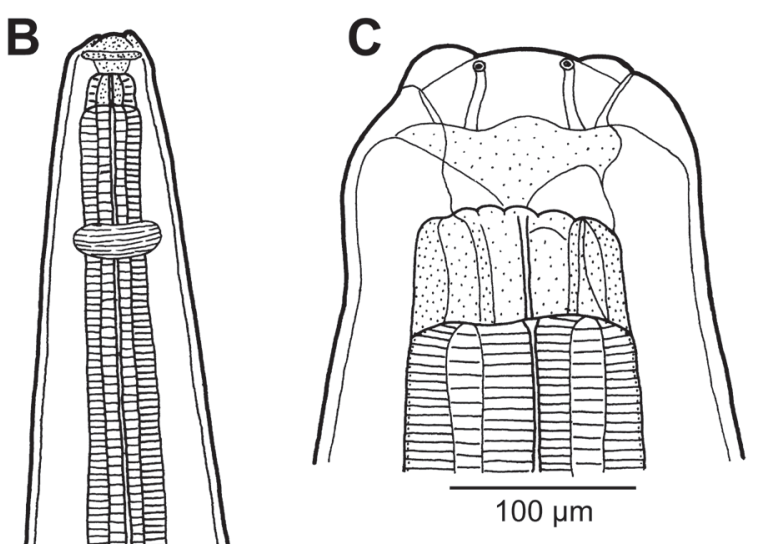

E

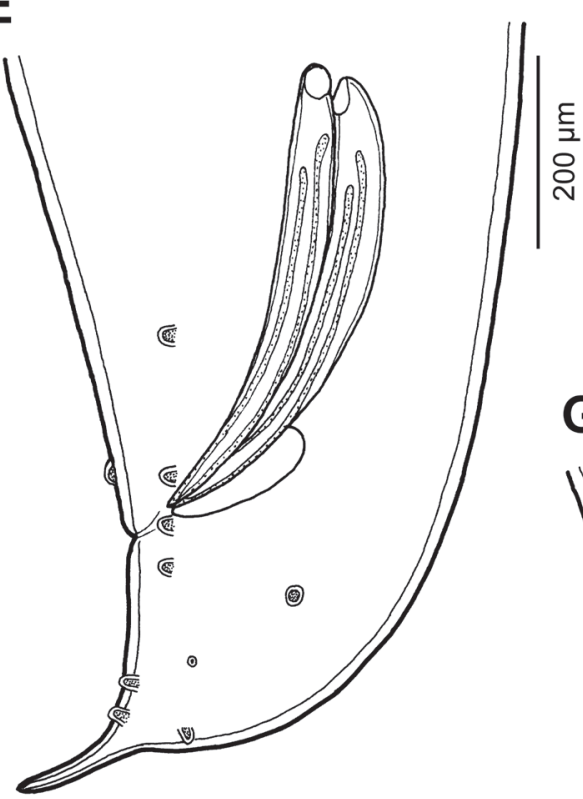

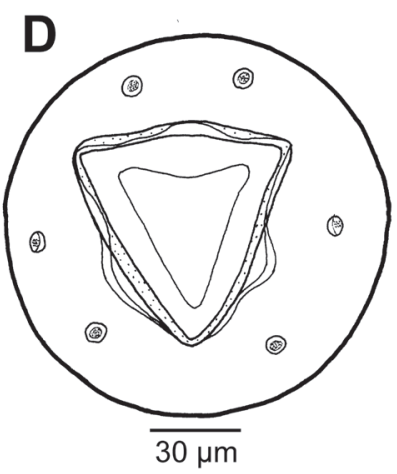

F
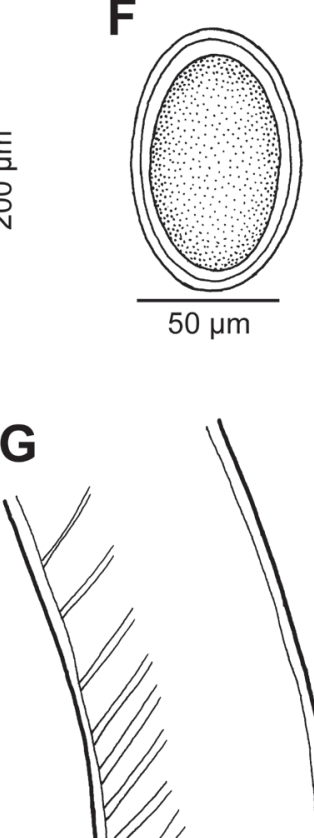

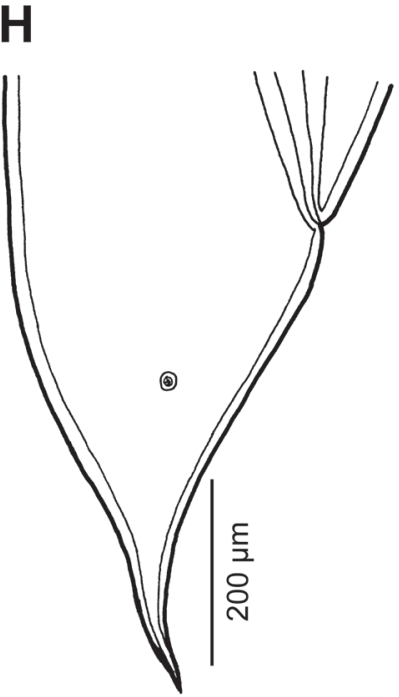

I
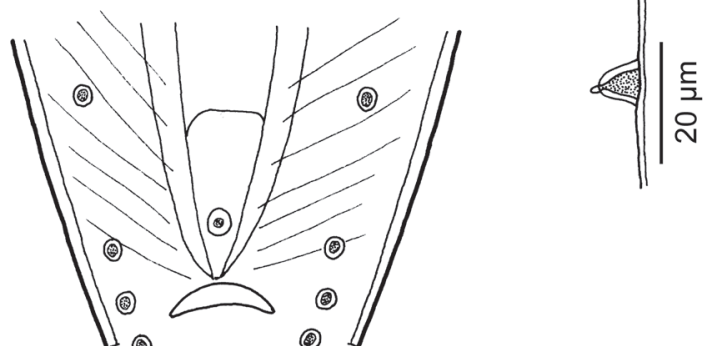

J 


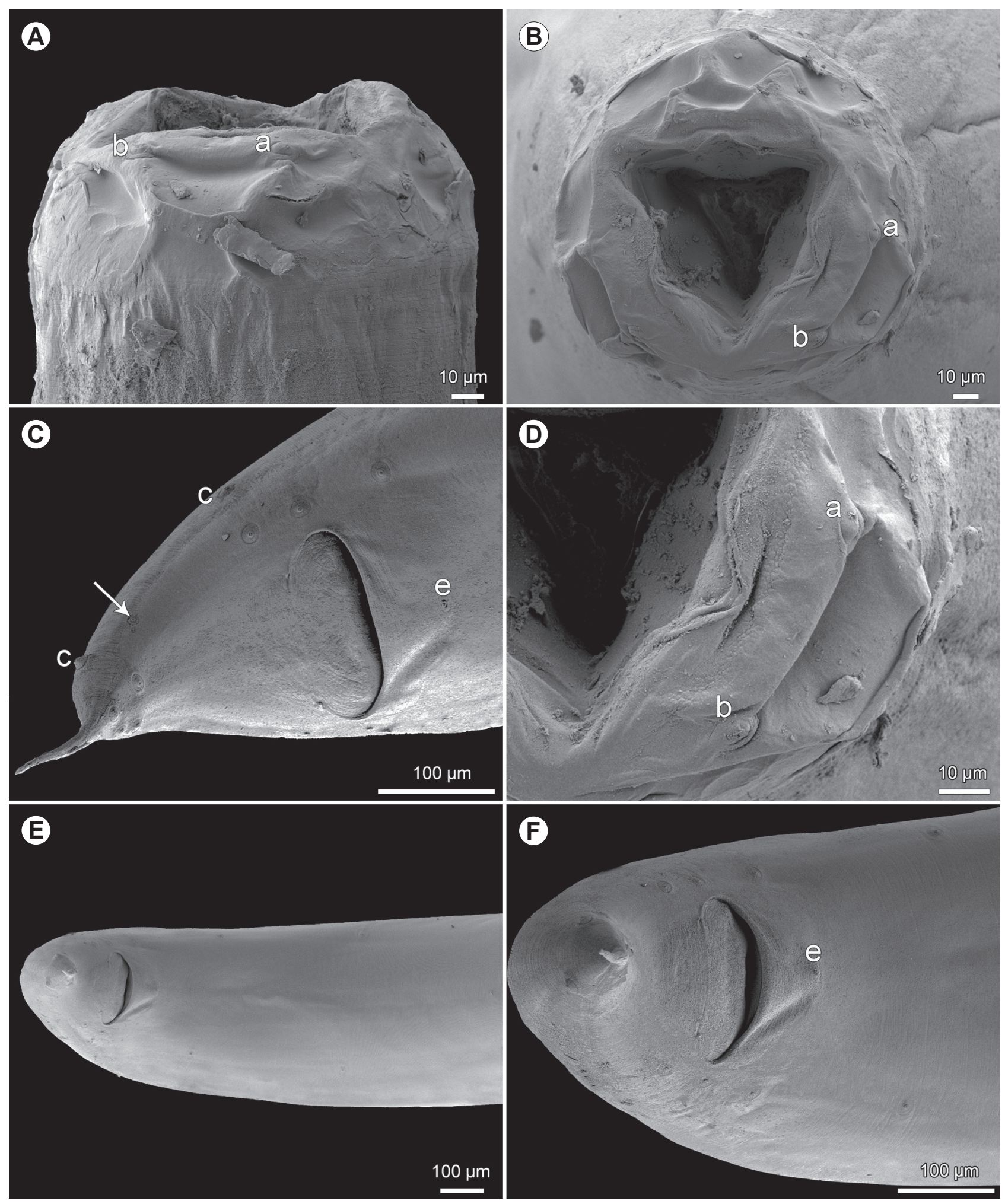

Fig. 5. Falcaustra piscicola (von Linstow, 1907) from Distichodus lusosso Schilthuis, scanning electron micrographs of male. A, B - cephalic end, sublateral and apical views, respectively; C - tail, subventral view (arrow indicates phasmid); $\mathbf{D}$ - detail of mouth, apical view; $\mathbf{E}$ - posterior end of body, ventral view; F - tail, ventral view. Abbreviations: a - amphid; b - cephalic papilla; c - lateral postanal papilla; e - median unpaired preanal papilla.

Locality: Sangha River adjacent to Sangha Lodge, $02^{\circ} 59^{\prime} 06^{\prime \prime N}$; $16^{\circ} 13^{\prime} 59^{\prime \prime}$ (Congo basin), DSPA, Central African Republic (collected 14 September 2012).

Prevalence and intensity: 1 fish infected/1 fish examined; 33 nematodes.
Deposition of voucher specimens: IPCAS N-1136.

Remarks. This species was originally described as Nematoxys piscicola from Distichodus sp. in the Cameroon (von Linstow 1907). Later Inglis (1959) re-studied 
its type specimens and transferred this species to Spironoura Leidy, 1856. He found these to be indistinguishable from Spironoura congolense, a species reported from an unidentified fish in the present Democratic Republic of the Congo (Taylor 1925), which became a junior synonym of S. piscicola. Spironoura is now considered by most authors a genus dubium and all species listed in it are reported in Falcaustra Lane, 1915 (see Anderson et al. 2009).

The morphology of present specimens is more or less in agreement with the descriptions of $F$. piscicola by von Linstow (1907) and Taylor (1925); they were collected from a congeneric host in the same or nearby regions and, therefore, they are considered to belong to $F$. piscicola. The present study, which included the first use of SEM for observing $F$. piscicola, made it possible to solve problems on the description of number of postanal papillae: whereas von Linstow (1907) observed four pairs and Taylor (1925) reported eight papillae on either side or eight to nine papillae on the right-hand side and seven on the left, the present results confirmed six pairs of caudal postanal papillae (including phasmids) in $F$. piscicola.

In addition to the above-mentioned findings of $F$. piscicola in the Cameroon and the Democratic Republic of the Congo by von Linstow (1907) and Taylor (1925), this species was recorded from Distichodus brevipinnis Günther and D. rostratus Günther in Lake Chad, Chad (Vassiliadès and Troncy 1974). Accordingly, the present finding of F. piscicola in Distichodus lusosso in the Central African Republic represents new host and geographical records of this species.

\section{Falcaustra similis Moravec et Van As, 2004}

Host: Synodontis acanthomias (Siluriformes: Mochokidae).

Site of infection: Intestine.

Locality: Lower Congo River, right bank near Bulu, Democratic Republic of the Congo, $05^{\circ} 01^{\prime} 30^{\prime \prime} \mathrm{N} ; 1^{\circ} 00^{\prime} 25^{\prime \prime} \mathrm{E}$ (collected 11 July 2008).

Prevalence and intensity: 1 fish infected/4 fish examined; 3 nematode (only 2 specimens analysed morphologically).

Deposition of voucher specimens: IPCAS N-819.

Remarks. The present material consisted of only two specimens (one male and one gravid female, plus one specimen preserved in absolute alcohol), whose morphology and measurements are in full agreement with the descriptions of $F$. similis provided by Moravec and Van As (2004, 2015a), thus we refrain from redescribing this species again.

Falcaustra similis is a specific parasite of African catfishes, previously reported from Synodontis frontosus Vaillant, S. nigrita Valenciennes, S. nigromaculatus (type host), S. schall (Bloch et Schneider), S. serratus Rüppel, $S$. vanderwaali Skelton et White (all Mochokidae) and Schilbe intermedius (Schilbeidae) in Botswana and Sudan (Moravec and Van As 2004, 2015a, Moravec and Scholz 2017). The findings of $F$. similis from $S$. acanthomias in the Democratic Republic of the Congo represent new host and geographical records.

\section{Oxyuroidea Cobbold, 1864}

Pharyngodonidae Travassos, 1919

Cithariniella khalili Petter, Vassiliadès et Troncy, 1972

Figs. 6, 7

Syn.: Cithariniella gonzalezi Van Waerebeke, Chabaud, Bain et Georges, 1988

Description (based on specimens from S. acanthomias). Small, whitish nematodes with very long, slender tail and fine transverse striation of cuticle in cervical and middle part of body. Lateral alae not observed. Oral aperture roughly triangular, surrounded by 3 lip-like structures provided with 6 oral lamellae ( 2 dorsolateral and 4 ventrolateral) protruding out of mouth, 4 oval cephalic papillae and pair of lateral amphids (Figs. 6C, 7A,B). Buccal cavity shallow, with 3 sclerotised longitudinal flaps, each of them with longitudinal tooth-like structures (Figs. 6B,C, 7B,D). Oesophagus cylindrical, almost uniform in diameter, ending in globular bulb provided with valvular apparatus and separated from corpus by constriction (isthmus) (Fig. 6A). Intestine straight, narrow. Excretory pore situated relatively far posterior to level of bulb (Fig. 6A).

Male (10 specimens). Length of body $1.9-2.0 \mathrm{~mm}$, maximum width 177-204. Buccal cavity 15-21 long. Entire oesophagus 372-522 long; length of corpus 243-399, width 30-51, length of isthmus 18-42, width 39-51, length of bulb 90-105, width 90-105. Nerve ring and excretory pore 163-174 and 517-598, respectively, from anterior extremity. Single spicule narrow, 90-108 long, with pointed distal tip; its capitulum 18-24 long (Figs. 6D,F, 7C,E,F). Gubernaculum weakly sclerotised, 33-42 long. Region of cloacal opening elevated, bearing 1 pair of large subventral preanal papillae and 2 pairs of small postanal papillae located on 2 large subventral postcloacal lobes (Figs. 6F,G, $7 \mathrm{C}, \mathrm{E}, \mathrm{F})$. Two parallel or nearly parallel papillae located close to each other situated 66-108 posterior to cloacal aperture (at 19-36\% of length of tail) and 159-282 from end of tail (Figs. 6F,H, 7E,F). Pair of minute lateral phasmids located approximately in mid-way between last two pairs of caudal papillae (Fig. 7E). Ventral precloacal pseudosucker absent. Tail conical, attenuated, 272-354 long, representing $14-18 \%$ of body length (Fig. 6F).

Female (10 gravid specimens). Length of body 3.0$3.5 \mathrm{~mm}$, maximum width 245-367. Buccal cavity 27-33 long. Entire oesophagus 501-552 long; length of corpus 342-399, width 63-69, length of isthmus 30-39, width 5160 , length of bulb 105-120, width 105-132. Nerve ring and excretory pore 195-204 and 340-394, respectively, from anterior extremity. Vulva situated 1.86-2.24 from anterior extremity (at $60-66 \%$ of body length), $435-598$ anterior to anus; vulval lips not elevated (Figs. 6E, 7G). Vagina muscular, directed anteriorly from vulva. Uterus filled with many eggs. Eggs elongate, thin-walled, unembryonated, provided at each pole with many very long thread-like filaments; eggs 114-132 long, 39-45 wide (Fig. 6I). Tail 598-680 long, representing $18-23 \%$ of body length (Fig. $6 \mathrm{E}$ ). 

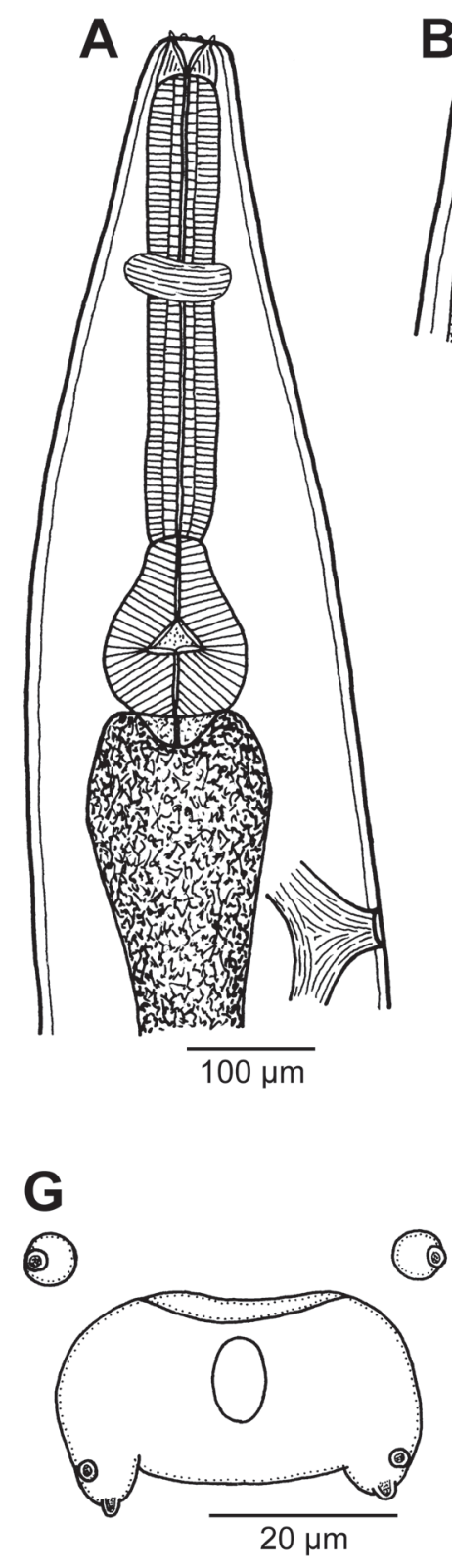
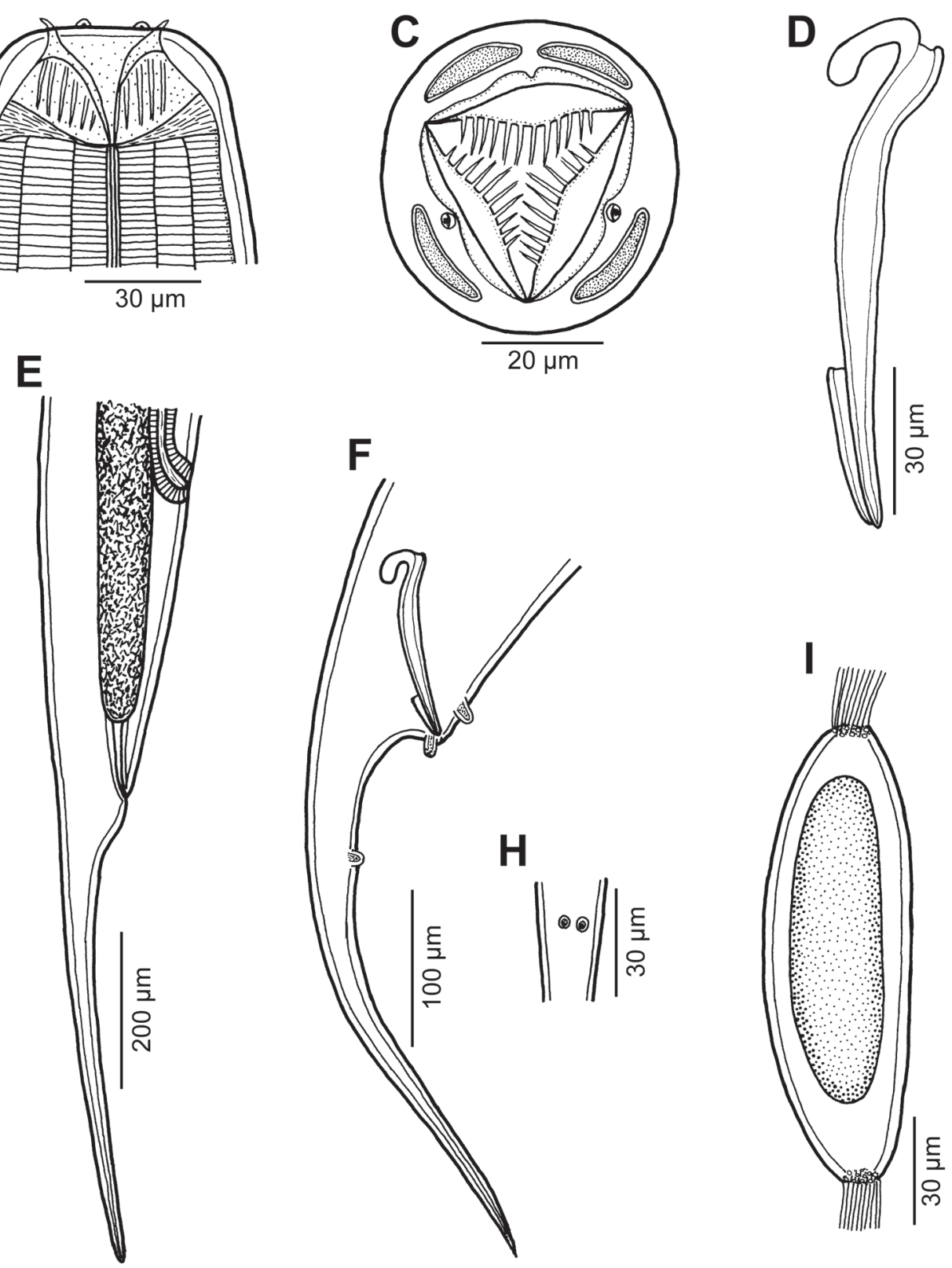

Fig. 6. Cithariniella khalili Petter, Vassiliadès et Troncy, 1972 from Synodontis acanthomias Boulenger. A - anterior end of young female, lateral view; B, C - cephalic end, lateral and apical views, respectively; $\mathbf{D}$ - spicule and gubernaculum, lateral view; $\mathbf{E}$ - posterior end of young female, lateral view; $\mathbf{F}$ - posterior end of male, lateral view; $\mathbf{G}$ - distribution of caudal papillae in region of cloaca, ventral view; $\mathbf{H}$ - last pair of postcloacal papillae, ventral view; I - egg (only basal parts of filaments illustrated).

Host: Synodontis acanthomias and S. greshoffi Schilthuis (both Siluriformes: Mochokidae).

Site of infection: Intestine.

Localities: Lower Congo River, right bank near Bulu, Democratic Republic of the Congo, $05^{\circ} 01^{\prime} 30^{\prime \prime} \mathrm{N} ; 1^{\circ} 00^{\prime} 25^{\prime \prime} \mathrm{E}$ (S. acanthomias, collected 11 July 2008); and Sangha River adjacent to Sangha Lodge, 02 $59^{\prime} 06^{\prime \prime} \mathrm{N} ; 16^{\circ} 13^{\prime} 59^{\prime \prime} \mathrm{E}$ (Congo basin), DSPA, Central African Republic (S. greshoffi, collected 11-12 September 2012).

Prevalence and intensity: S. acanthomias: 2 fish infected/4 fish examined; 11-41 nematodes. S. greshoffi: 2/9; 12-16.

Deposition of voucher specimens: IPCAS N-906.

Remarks. To date, Cithariniella Khalil, 1964 contains five valid species, all parasitic in African freshwater fishes: C. citharini Khalil, 1964 (type species), C. khalili,
C. koubkovae Moravec et Van As, 2015, C. longicaudata Moravec et Van As, 2015 and C. petterae Khalil, 1974 (see Moravec and Van As 2015a). The identification of present specimens as $C$. khalili is based on their general morphology, especially the shape and size of cephalic papillae and presence of two closely adjoing ventral postanal papillae located some distance posterior to cloaca on the male tail (Petter et al. 1972, Koubková et al. 2010, Moravec and Van As 2015a).

The cephalic end of $C$. khalili (misidentified as C. $\mathrm{ci}$ tharini) was previously first studied using SEM by Moravec (1994) based on specimens from Synodontis schall in Egypt and later by Mašová (2012) in the same host species from Lake Turkana, Kenya, who also studied the eggs using this method. Mašová (2012) referred to 


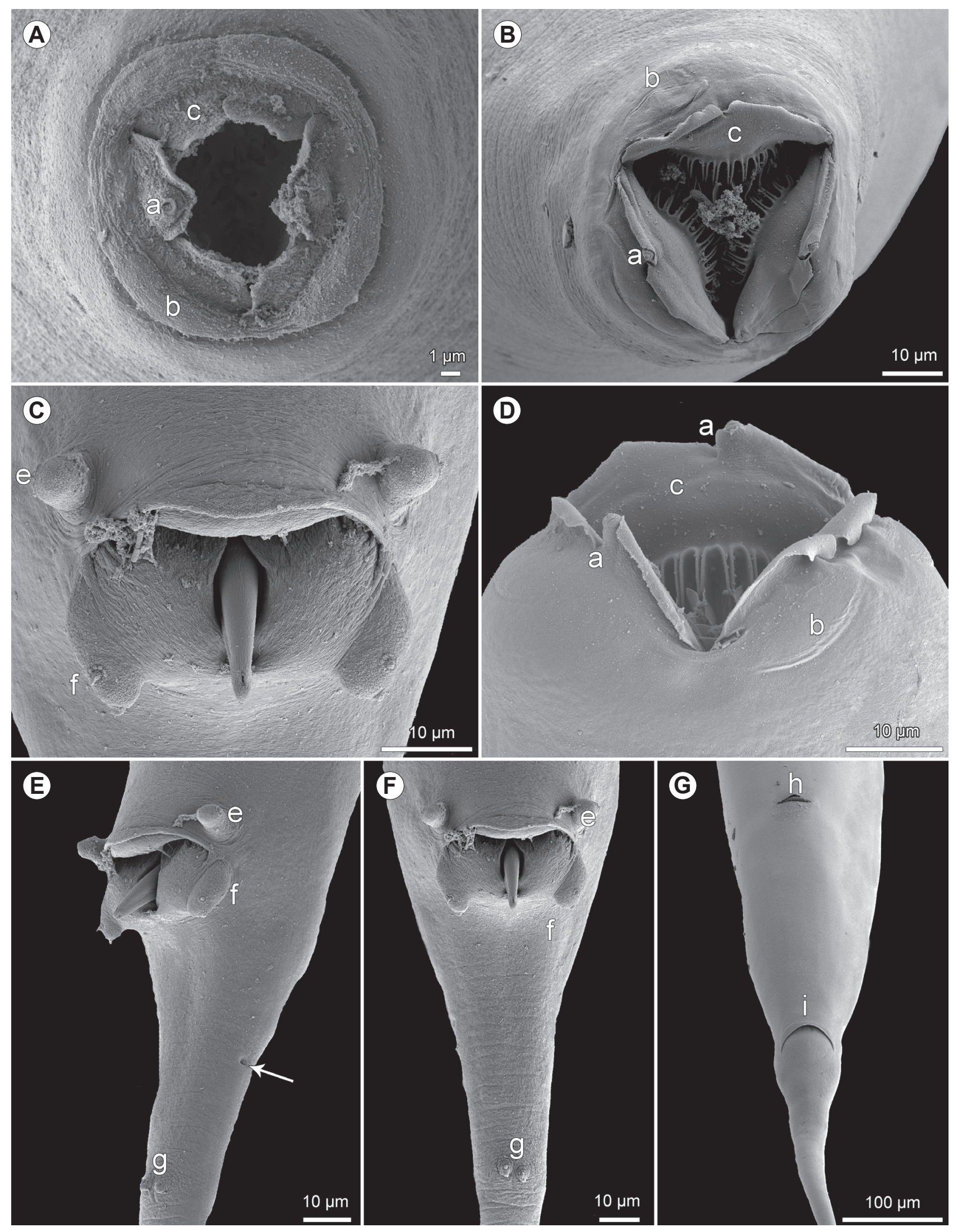

Fig. 7. Cithariniella khalili Petter, Vassiliadès et Troncy, 1972 from Synodontis acanthomias Boulenger, scanning electron micrographs. A - cephalic end of male, apical view; B - cephalic end of female, apical view; $\mathbf{C}$ - region of cloaca, ventral view; $\mathbf{D}$-cephalic end of female, dorsolateral view; $\mathbf{E}, \mathbf{F}$ - region of cloaca and anterior part of tail, subventral and ventral views, respectively (arrow indicates phasmid); $\mathbf{G}$ - posterior part of female body, ventral view. Abbreviations: a - amphid; b - cephalic papilla; c - cephalic lamella; $\mathrm{e}$ - preanal papilla; $\mathrm{f}$ - postanal double papilla; $\mathrm{g}$ - median pair of postanal papillae situated some distance posterior to cloaca; $\mathrm{h}$ - vulva; $\mathrm{i}$ - anus. 
Synodontis frontosus, but molecular determination confirmed identity of host as $S$. schall; data will be published elswhere. Koubková et al. (2010) used SEM for observing specimens of $C$. khalili from four species of Synodontis Cuvier in Senegal and reported the presence of lateral alae in both males and females (but this feature is not visible on their micrographs). However, no lateral alae were found in specimens examined in the present study. Nevertheless, our SEM examinations confirmed the most important taxonomic features of $C$. khalili (see above), and, for the first time, showed the presence of two small postanal papillae on each of the two large subventral postcloacal lobes (the lobes were previously considered to be large single papillae) and minute phasmids.

According to Moravec and Van As (2015a), C. khalili is a parasite of African catfishes of the genus Synodontis (Mochokidae), reported from Synodontis batensoda Rüpel, S. frontosus, S. longirostris Boulenger, S. membranaceus (Geoffroy Saint-Hilaire), S. nigrita Valenciennes, S. ocellifer Boulenger, S. schall (type host), S. serratus and S. sorex Günther (all Mochokidae) and, exceptionally, from catfishes of other families, e.g. Auchenoglanis biscutatus (Geoffroy Saint-Hilaire) (Claroteidae), in Chad, Central African Republic, Senegal, Egypt, Sudan and Kenya (e.g. Petter et al. 1972, Moravec 1974a, Vassiliadès and Troncy 1974, Fahmy et al. 1976, El-Naffar et al. 1983, Van Waerebeke et al. 1988, Imam et al. 1991, Koubková et al. 2010; Mašová 2012, Moravec and Scholz 2017). The present finding of this parasite in $S$. acanthomias and $S$. greshoff from the Democratic Republic of the Congo and Central African Republic, respectively, represents new host and geographical records.

Synodontisia thelastomoides Petter, Vassiliadès et Troncy, 1972

Figs. 8, 9

Description (based on specimens from S. acanthomias). Small fusiform nematodes with distinctly transversely annulated cuticle (Figs. 8A,B,E,F, 9A,C,F). Narrow lateral alae arise anteriorly somewhat anterior to level of nerve ring and extend posteriorly slightly posterior to level of anus in female and to short distance posterior to median pair of postanal papillae in male (Figs. 8E, 9C,F). Oral aperture hexagonal, surrounded by 6 small lip-like formations ( 2 dorsolateral, 2 ventrolateral and 2 lateral), each of them provided with anteriorly protruding mouth lamella on inner side. Four large, oval submedian cephalic papillae and pair of small amphids present (Figs. 8C, 9A,B). Buccal cavity spacious (Fig. 8A,B). Oesophagus formed by cylindrical corpus, short isthmus and well-developed bulb; oesophagus opens into intestine through small valve (Fig. 8A,E,F). Nerve ring situated at about mid-level of corpus; excretory pore at some distance posterior to oesophagus (Figs. 8A,E,F). Tail of both sexes forms very long, slender caudal spike (Fig. 8D,E,F).

Male (one specimen). Length of body including caudal spike $1.3 \mathrm{~mm}$, maximum width 150. Buccal cavity 12 long. Entire oesophagus 246 long (18\% of body length); corpus 138 long, 33 wide; isthmus 39 long, 33 wide; bulb 69 long,
60 wide. Nerve ring and excretory pore 96 and 408, respectively, from anterior extremity. Testis reaching anteriorly to about level of excretory pore (Fig. 8F). Region of cloaca elevated, surrounded by broad oval cuticular mound (Figs. $8 \mathrm{D}, \mathrm{F}-\mathrm{H}, 9 \mathrm{C}, \mathrm{D})$ and bearing 1 pair of large preanal papillae immediately anterior to cloaca and 2 pairs of small postanal papillae (Fig. 8D,F-H); large, median ventral caudal lobe bearing somewhat depressed pair of small postanal papillae present 93 posterior to cloacal aperture or 243 anterior to end of tail (Figs. 8D,F,I, 9C,E). Spicule simple, well sclerotised, 75 long, with sharply pointed distal tip (Fig. 8D,F,G). Tail including slender caudal spike 326 long (24\% of body length) (Fig. 8D).

Female (one nongravid specimen). Body fusiform; length including caudal spike $1.6 \mathrm{~mm}$, maximum width 218. Buccal cavity 9 long. Entire oesophagus 240 long (15\% of body length); corpus 150 long, 39 wide; isthmus 30 long, 39 wide; bulb 60 long, 75 wide. Nerve ring and excretory pore 87 and 285, respectively, from anterior extremity. Vulva 653 from anterior end of body (at $41 \%$ of body length); vulval lips not elevated (Fig. 8E). Vagina muscular, short, directed anteriorly from vulva. Reproductive apparatus didelphic. Uterus empty (Fig. 8E). Tail including slender caudal spike 571 long (36\% of body length), provided with pair of minute lateral phasmids located short distance posterior to posterior ends of lateral alae (Fig. 8E).

Hosts: Synodontis acanthomias, clown squeaker $S$. decorus Boulenger, S. greshoffi, blotched upsidedown catfish S. nigriventris David, Congo squeaker S. pleurops Boulenger (all Mochokidae, Siluriformes) and Xenocharax spilurus Günther (Distichodontidae, Characiformes).

Site of infection: Intestine.

Localities: Lower Congo River, right bank near Bulu, Democratic Republic of the Congo, $05^{\circ} 01^{\prime} 30^{\prime \prime} \mathrm{N} ; 1^{\circ} 00^{\prime} 25^{\prime \prime} \mathrm{E}$ (S. acanthostomias, collected 11 July 2008); Sangha River (S. decorus, S. greshoffi, S. pleurops, X. spilurus) and small forest stream ( $S$. nigriventris) adjacent to Sangha Lodge, $02^{\circ} 59^{\prime} 06^{\prime \prime N}$; 16¹3'59"E (Congo basin), DSPA, Central African Republic (collected 11-14 September 2012).

Prevalence and intensity: S. acanthomias: 1 fish infected/4 fish examined; 2 nematodes. S. decorus: $1 / 3 ; 8$. S. greshoff: $6 / 9 ; 1-10$. S. nigriventris: $1 / 2 ; 1$. S. pleurops: $1 / 3 ; 9$. X. spilurus: $1 / 1 ; 12$.

Deposition of voucher specimens: IPCAS N-1142.

Remarks. The morphology and measurements of present specimens correspond more or less to the original description of $S$. thelastomoides provided by Petter et al. (1972) and, accordingly, they are assigned to this species. The present and first SEM observation of S. thelastomoides revealed more details of some features that are hardly visible using light microscopy (LM), mainly regarding the structure of the cephalic end and of the male cloacal region including the caudal papillae.

Synodontisia thelastomoides has so far been reported from Synodontis nigrita, S. ocellifer, S. sorex (type host) and S. zambezensis in Senegal, Chad, Benin and South Africa (Petter et al. 1972, Vassiliadès and Troncy 1974, Vassiliadès 1976, Boomker 1994, Dougnon et al. 2012). In 

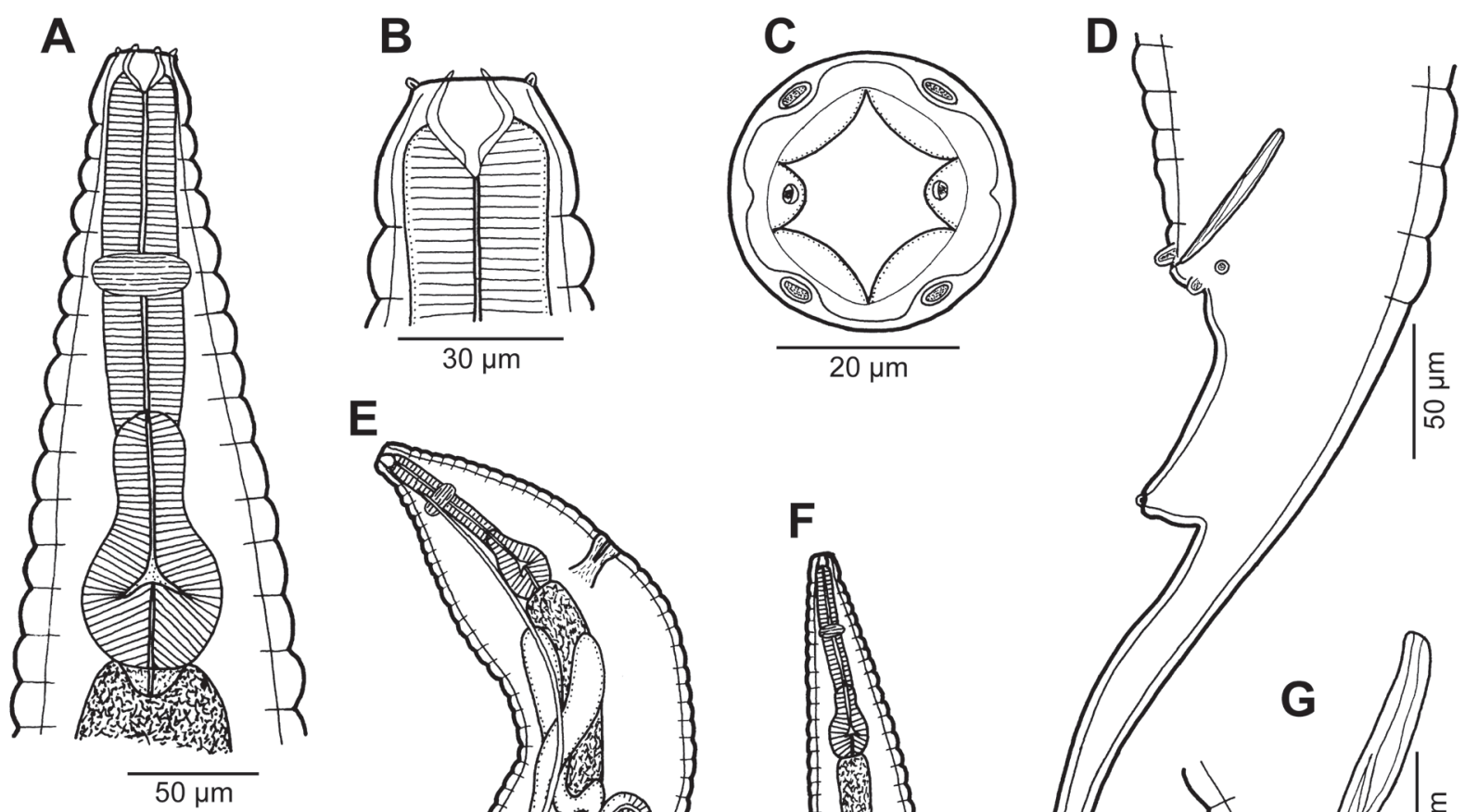

$\mathbf{E}$
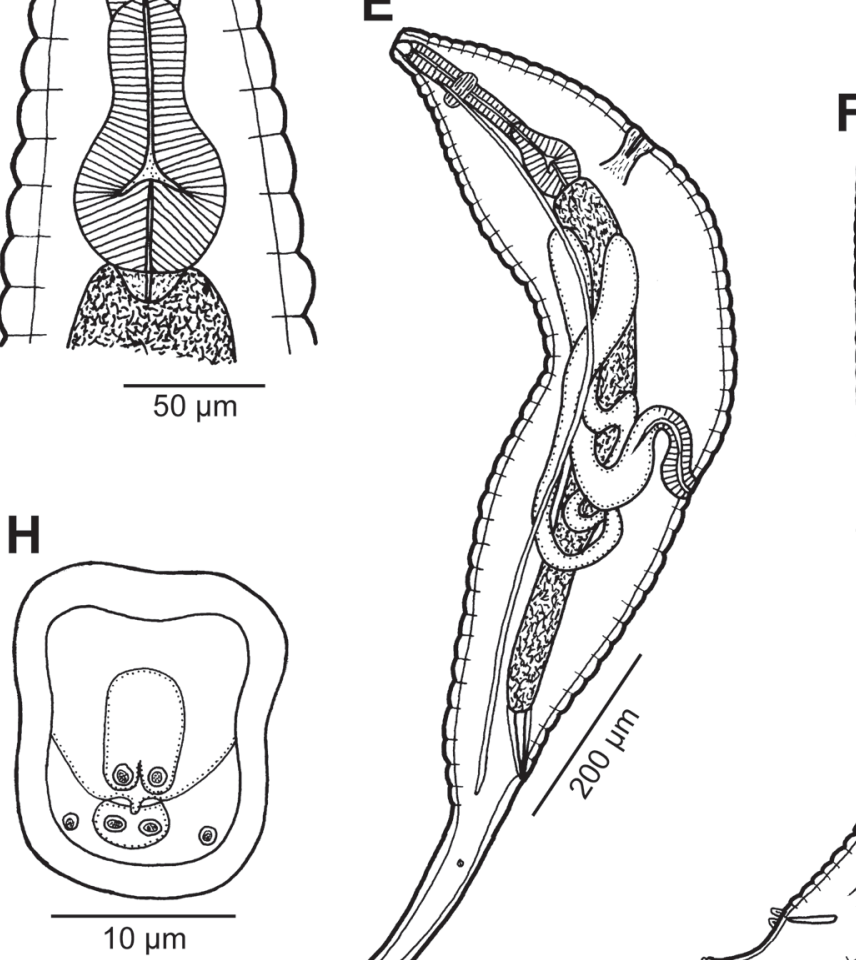

$\mathbf{F}$

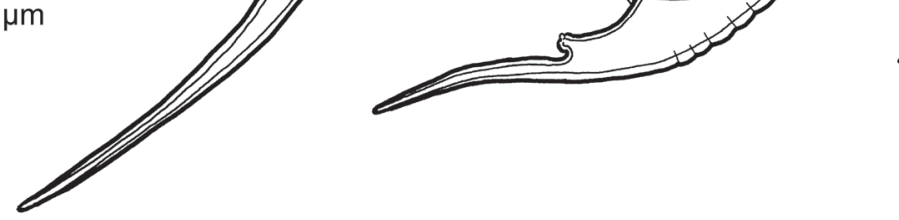

Fig. 8. Synodontisia thelastomoides Petter, Vassiliadès et Troncy, 1972 from Synodontis acanthomias Boulenger. A - anterior end of male, lateral view; B, C - cephalic end of male, lateral and apical views, respectively; $\mathbf{D}$ - posterior end of male, lateral view; $\mathbf{E}, \mathbf{F}$ - total view of young female and male, respectively, lateral views; $\mathbf{G}$ - spicule, lateral view; $\mathbf{H}$ - region of cloaca, ventral view; $\mathbf{I}$ - last pair of postanal papillae, sublateral view.

South Africa, this species was recorded by Boomker (1994) from $S$. zambezensis, but no morphological data were provided. Considering the geographical region, it may well be that his nematodes belonged in fact to S. okavangoensis Moravec et Van As, 2004, a parasite of Synodontis nigromaculatus in nearby Botswana; this congeneric species was described only ten years later (Moravec and Van As 2004). In contrast to $S$. thelastomoides, the cephalic papillae of $S$. okavangoensis are crescent-shaped. The present finding of $S$. thelastomoides in S. acanthomias in the Democratic Republic of the Congo and those from S. greshoffi, $S$. decorus, $S$. nigriventris, $S$. pleurops and $X$. spilurus in the Central African Republic represent new host and geographical records of this nematode species.
Seuratoidea Hall, 1916

Quimperiidae Gendre, 1928

Gendria longispiculata sp. n.

Figs. 10-12

ZooBank number for species:

urn:lsid:zoobank.org:act:1C60406E-BD12-476D-8CD7-F5991C905919

Description male (1 specimen, holotype). Medium-sized, whitish nematode with bulbous cephalic region and smooth cuticle. Length of body $16.3 \mathrm{~mm}$, maximum width 422. Cephalic vesicle well developed, 123 long and 141 wide (Figs. 10A,B, 11A,H). Oral aperture almost 

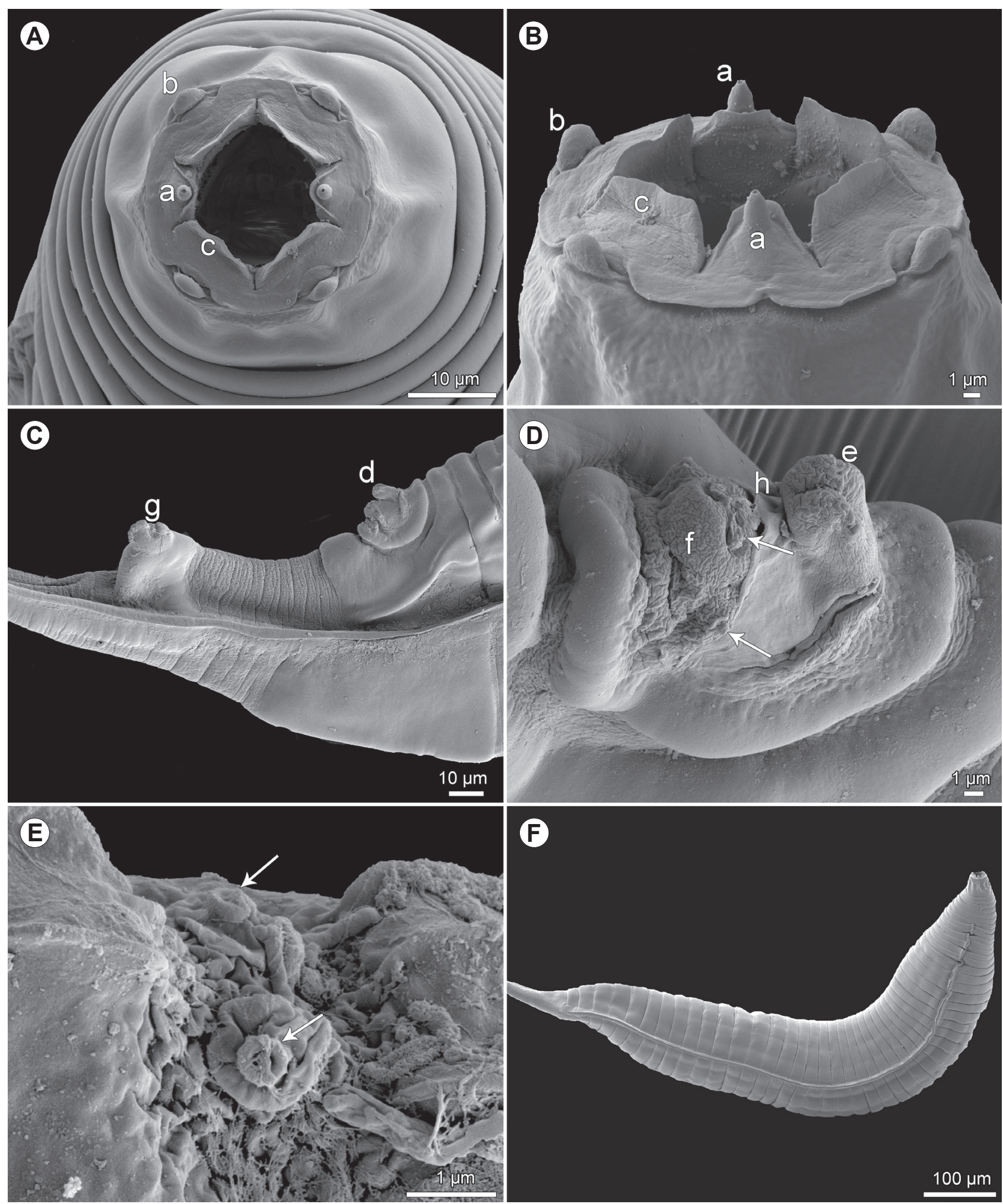

Fig. 9. Synodontisia thelastomoides Petter, Vassiliadès et Troncy, 1972 from Synodontis acanthomias Boulenger, scanning electron micrographs. A, B - cephalic end of male, apical and lateral views, respectively; $\mathbf{C}$ - region of cloaca and anterior part of tail, lateral view; $\mathbf{D}$ - region of cloaca, subventral view (arrows indicate subventral and lateral postanal papillae); $\mathbf{E}$ - median pair of postanal papillae (see arrows) on ventral caudal lobe situated some distance posterior to cloaca; $\mathbf{F}$ - body of male with distinct lateral alae, lateral view. Abbreviations: $\mathrm{a}$-amphid; $\mathrm{b}$ - cephalic papilla; $\mathrm{c}$-cephalic lamella; $\mathrm{d}$-genital cone; $\mathrm{e}$ - pair of preanal papillae; $\mathrm{f}$ - postcloacal region with two pairs of postanal papillae; $\mathrm{g}$ - ventral caudal lobe bearing median pair of postanal papillae; $\mathrm{h}$ - cloacal aperture.

circular, surrounded by 6 (2 dorsolateral, 2 ventrolateral and 2 lateral) slightly outlined cuticular lobes giving hexagonal appearance of mouth in apical view; these lip-like formations, 15 high, continuous posteriorly with cephalic vesicle. Oral aperture surrounded by 8 submedian cephalic papillae arranged in 2 circles, each formed by 4 papil- 

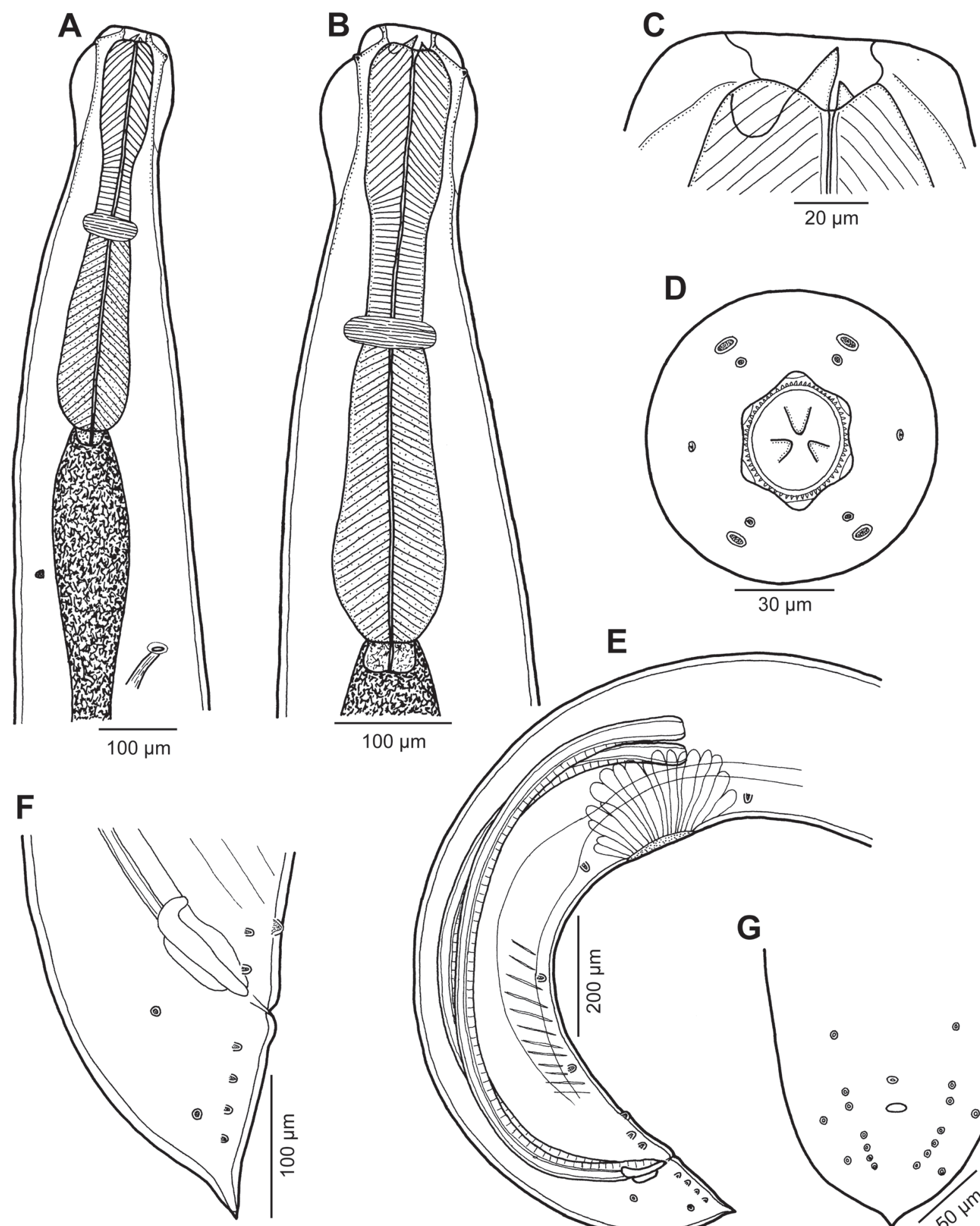

E

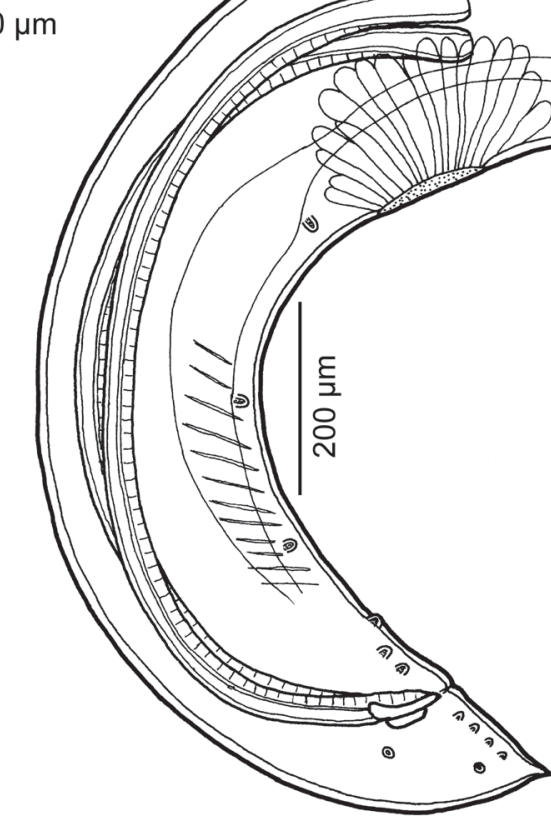

Fig. 10. Gendria longispiculata sp. n. from Schilbe grenfelli (Boulenger), male. A - anterior end of body, sublateral view; B - same, larger magnification; C, D - cephalic end, sublateral and apical views, respectively; $\mathbf{E}$ - posterior end, lateral view; F, G-tail, lateral and ventral views, respectively.

lae, and 2 small lateral papilla-like amphids; papillae of inner circle distinctly smaller than those of outer circle (Figs. 10D, 11A-C). Anterior edge of proper oral aperture provided internally with row of numerous small denticles visible only in SEM (Figs. 10D, 11D,E). Mouth depressed, buccal cavity with 3 conical teeth, 1 large dorsal (12 high) and 2 smaller ventrolateral (9 high) (Fig. 10A-D). Oesoph- agus 558 long, at level of nerve ring subdivided into anterior muscular portion and posterior muscular-glandular portion opening into intestine through large valve; anterior half of anterior portion of oesophagus somewhat expanded, 159 long and 78 wide; posterior portion of oesophagus expanding posteriorly, 261 long and 102 wide; minimum width of oesophagus 48 (Fig. 10A,B). Nerve ring 

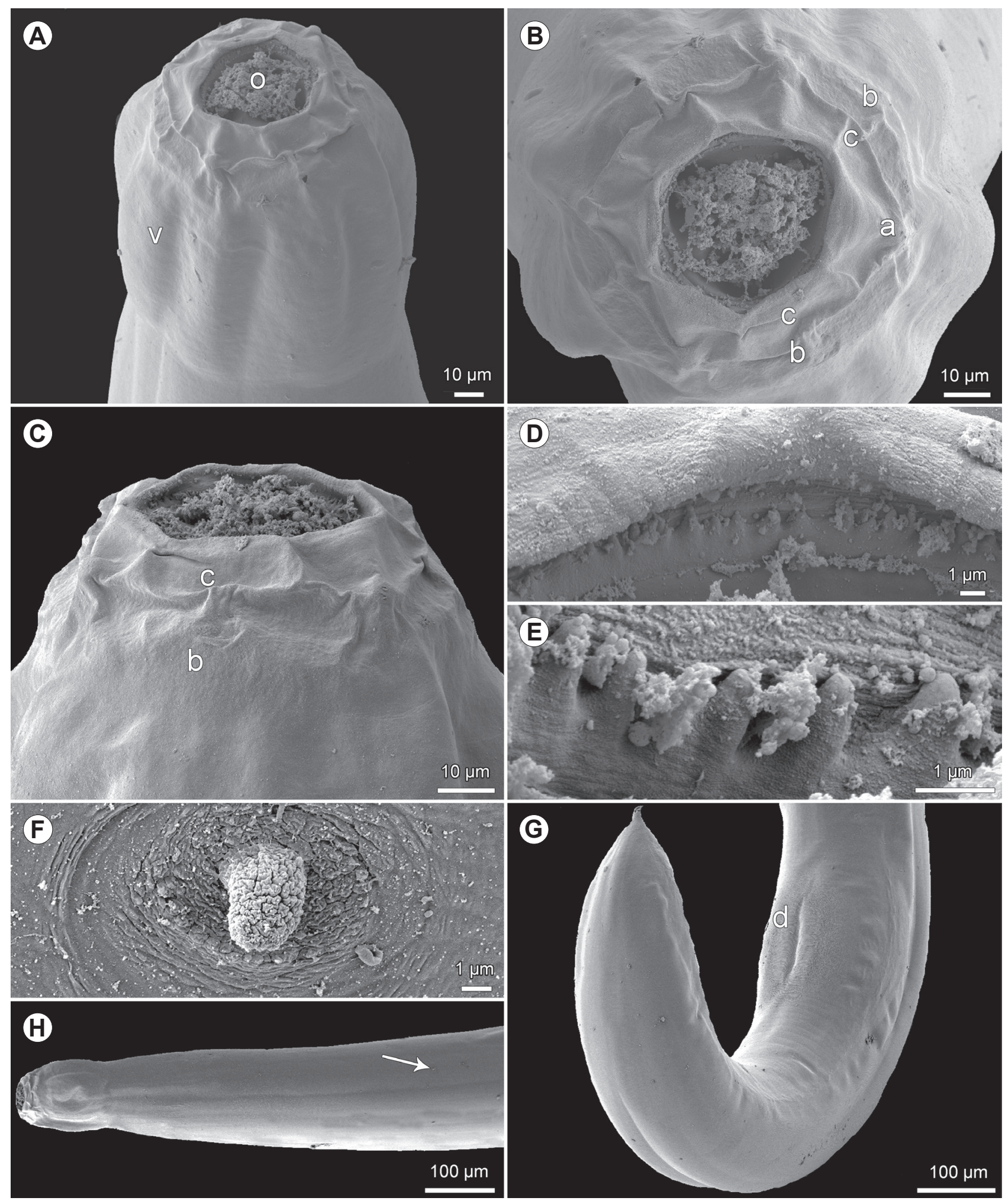

Fig. 11. Gendria longispiculata sp. n. from Schilbe grenfelli (Boulenger), scanning electron micrographs of male. A - anterior end of body, lateral view; B, C - cephalic end, apical and sublateral views, respectively; D - edge of oral aperture with row of denticles; $\mathbf{E}$ - same, enlarged denticles; $\mathbf{F}$ - deirid; $\mathbf{G}$ - posterior end of male, ventrolateral view; $\mathbf{H}$ - anterior portion of body, lateral view (arrow indicates deirid). Abbreviations: a - amphid; b - cephalic papilla of outer circle; c - cephalic papilla of inner circle; $\mathrm{d}$ - ventral sucker; $\mathrm{o}$ - oral aperture; $\mathrm{v}$ - cephalic vesicle.

and small deirids 286 and 798, respectively, from anterior end of body (Figs. 10A, 11F). Excretory pore located short distance posterior to level of deirids, at 884 from anterior extremity. Posterior end of body ventrally curved, provided with distinct ventral sucker located 884 anterior to cloacal opening and with many inconspicuous, paired oblique subventral muscle bands in region between sucker and cloaca (Figs. 10E, 11G, 12A). Testis reaching anteriorly to $2.4 \mathrm{~mm}$ 

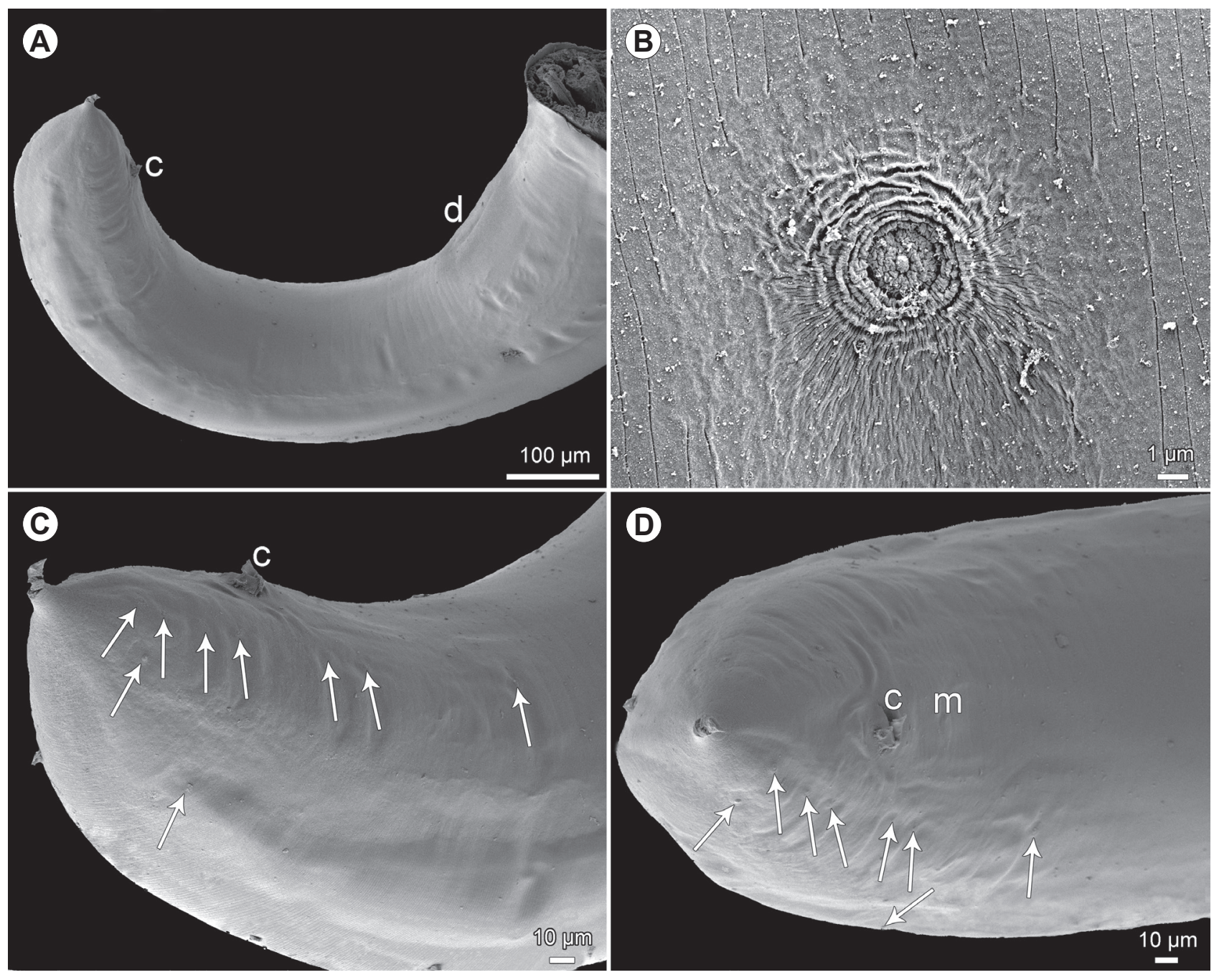

Fig. 12. Gendria longispiculata sp. n. from Schilbe grenfelli (Boulenger), scanning electron micrographs of male. A - posterior end of body, lateral view; B - subventral genital papilla located anterior to ventral sucker; C, D - caudal end, lateral and ventral views, respectively (arrows indicate genital papillae). Abbreviations: c - cloacal opening; $\mathrm{d}$ - ventral sucker; $\mathrm{m}$ - median precloacal papilla.

below posterior end of oesophagus; seminal vesicle posterior to level of pseudosucker. Spicules alate, equal, 1,224 long; withdrawn spicules reach approximately from anterior margin of pseudosucker to cloacal opening (Fig. 10E). Gubernaculum of complex structure, 99 long, with proximal tip ventrally curved in lateral view (Fig. 10F). Genital papillae very small, difficult to observe (Fig. 12B). Preanal papillae: 6 subventral pairs and 1 median ventral papilla located short distance anterior to cloaca. Postanal papillae: 6 pairs (4 subventral and 2 lateral) (Figs. 10E-G, 12C,D). Tail conical, pointed, 150 long, forming short posterior narrowed portion 30 long and 15 wide (Figs. 10E-G, 11G, 12A,C).

Female. Not known.

Type host: Schilbe grenfelli (Boulenger) (Schilbeidae, Siluriformes).

Site of infection: Intestine.

Type locality: Lower Congo River, right bank near Bulu, Democratic Republic of the Congo, $05^{\circ} 01^{\prime} 30^{\prime \prime} \mathrm{N} ; 1^{\circ} 00^{\prime} 25^{\prime \prime} \mathrm{E}$ (collected 11 July 2008).

Prevalence and intensity: 1 nematode found in one of two specimens of $S$. grenfelli examined.
Deposition of type specimen: IPCAS N-1132 (body ends of holotype mounted on SEM stub, middle part of body in a vial).

Etymology: The name longispiculata relates to the most characteristic feature of this nematode species, i.e. the presence of unusually long spicules as compared with congeners.

Remarks. Three quimperiid genera, Buckleynema Ali et Singh, 1954, Chabaudus Inglis et Ogden, 1965 and Gendria Baylis, 1930, include morphologically very similar species parasitising freshwater fishes and amphibians in Africa and South Asia. The only intergeneric features are some details in the cephalic structure (Ivashkin and Khromova 1976, Anderson et al. 2009). Whereas the buccal cavity of Buckleynema is allegedly armed with six teeth, that of Chabaudus or Gendria possesses three teeth; the oral aperture of Chabaudus is surrounded by three bilobed lip-like formations giving it a hexagonal appearance of mouth in apical view, in contrast to allegedly circular oral aperture in Gendria. However, it is necessary to remark that these structures are very difficult to observe in LM and can be properly studied only by SEM. However, none of the species of Buckleynema and Gendria has so far been 
examined using SEM and the only species of Chabaudus studied by this method is C. leberrei (Bain et Philippon, 1969), a parasite of African frogs and toads (Jackson et al. 2001). Most species of these three genera were inadequately described and their cephalic ends were rarely studied in apical view under the LM.

Of ten nominal species of Gendria (see Baylis 1930, Vassiliadès and Chevalier 1973, Ivashkin and Khromova 1976, Baker 1987, Sood 1990), most have been described from amphibians in Africa and South Asia, whereas only two are known to parasitise freshwater fishes in Africa: G. tilapiae Baylis, 1930 from Sarotherodon galilaeus (Linnaeus) (Cichlidae) in Mali (Baylis 1930, Chabaud 1956) and G. polypteri Vassiliadès et Chevalier, 1973 from Polypterus senegalus Cuvier and Erpetoichthys calabaricus Smith (both Polypteridae) in Senegal (Vassiliadès and Chevalier 1973, Vassiliadès 1976) and Nigeria (fish imported into the Czech Republic), respectively (Řehulková et al. 2005).

To date, six species of Chabaudus are known, four of which occur in Africa: C. chabaudi Inglis et Ogden, 1965 and C. thysi (Puylaert, 1970) from catfishes Heterobranchus bidorsalis Geoffroy Saint-Hilaire (Clariidae) in Sierra Leone and Parauchenoglanis punctatus (Boulenger) (Claroteidae) in the Democratic Republic of Congo, respectively (Inglis and Ogden 1965, Puylaert 1970a), and C. leberrei and C. williamsi (Puylaert, 1970a) from amphibians in Togo, Sudan and Swaziland, and from Sierra Leone, respectively (see Rizvi et al. 2016). Two other species of this genus, C. alaini Alfonso-Roque, 1981 and C. dehradunensis Rizvi, Bursey et Maity, 2016, are known from amphibians in Indonesia and India, respectively (see Rizvi et al. 2016).

The genus Buckleynema includes four inadequately described species, all from freshwater fishes in India: B. buckleyi Ali et Singh, 1954 from Mystus cavasius (Hamilton) (Bagridae), B. channai Gupta et Srivastava, 1983 from Channa striata (Bloch) (Channidae), B. notopteri Gupta et Srivastava, 1983 from Notopterus notopterus (Pallas) (Notopteridae) and B. singhi Rai, 1969 from Sperata seenghala (Sykes) (Bagridae) (see Sood 1989).

By its general morphology and in having the mouth with six circumoral cuticular lobes, the present specimen should belong to Chabaudus. However, the validity of this genus is questionable. The cephalic end of the type species of Gendria, G. tilapiae, was studied in apical view by Chabaud (1956) and Inglis (1967) under the LM; they reported the oral aperture to be circular, without lips, but their line drawings are too schematic, indicating that slightly developed circumoral cuticular lobes might have been easily overlooked. Moreover, cephalic cuticular lobes (or lip-like formations) may be poorly developed in some species of Chabaudus, as for example in C. dehradunensis, and in different congeneric species the shape of mouth is from triangular to hexagonal, and might apparently appear as almost circular; the shape of the proper oral aperture may be circular, as visible in the present specimen (Fig. 10D). Reliable data on the cephalic structure of other species of Gendria are absent, only Vassiliadès and Chevalier (1973) illustrated six lip-like formations on the cephalic end (in apical view) of G. polypteri studied by LM, which is, however, characteristic of Chabaudus.

Taking into account the above discussion, in our opinion the reported differences in the shape of mouth (hexagonal or circular) cannot be taken for the feature of a generic importance and, therefore, we consider Chabaudus to be a junior synonym of Gendria. Accordingly, species listed in the former genus are transferred to Gendria as G. alaini (Alfonso-Roque, 1981) comb. n., G. chabaudi (Inglis et Ogden, 1965) comb. n., G. dehradunensis (Rizvi, Bursey et Maity, 2016) comb. n., G. thysi (Puylaert, 1970) comb. n. and G. williamsi (Puylaert, 1970) comb. n.

Gendria longispiculata sp. n. is easily distinguished from all other species of Gendria, as well as of those belonging to Buckleynema, by its conspicuously long spicules; whereas spicules of the new species measure $1.2 \mathrm{~mm}$ and, when withdrawn, they reach anteriorly the level of the ventral sucker, those in all other species of Gendria and Buckleynema are at most $570 \mu \mathrm{m}$ long (but usually much shorter), reaching anteriorly to about midlength between the cloacal opening and the ventral sucker or less when withdrawn. The new species also differs from its congeners from African fishes in the shape of the oesophagus or cephalic vesicle, distribution of postanal papillae and in the host family (Schilbeidae vs Cichlidae, Clariidae, Claroteidae and Polypteridae).

The presence of a row of small denticles at the edge of the oral apeture (Fig. 11D,E) in a species of Gendria is reported for the first time. Similar denticles at the edge of the oral aperture are also present in representatives of some other seuratoid genera, e.g. Cucullanus Müller, 1777, Seuratum Hall, 1916 or Skrjabinura Gnedina, 1933 (see Inglis 1967). Gendria longispiculata is the first quimperiid species reported parasitising catfishes of the family Schilbeidae.

Gendria sanghaensis sp. n.

Figs. 13-15

ZooBank number for species:

urn:lsid:zoobank.org:act:E8A7CB6C-43BD-4070-AA25-3D3156043085

Description. Medium-sized, whitish nematodes with bulbous cephalic region and smooth cuticle. Cephalic vesicle well developed (Figs. 13A-C, 14D). Oral opening almost oval, surrounded by 6 (2 dorsolateral, 2 ventrolateral and 2 lateral) slightly outlined cuticular lobes giving hexagonal appearance of mouth in apical view; these liplike formations are continuous posteriorly with cephalic vesicle (Figs. 13A-D, 14A,B). Oral aperture surrounded by 8 submedian cephalic papillae arranged in 2 circles, each formed by 4 papillae, and 2 small lateral papilla-like amphids; papillae of inner circle distinctly smaller than those of outer circle (Figs. 13D, 14A,B). Anterior edge of proper oral aperture internally with row of small denticles (Figs. 13D, 14C). Mouth depressed, buccal cavity with 3 conical teeth (Figs. 13A-D, 14B). Oesophagus at level of nerve ring subdivided into anterior muscular portion and posterior muscular-glandular portion opening into intes- 

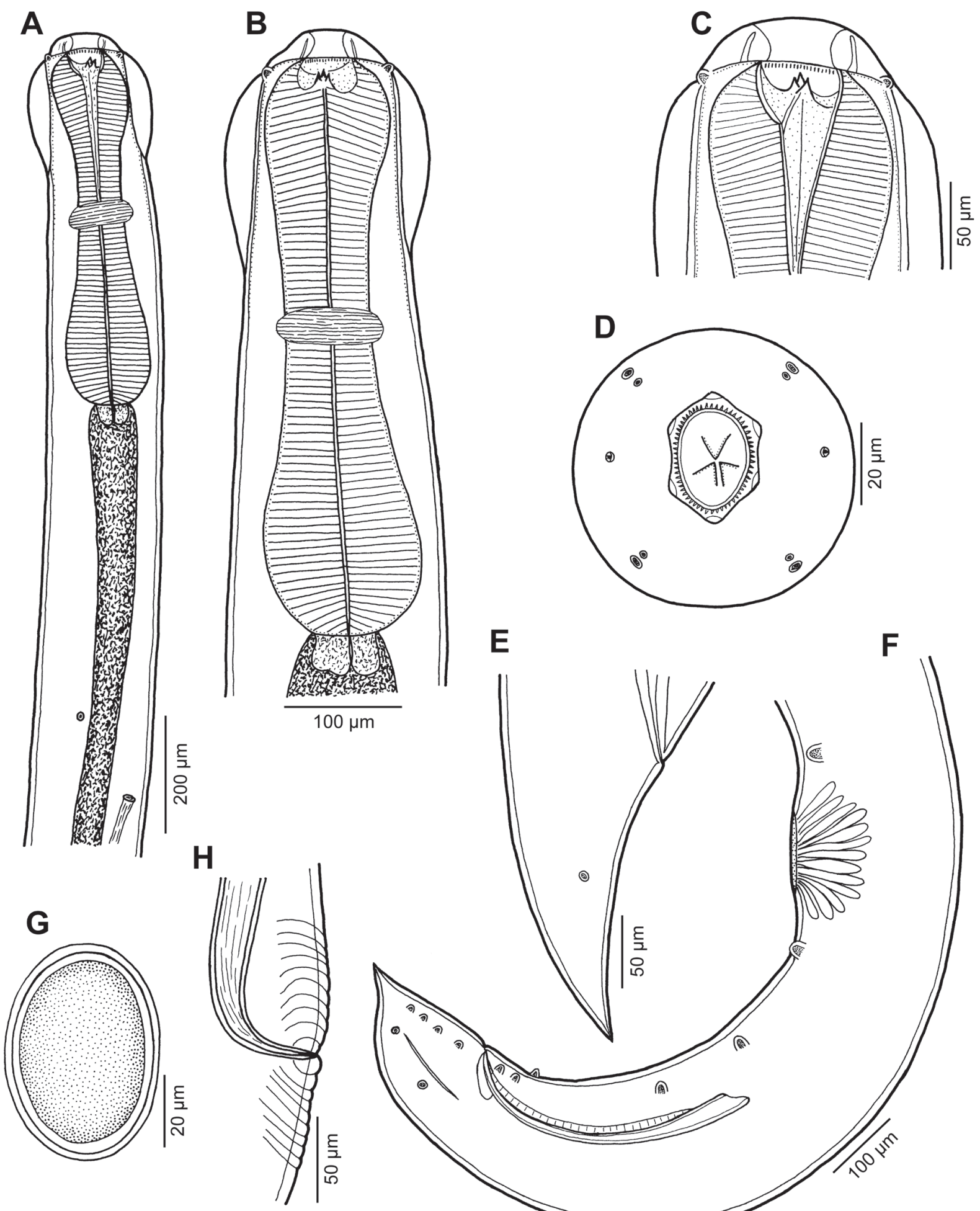

G

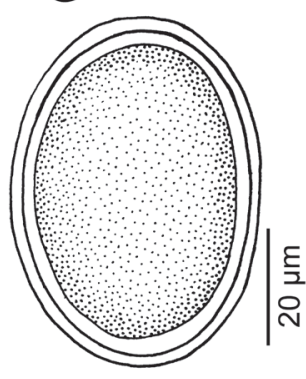

E

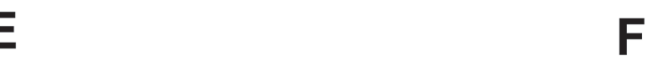

F

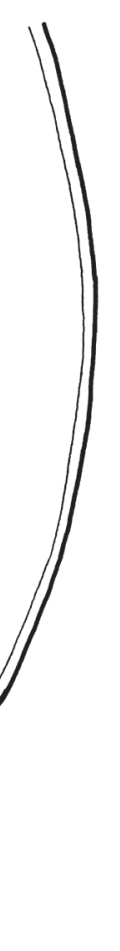

Fig. 13. Gendria sanghaensis sp. n. from Schilbe marmoratus Boulenger. A - anterior end of female, sublateral view; $\mathbf{B}$ - same, enlarged; C, D - cephalic end of female, lateral and apical views, respectively; $\mathbf{E}$ - tail of female, lateral view; $\mathbf{F}$ - posterior end of male, lateral view; $\mathbf{G}$ - egg; H - vulva, lateral view.

tine through large valve; anterior half of anterior portion of oesophagus somewhat expanded; posterior portion of oesophagus expanding posteriorly (Fig. 13A-C). Nerve ring approximately at mid-length of oesophagus, small deirids situated far posterior to posterior end of oesophagus. Excretory pore located short distance posterior to level of deirids (Figs. 13A, 14D,E). Tail conical, pointed.
Male (two specimens; holotype; measurements of paratype in parentheses). Length of body $14.7 \mathrm{~mm}(15.2 \mathrm{~mm})$, maximum width 326 (340). Cephalic vesicle 165 (120) long and 129 (120) wide. Lip-like formations 12 (15) high. Oesophageal teeth in buccal cavity 6 (6-9) high. Oesophagus 517 (503) long; its anterior portion anterior to nerve ring 204 (240) long and 109 (93) wide; posterior expand- 

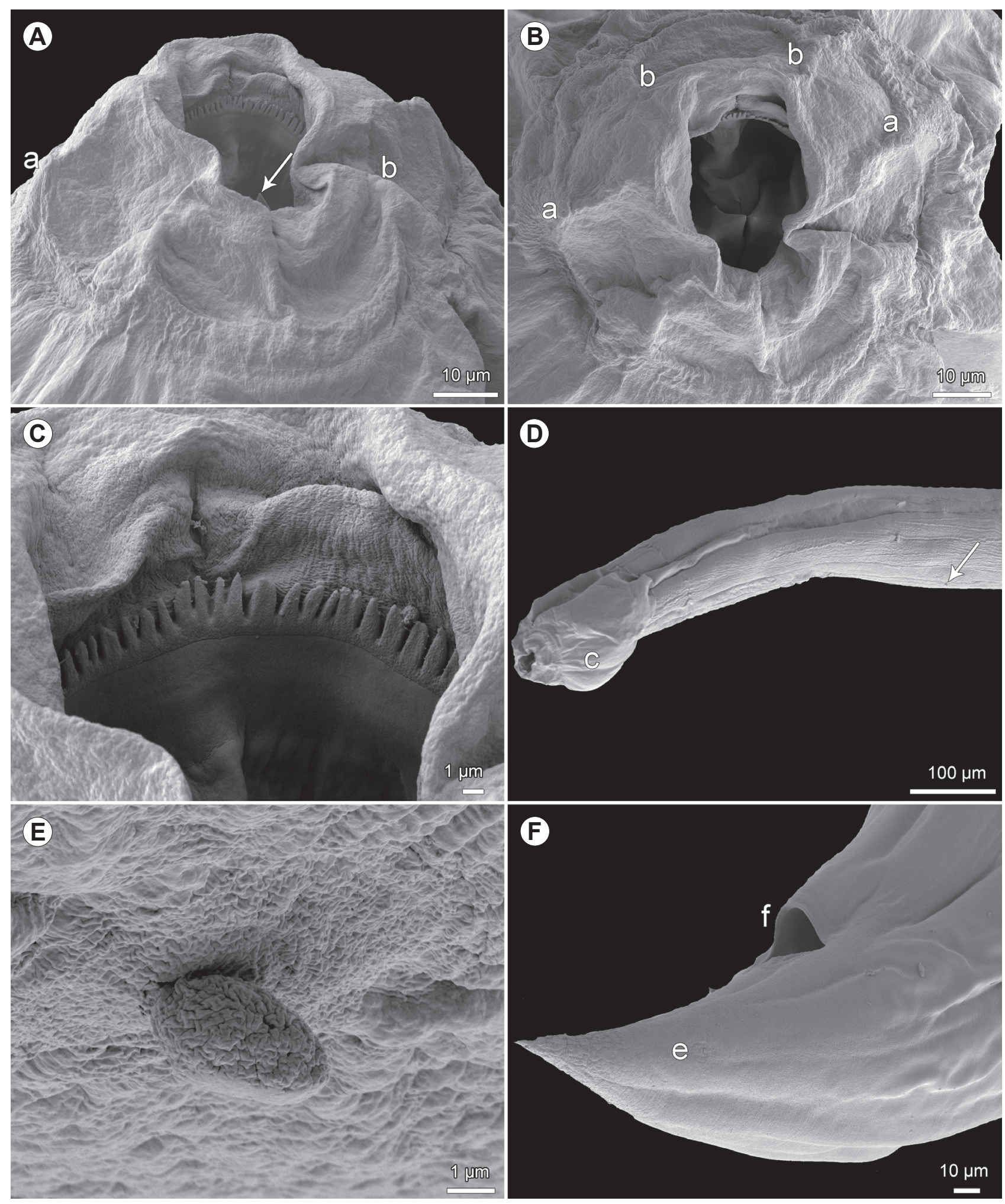

Fig. 14. Gendria sanghaensis sp. n. from Schilbe marmoratus Boulenger, scanning electron micrographs. A, B - cephalic end of male, subapical and apical views (arrow indicates protruding oesophageal tooth); $\mathbf{C}$ - row of denticles in mouth, ventral view; $\mathbf{D}$ - anterior end of male, ventral view (arrow indicates deirid); $\mathbf{E}$ - deirid; F - tail of female, lateral view. Abbreviations: a - amphid; b - two submedian cephalic papillae; $\mathrm{c}$ - cephalic vesicle; $\mathrm{e}$ - phasmid; $\mathrm{f}$ - anus.

ed portion posterior to nerve ring 272 (243) long and 122 (129) wide; minimum width of oesophagus 57 (72). Nerve ring, deirids and excretory pore 245 (299), 830 (789) and 870 (830), respectively, from anterior end of body. Posterior end of body ventrally curved, provided with ventral sucker located 734 (843) anterior to cloaca (Fig. 13F). Spicules alate, equal, 438 (414) long; withdrawn spicules reach approximately to mid-way between cloaca and ventral sucker (Fig. 13F). Gubernaculum 54 (57) long. Preanal papillae: 6 subventral pairs and 1 median ventral papilla lo- 

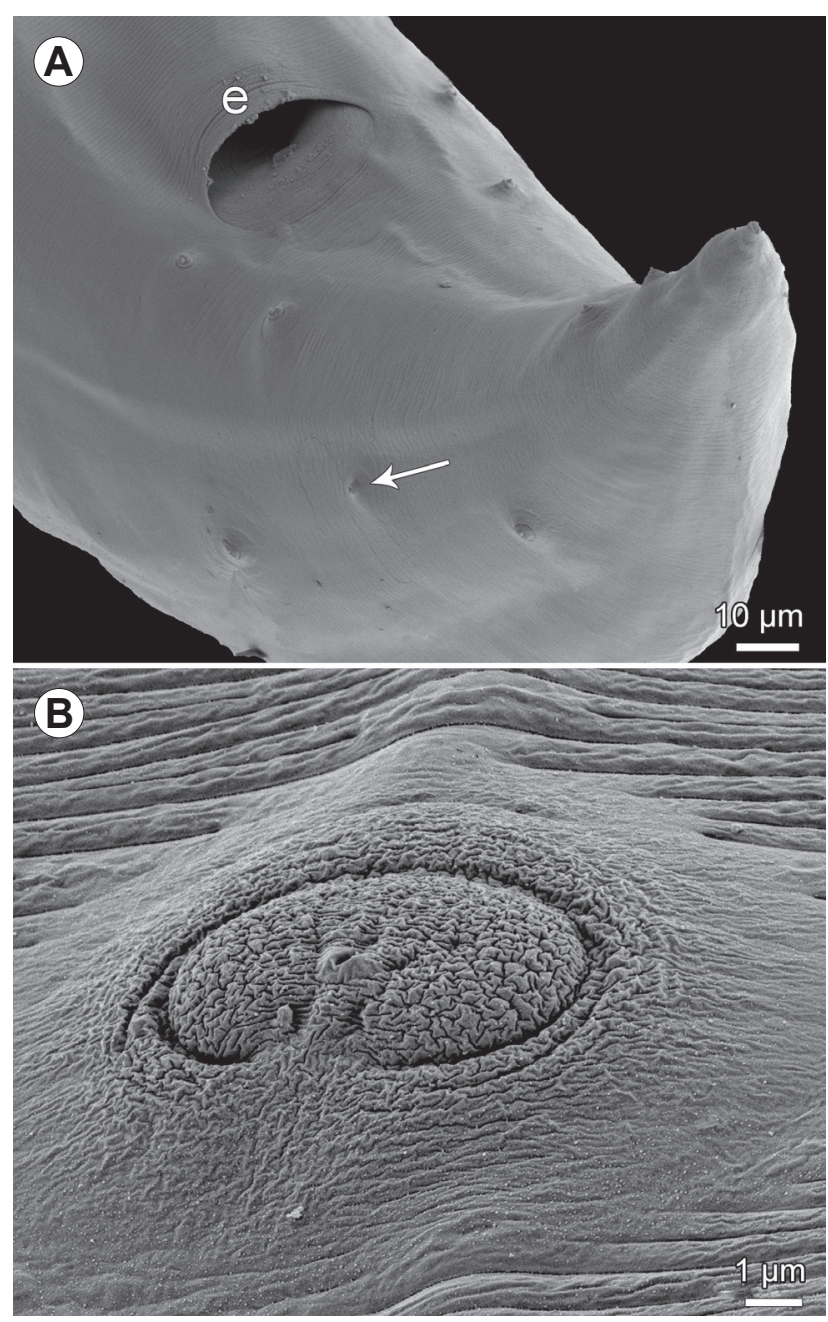

Fig. 15. Gendria sanghaensis sp. n. from Schilbe marmoratus Boulenger, scanning electron micrographs. A - tail of male, ventrolateral view (arrow indicates phasmid); $\mathbf{B}$ - median precloacal papilla. Abbreviation: e - cloacal aperture.

cated short distance anterior to cloaca (Figs. 13F, 15A,B). Postanal papillae: 6 pairs (4 subventral and 2 lateral); small lateral phasmids located between lateral postanal papillae (Figs. 13F, 15A). Tail conical, pointed, 201 (180) long.

Female (two gravid specimens; allotype; measurements of paratype in parentheses). Length of body $21.5 \mathrm{~mm}$ $(17.9 \mathrm{~mm})$, maximum width 490 (435). Cephalic vesicle 174 (180) long and 174 (174) wide. Lip-like formations 18 (18) high. Oesophageal teeth in buccal cavity 9 (9) high. Oesophagus 558 (558) long; its anterior portion anterior to nerve ring 233 (228) long and 123 (123) wide; posterior expanded portion posterior to nerve ring 300 (300) long and 159 (120) wide; minimum width of oesophagus 87 (81). Nerve ring, deirids and excretory pore 256 (272), 1,034 $(1,061)$ and $1,156(1,170)$, respectively, from anterior end of body. Uteri opposed. Vulva situated $13.8 \mathrm{~mm}(11.2 \mathrm{~mm})$ from anterior extremity, at 64\% (62\%) of body length. Vulval lips not elevated, with distinctly transversely striated cuticule (Fig. 13H). Vagina short, directed anteriorly from vulva. Uterus filled with many eggs. Eggs irregularly oval, thin-walled, size 51-63 × 42-51 $(60-66 \times 45-51)$, with content uncleaved or rarely cleaved into two blastomeres (Fig. 13G). Tail conical, 394 (225) long (Figs. 13E, 14F).

Type host: Shoulderspot catfish Schilbe marmoratus Boulenger (Siluriformes: Schilbeidae).

Site of infection: Intestine.

Type locality: Sangha River adjacent to Sangha Lodge, $02^{\circ} 59^{\prime} 06^{\prime \prime} \mathrm{N} ; 16^{\circ} 13^{\prime} 59^{\prime \prime} \mathrm{E}$ (Congo basin), DSPA, Central African Republic (collected 12 September 2012).

Prevalence and intensity: 1 fish infected/4 fish examined; 5 nematodes (only four specimens analysed morphologically).

Deposition of type specimens: IPCAS N-1133 (holotype and allotype).

Etymology: The name sanghaensis relates to the type locality of this nematode species, i.e. the Sangha River.

Remarks. By the length of spicules, G. sanghaensis sp. n. resembles only G. tilapiae from African cichlids (spicules 410-490 $\mu \mathrm{m}$ long) and G. ranarum Karve, 1944 from amphibians in India (spicules 330-570 $\mu \mathrm{m}$ ) (the latter designated as species inquirenda by Baker 1987); spicules of all other congeneric species (except for G. longispiculata sp. n.), as well as those of Buckleynema spp., are distinctly shorter. However, in contrast to the new species, G. tilapi$a e$ has a circular oral aperture without lip-like structures ( $v s$ oral aperture hexagonal, with lip-like structures), the posterior portion of the oesophagus is moderately expanded ( $v s$ markedly expanded) and the body is distinctly shorter (the body length of males 7-8 mm, of females $7.7-11.5 \mathrm{~mm}$ vs males 14.7-15.2 mm, females 17.9-21.5 mm), whereas G. ranarum possesses lateral cervical alae (vs lateral alae absent), nine (vs six) pairs of preanal papillae and deirids are located at the level of the posterior end of the oesophagus ( $v s$ far posterior to the oesophagus end).

\section{Gendria sp.}

Figs. 16-18

Description. Male (body fragment with missing posterior end). Body elongate, whitish, with smooth cuticle; length of available body fragment $9.6 \mathrm{~mm}$, maximum width 231. Anterior end rounded, cephalic vesicle reduced to inflation of cuticle surrounding mouth anterior to oesophagus, 15 high (Figs. 16A-E, 17A-E, 18A-C). Mouth almost circular, with 6 rounded inner lip-like lamellae (2 dorsal, 2 ventral and 2 lateral) giving it hexagonal appearance; in addition, there is circumoral row of small denticles below these lip-like structures (Figs. 16D, 17C-E, 18AC). Bottom of buccal cavity formed by 3 flat triangular oesophageal lobes, corresponding to 3 sectors of oesophagus, with somewhat forwardly oriented tips appearing as small, moderately developed oesophageal teeth (Figs. 16D, 17D, 18B). Narrow lateral alae about 750 long present, starting just posterior to anterior extremity and extending posteriorly approximately to middle of oesophageal posterior extension (Figs. 16B,C,E, 17A-C). Oesophagus muscular, 544 long, somewhat expanded at both ends (Fig. 16A,C,E); its width at anterior end 75 , near posterior end 102; minimum width of oesophagus 51. Nerve ring encircles oesophagus at 190 from anterior extremity. Deirids small, situat- 

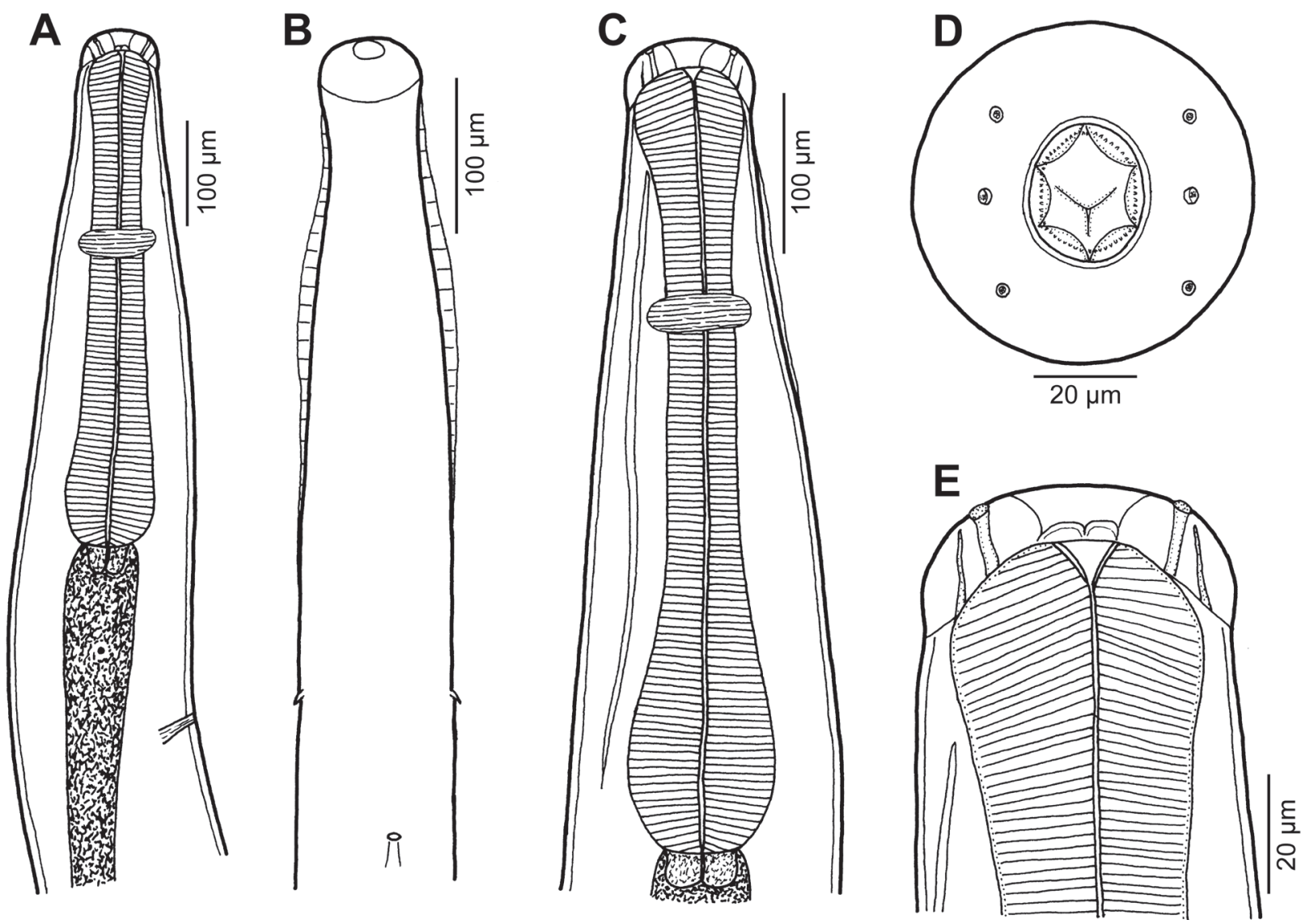

Fig. 16. Gendria sp. from Pantodon buchholzi from Pantodon buchholzi Peters, male. A, B, C - anterior end of body, lateral, ventral and sub-dorsoventral views, respectively (internal structures not illustrated in B); D, E - cephalic end, apical and sub-dorsoventral views, respectively.

ed at level of posterior oesophageal extension (Figs. 16B, 17B,C, 18D). Excretory pore located some distance posterior to end of oesophagus and deirids, at 748 from anterior end of body. Posterior end of body absent.

Female. Not known.

Host: Freshwater butterflyfish Pantodon buchholzi Peters (Osteoglossiformes: Pantodontidae).

Site of infection: Intestine.

Locality: Forest stream near Mongambe research camp, 0255'26"N; 16²3'24"E (Congo basin), DSPA, Central African Republic (collected 18 September 2012).

Prevalence and intensity: 1 fish infected/3fish examined; 1 nematode.

Deposition of voucher specimen: IPCAS N-1141.

Remarks. The general structure of the mouth of this nematode resembles that of Gendria spp. and also the presence of circumoral denticles shows its affinity with two representatives of this genus ( $G$. longispiculata and G. sanghaensis) described in this paper. However, in contrast to the type species of Gendria (G. tilapiae) and some other congeners, the present nematode possesses six well-developed circumoral lip-like structures, its cephalic vesicle is reduced to a cuticular inflation surrounding the mouth and it has distinct cervical lateral alae.

Of the species of Gendria parasitising African freshwater fishes, cervical alae were described only in G. thysi, a parasite of the catfish Parauchenoglanis punctatus (Claroteidae) in the Democratic Republic of the Congo (Puylaert 1970a), but this species differs from the present specimen mainly in having much broader cervical alae and a bifid dorsal oesophageal tooth in the mouth. Since no quimperiid has so far been reported from fishes of the order Osteoglossiformes, it is highly probable that the specimen from P. buchholzi represents a new species. However, a prerequisite for the species description and its taxonomic evaluation is a new collection of specimens from this host species. Therefore, for the time being, the present specimen is tentatively assigned to Gendria as Gendria sp.

Quimperia lanceolata Gendre, 1926

Figs. 19-21

Description. Small nematodes with smooth cuticle. Broad lateral cervical alae present, initiating short distance posterior to base of lips and extending posteriorly to level of small deirids situated somewhat anterior to level of posterior end of oesophagus (Figs. 19A-C, 20C,E,F). Buccal cavity absent. Mouth triangular, with 3 small lips. Oral aperture surrounded by 4 submedian double papillae and 2 small lateral amphids (Figs. 19D, 20A-C). Oesophagus divided into 2 portions; anterior narrow cylindrical muscular portion extends to level of nerve ring, posterior longer muscular-glandular portion somewhat broader towards its posterior end (Fig. 19A,B). Excretory pore at level of nerve 

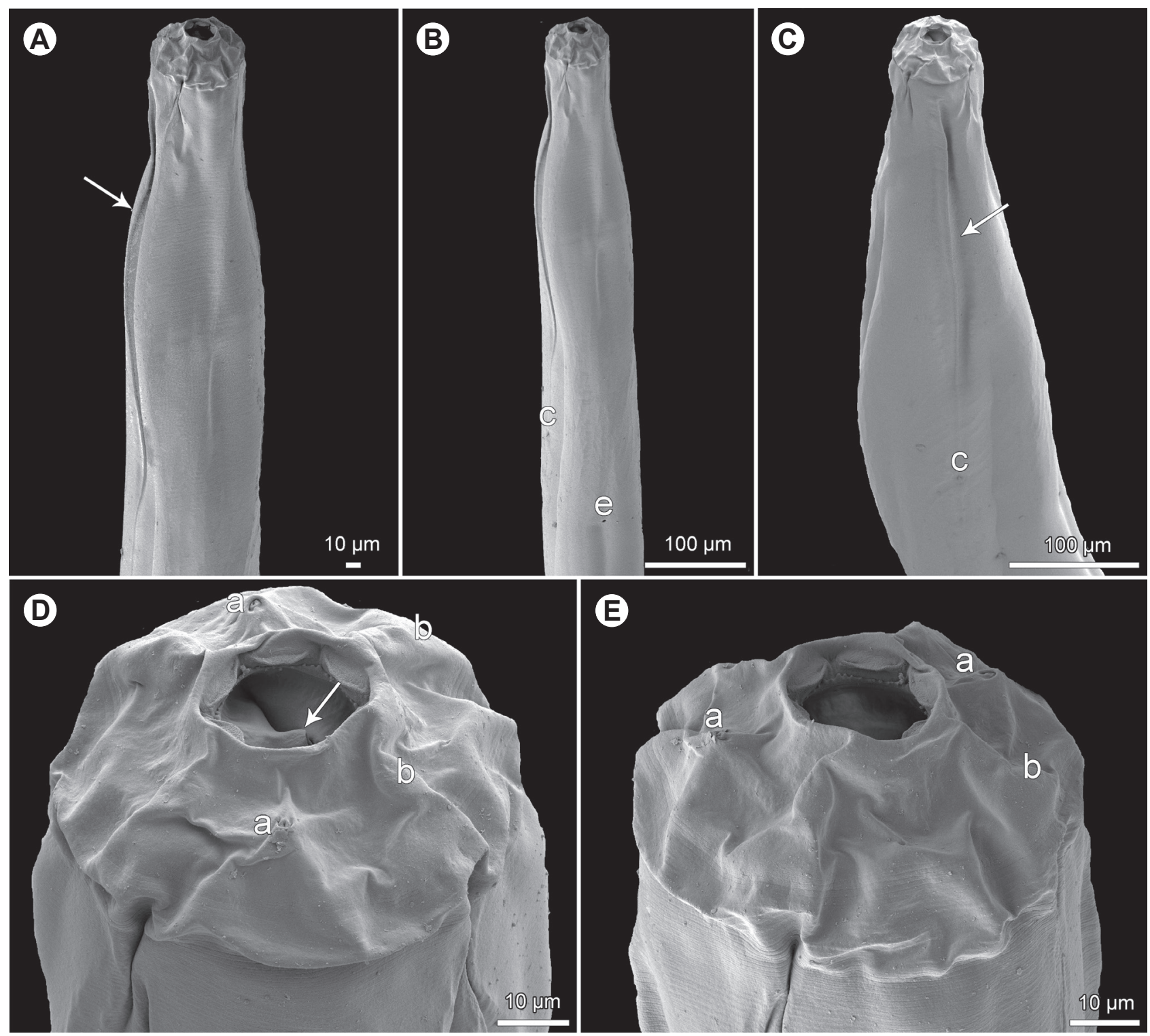

Fig. 17. Gendria sp. from Pantodon buchholzi Peters, scanning electron micrographs of male. A - anterior end, subventral view (arrow indicates lateral ala); B - same, lower magnification; C - anterior end, lateral view (arrow indicates lateral ala); D - cephalic end, subapical view from lateral side (arrow indicates protruding dorsal oesophageal tooth); $\mathbf{E}$ - cephalic end, subapical view oriented dorsoventrally. Abbreviations: a - amphid; b-cephalic papilla; c-deirid; e - excretory pore.

ring. Deirids just posterior to posterior ends of cervical alae (Figs. 19A,B, 20F). Tail of both sexes conical, pointed.

Male (1 specimen). Length of body $9.8 \mathrm{~mm}$ and maximum width 245 . Nerve ring, excretory pore and deirids 340, 340 and 911, respectively, from anterior extremity. Lateral alae $653 / 762$ long and 45 wide. Total length of oesophagus 938; anterior portion of oesophagus 288 long and 33 wide; posterior portion 612 long and 96 wide; minimum width of oesophagus 30 . Ventral precloacal sucker slightly muscular, 394 from cloacal aperture (Figs. 19E,F, 21A). Preanal papillae: 4 subventral pairs ( 1 of them anterior to sucker) and 1 unpaired median papilla situated anteriorly to cloaca. Postanal papillae: 6 pairs (4 subventral and 2 lateral). Pair of small lateral phasmids located between lateral pairs of postanal papillae (Figs. 19E,F, 20D,G, 21B). Spicules short, 341 long (Fig. 19E). Gubernaculum mod- erately sclerotised, 36 long. Caudal end ventrally curved, ending in point. Length of tail 231.

Female (1 gravid specimen). Body length $15.6 \mathrm{~mm}$, width 258. Nerve ring, excretory pore and deirids 367 , 367 and 966, respectively, from anterior extremity. Cervical alae 789 long and 30 wide. Total length of oesophagus $1.0 \mathrm{~mm}$; its anterior portion 340 long, 36 wide; posterior portion 625 long, 99 wide. Vulva not elevated, postequatorial, $10.2 \mathrm{~mm}$ from anterior extremity (at $65 \%$ of body length). Vagina short, directed anteriorly from vulva. Uterus opposed. Eggs irregularly oval, thin-walled, non-embryonated, size 69-75 × 54-60 (Fig. 19G). Tail conical with pointed end, 231 long (Fig. 19H).

Host: Tailspot ctenopoma Ctenopoma cf. kingsleyae Günther (Anabantidae, Perciformes).

Site of infection: Intestine. 

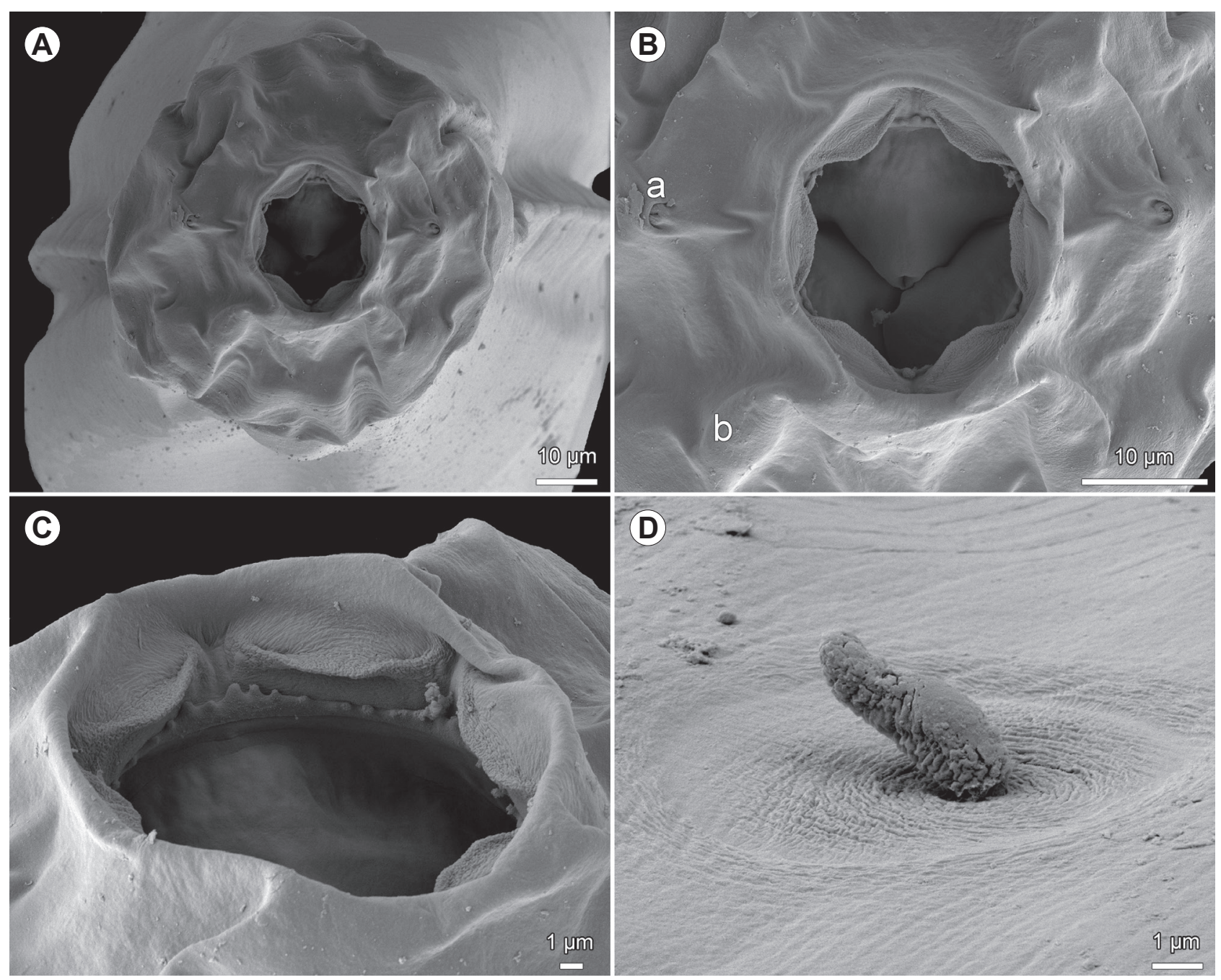

Fig. 18. Gendria sp. from Pantodon buchholzi Peters, scanning electron micrographs of male. A - cephalic end, apical view; $\mathbf{B}-$ mouth, apical view; C - mouth with visible circumoral row of denticles, subapical view; D - deirid. Abbreviations: a - amphid; b - cephalic papilla.

Locality: Forest stream adjacent to Sangha Lodge, $02^{\circ} 59^{\prime} 06^{\prime \prime N}$; $16^{\circ} 13^{\prime} 59^{\prime \prime E}$ (Congo basin), DSPA, Central African Republic (collected 14 September 2012).

Prevalence and intensity: 1 fish infected/3 fish examined; 2 nematodes.

Deposition of voucher specimen: IPCAS N-1139 (mounted on SEM stub).

Remarks. This species was originally described by Gendre (1926) from an undetermined fish (,poisson acanthoptérygien“) in Guinea. Later, based on specimens from Ctenopoma kingsleyae Günther in Senegal, Vassiliadès (1971, 1972, 1976) redescribed Q. lanceolata and carried out some experiments to elucidate the life cycle of this nematode. The morphology of present specimens is more or less in agreement with this redescription (although some measurements are somewhat greater), the host species is probably identical with that reported by Vassiliadès (1971), so there is no doubt that they belong to Q. lanceolata.

The SEM examination, for the first time used in this species, made it possible to study some morphological features in more detail. The gubernaculum, the median pre- cloacal papilla and phasmids in the male are reported here for the first time; contrary, neither conical projections on lips nor male caudal alae mentioned by Vassiliadès (1971) were observed. The present finding of $Q$. lanceolata in the Central African Republic represents a new geographical record of this species.

\section{Cucullanidae Cobbold, 1864}

\section{Cucullanus congolensis sp. n.}

Figs. 22, 23

ZooBank number for species:

urn:lsid:zoobank.org:act:95D554AD-8D31-47B2-9B10-FBF4BB698FA6

Description. Medium-sized nematodes. Body whitish, elongate, with slightly transversely striated cuticle. Lateral alae absent. Cephalic end somewhat asymmetrical in lateral view. Oral aperture dorsoventrally elongate, surrounded by raised narrow membranous ala (collarette) supported by row of $c a 70$ minute basal teeth (Figs. 22C, 23A-C). Four submedian cephalic papillae and pair of lateral amphids present (Figs. 22C, 23A-C). Oesophagus muscular, 


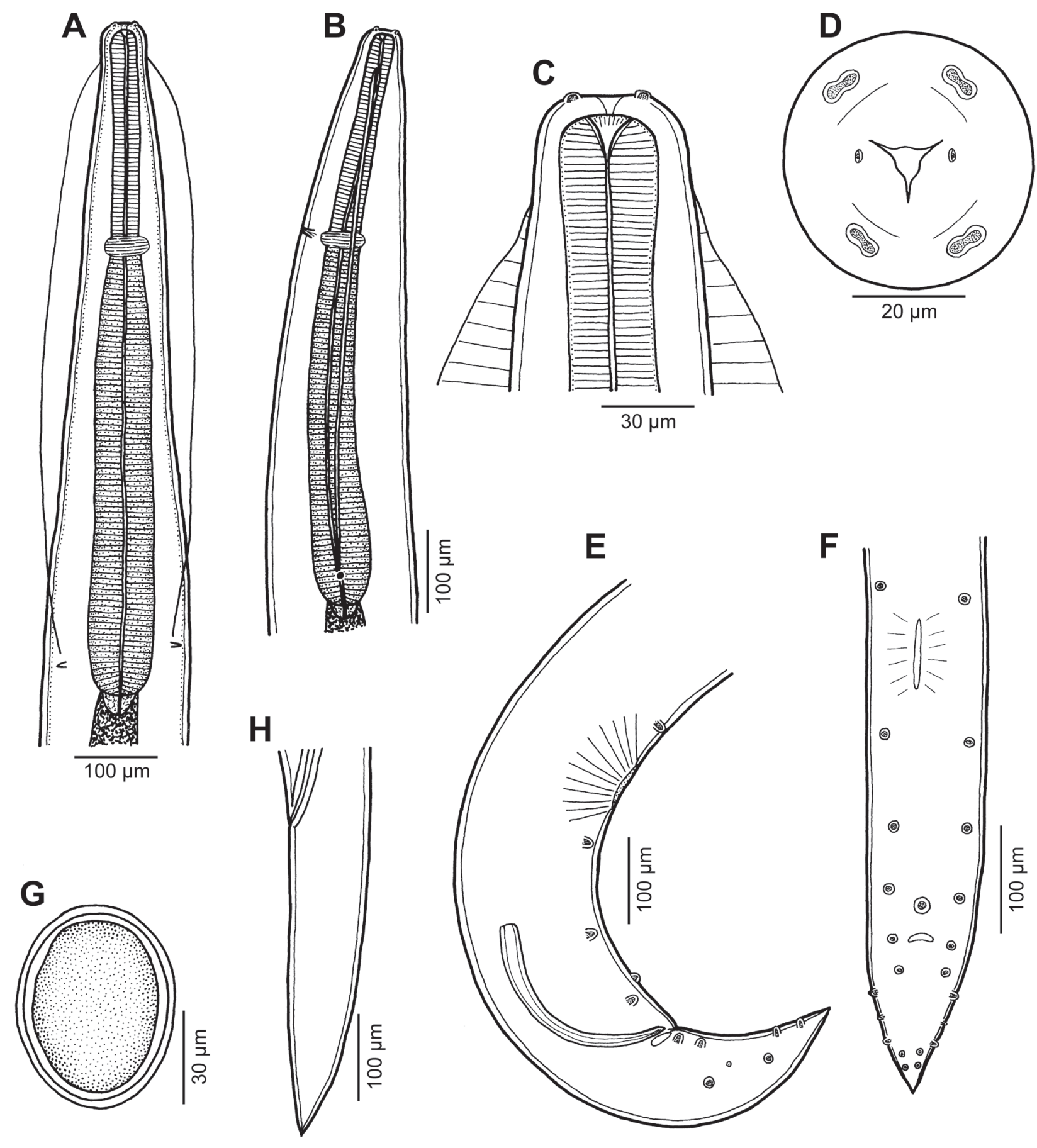

Fig. 19. Quimperia lanceolata Gendre, 1926 from Ctenopoma cf. kingsleyae Günther. A - anterior end of male, dorsoventral view; $\mathbf{B}$ - anterior end of female, lateral view; C, D - cephalic end of male, dorsoventral and apical views, respectively; E, F - posterior end of male, lateral and ventral views, respectively; $\mathbf{G}$ - egg; $\mathbf{H}$ - tail of female, lateral view.

expanded at anterior end to form bulbous pseudobuccal capsule (oesophastome); posterior part of oesophagus also expanded, somewhat narrower than oesophastome in lateral view (Fig. 22A,B). Oesophagus opens into intestine through large valve. Nerve ring encircles oesophagus at distance representing $35-42 \%$ of oesophageal length. Deirids small, situated approximately at midway between nerve ring and posterior end of oesophagus (Figs. 22A,B,E, $23 \mathrm{H})$. Postdeirids not found. Excretory pore in region of oesophago-intestinal junction (Fig. 22B). Tail of both sexes conical, sharply pointed at tip.
Male (2 specimens; holotype; measurements of paratype in parentheses). Length of body $6.7 \mathrm{~mm}(5.0 \mathrm{~mm})$, maximum width 231 (163); width at level of oesophastome 165 (150), at middle of oesophagus 159 (136). Length of entire oesophagus 775 (775), representing 12\% (16\%) of whole body length; length of oesophastome 240 (225), its width 150 (111); minimum width of oesophagus 63 (45); maximum width of posterior part of oesophagus 120 (105). Distance of nerve ring from anterior extremity 313 (326), representing $40 \%(42 \%)$ of oesophageal length. Deirids and excretory pore 517 (707) and 748 (775), respectively, from 

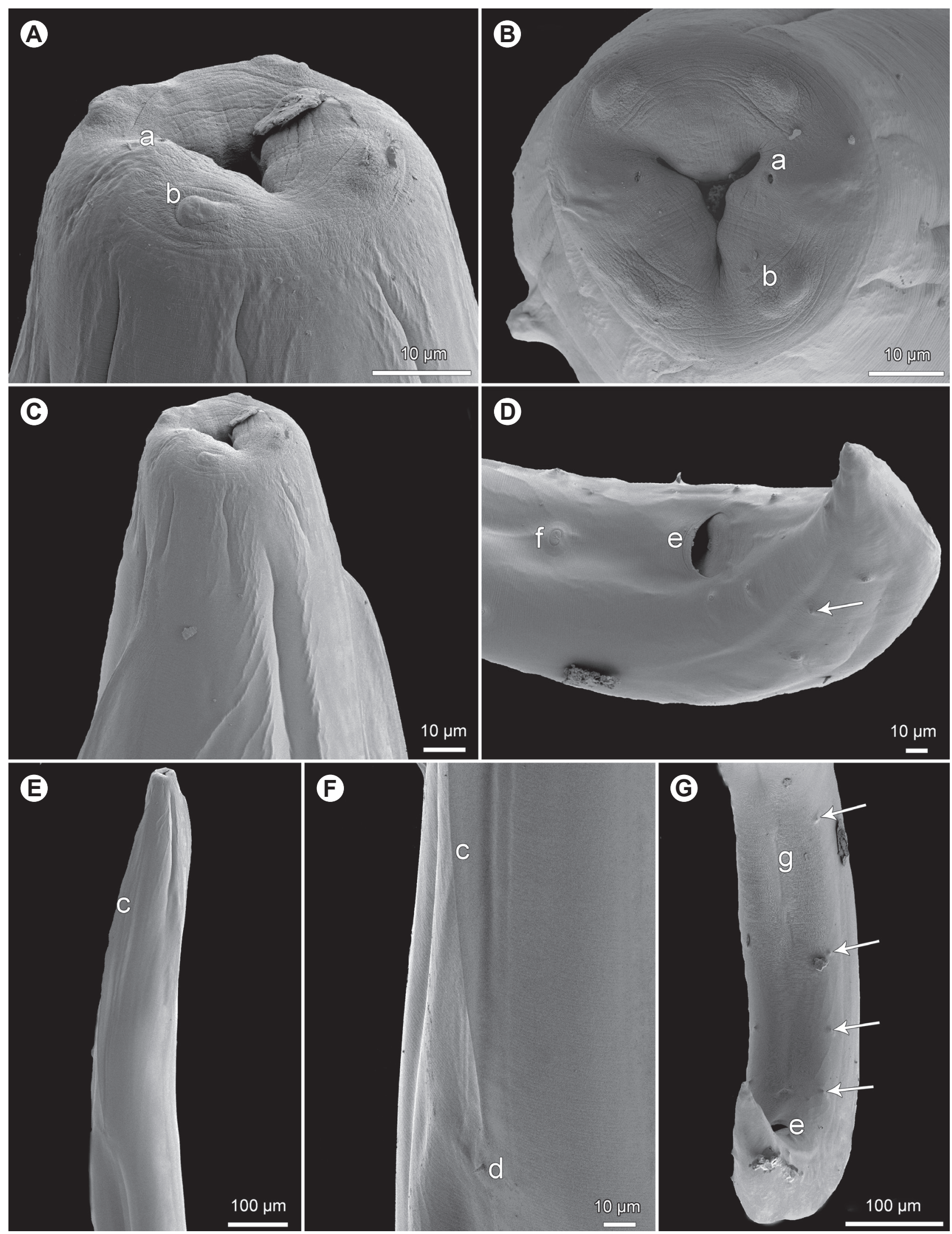

Fig. 20. Quimperia lanceolata Gendre, 1926 from Ctenopoma cf. kingsleyae Günther, scanning electron micrographs. A, B - cephalic end of male, subdorsal and apical views; $\mathbf{C}$ - cephalic end of male with initiating lateral alae, subdorsal view; $\mathbf{D}$ - posterior end of male, ventrolateral view (arrow indicates phasmid); $\mathbf{E}$ - anterior end of male with distinct lateral alae, subdorsal view; $\mathbf{F}$ - deirid situated just posterior to posterior end of lateral ala, sublateral view; $\mathbf{G}$ - posterior end of male, ventral view (arrows indicate preanal papillae). Abbreviations: $\mathrm{a}$-amphid; $\mathrm{b}$ - submedian double cephalic papilla; $\mathrm{c}$ - lateral ala; $\mathrm{d}$ - deirid; $\mathrm{e}$ - cloacal aperture; $\mathrm{f}$ - median precloacal papilla; $g$ - ventral precloacal sucker. 

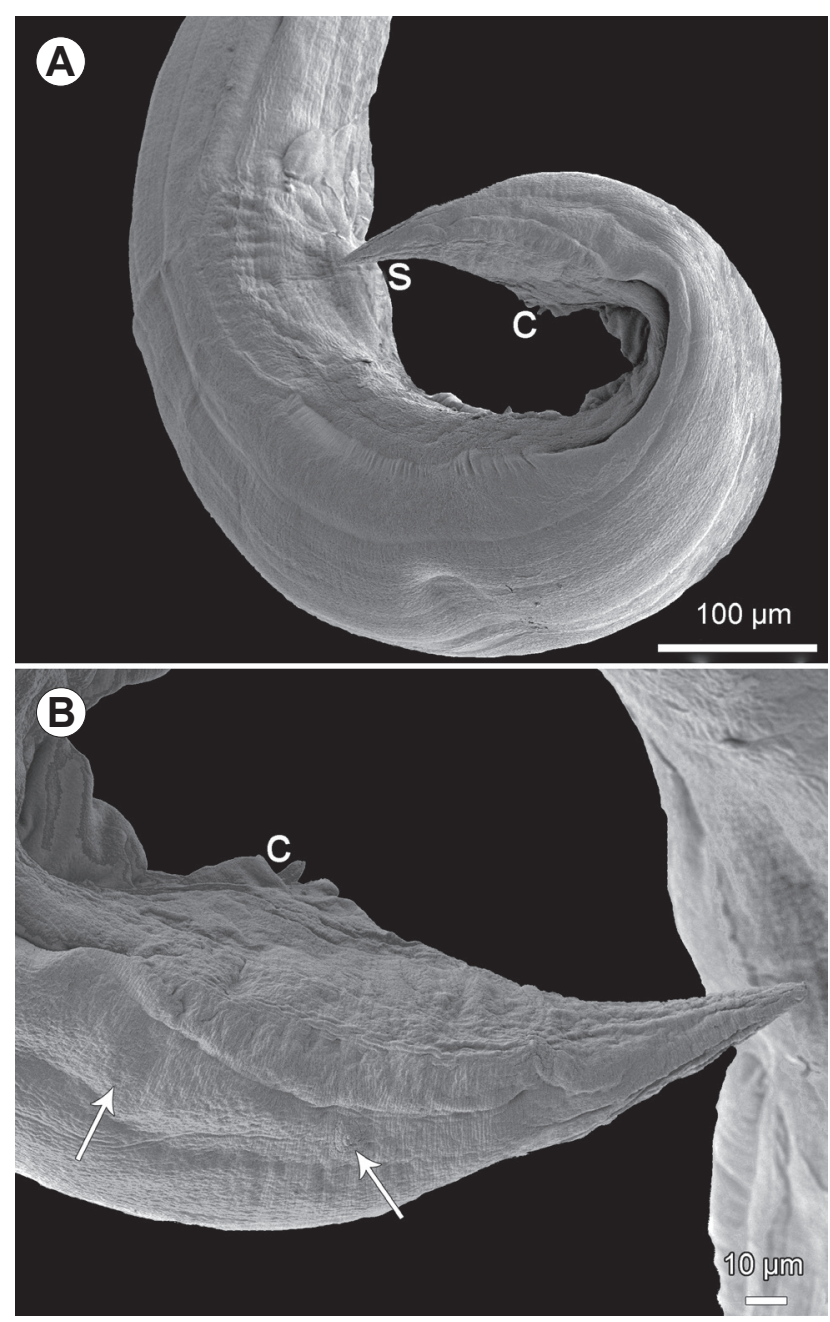

Fig. 21. Quimperia lanceolata Gendre, 1926 from Ctenopoma $\mathrm{cf}$ kingsleyae Günther, scanning electron micrographs of male. $\mathbf{A}$ - posterior end of body, lateral view; $\mathbf{B}$ - tail, lateral view (arrows indicate lateral postanal papillae). Abbreviations: $\mathrm{c}$ - cloacal aperture; $\mathrm{s}$ - ventral precloacal sucker.

anterior end of body. Posterior end of body curved ventrally. Ventral sucker and ventral precloacal oblique muscle bands absent (Figs. 22G, 23E). Cloacal region not elevated. Large median papilla-like formation present anterior to cloacal opening (Figs. 22F-H, 23D-G). Spicules equal, 480 (489) long, with rounded posterior ends (Fig. 22G), representing 7\% (10\%) of body length. Gubernaculum well sclerotised, small, rod-like with narrow proximal part in lateral view, 105 (63) long (Fig. 22F,G). Caudal papillae 11 pairs: 6 pairs of preanal papillae ( 5 subventral and 1 lateral) and 5 pairs of postanal papillae ( 3 subventral, 1 lateral and 1 dorsolateral); preanal pair of laterals located well anterior to cloacal opening; first postanal pair of subventrals just posterior to cloacal opening, second and third postanal pairs of subventrals in posterior half of tail; postanal pair of laterals (probably representing phasmids) slightly anterior to level of second subventral pair; papillae of dorsolateral postanal pair slightly anterior to level of last subventrals (Figs. 22F-H, 23D-G). Length of tail 216 (156).

Female (2 specimens with immature eggs; allotype; measurements of paratype in parentheses). Length of body
$6.2 \mathrm{~mm}$ (8.4 mm), maximum width 204 (218); width at level of oesophastome 163 (136), at middle of oesophagus 122 (136). Length of entire oesophagus 816 (898), representing $13 \%$ (11\%) of whole body length; length of oesophastome 245 (192), its width 136 (105); minimum width of oesophagus 109 (45); maximum width of posterior part of oesophagus 120 (99). Distance of nerve ring from anterior extremity 326 (313), representing 40\% $(35 \%)$ of oesophageal length. Deirids and excretory pore 694 (544) and 775 (870), respectively, from anterior end of body. Vulva postequatorial, $3.7 \mathrm{~mm}(4.6 \mathrm{~mm})$ from anterior extremity, at $60 \%(55 \%)$ of body length; vulval lips not elevated. Vagina directed anteriorly from vulva. Uteri opposed, containing few immature eggs. Length of tail 231 (340); phasmids indistinct (Fig. 22D).

Type host: Bubu Auchenoglanis occidentalis (Valenciennes) (Siluriformes: Claroteidae).

Site of infection: Intestine (distal part).

Type locality: Lower Congo River, left bank near Pioka, $04^{\circ} 54^{\prime} 25^{\prime \prime} \mathrm{N} ; 14^{\circ} 23^{\prime} 53^{\prime \prime} \mathrm{E}$, and right bank near Bulu, $05^{\circ} 01^{\prime} 30^{\prime \prime} \mathrm{N} ; 14^{\circ} 00^{\prime} 25^{\prime \prime} \mathrm{E}$, Democratic Republic of the Congo (collected 7 and 11 July 2008).

Prevalence and intensity: 2 fish infected/7 fish examined; 1 and 4 nematodes.

Deposition of type specimens: IPCAS N-1134 (holotype mounted on SEM stub, allotype and 2 paratypes in vials).

Etymology: The species name congolensis relates to the Congo River, where this parasite was found.

Remarks. The following six nominal species of $\mathrm{Cuc}$ ullanus have been, mostly inadequately, described from freshwater and brackish-water fishes in Africa: C. barbi Baylis, 1923, C. baylisi Campana-Rouget, 1961, C. clarotis Baylis, 1923, C. djilorensis Ndew, Diouf, Bâ et Morand, 2014, C. egyptae Abdel-Ghaffar, Bashtar, Abdel-Gaber, Morsy, Mehlhorn, Al Quraishy et Mohammed, 2014 and C. mormyri Moravec et Scholz, 2017 (see Baylis 1923a, Campana-Rouget 1961, Abdel-Ghaffar et al. 2014, Ndew et al. 2014, Moravec and Scholz 2017).

By the absence of a ventral precloacal sucker, the new species can be easily distinguished from C. egyptae, C. barbi and C. djilorensis, parasites of anguilliform, cypriniform and mugilliform fishes, respectively, in which the sucker is present. Cucullanus mormyri, a parasite of osteoglossiform fishes, differs from C. congolensis sp. n. mainly in the location of the excretory pore situated at a long distance posterior to the end of the oesophagus ( $v S$ in the region of the oesophago-intestinal junction) and the absence of lateral preanal papillae. Both C. baylisi and $C$. clarotis are parasites of siluriforms (catfishes) as the new species. However, C. baylisi, a specific parasite of Mochokidae (Synodontis spp.), possesses no lateral preanal papillae (see Moravec and Scholz 2017), in contrast to C. congolensis, in which large lateral preanal papillae are present (Figs. 22F-H, 23D-G).

The presence of large lateral preanal papillae, as in C. congolensis, was described and illustrated for C. clarotis (see Baylis 1923a); moreover, both species are parasites of Claroteidae. Baylis (1923a) reported female specimens 

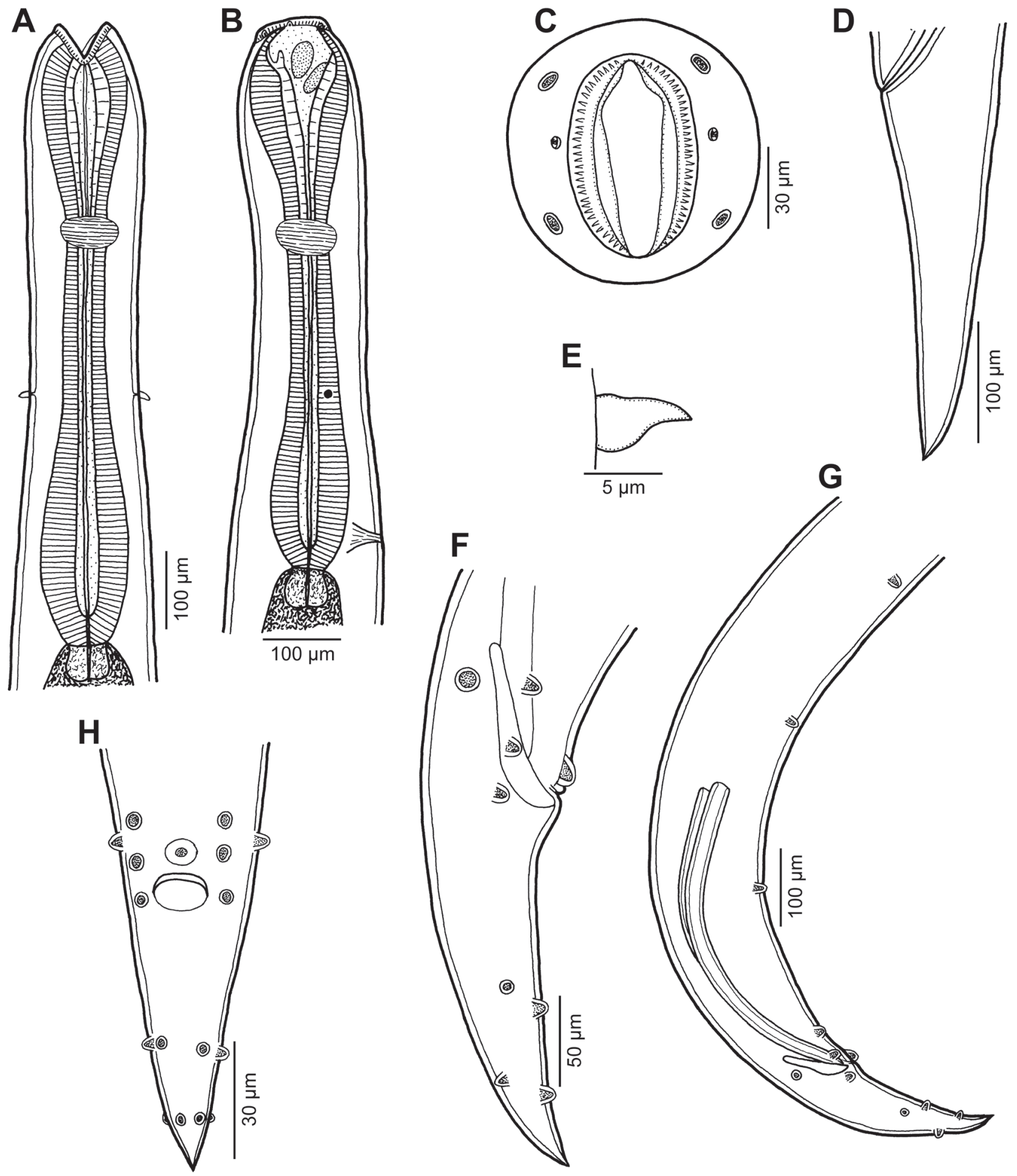

Fig. 22. Cucullanus congolensis sp. n. from Auchenoglanis occidentalis (Valenciennes). A - anterior end of female, dorsoventral view; $\mathbf{B}$ - anterior end of male, lateral view; $\mathbf{C}$ - cephalic end of male, apical view; $\mathbf{D}$ - tail of female, lateral view; $\mathbf{E}$ - deirid; $\mathbf{F}$ - tail of male, lateral view; $\mathbf{G}$ - posterior end of male, lateral view; $\mathbf{H}$ - tail of male, ventral view.

of C. clarotis also from Synodontis schall (Mochokidae), but these were subsequently assigned to $C$. baylisi based on a re-examination of Baylis' original specimens by Campana-Rouget (1961). However, in contrast to the original description of $C$. clarotis, specimens of the present material possess a large median precloacal papilla-like formation (vs such structure not reported for $C$. clarotis) and they also differ in the smaller body length of males $(5.0-6.7 \mathrm{~mm} v \mathrm{~s}$
7.0-10.0 mm), shorter spicules (480-489 $\mu \mathrm{m} v \mathrm{~s} 800 \mu \mathrm{m})$ and the oesophagus $(775 \mu \mathrm{m} v s 850-1,100 \mu \mathrm{m})$, location of the excretory pore in region of the oesophago-intestinal junction ( $v s$ approximately at mid-length of oesophagus), the genus and species of fish hosts (Aucheniglanis occidentalis vs Clarotes laticeps [Rüppel]) and different biogeographic affinity (Congolean ichthyological province vs Nilo-Sudanian ichthyological province). Although it can- 


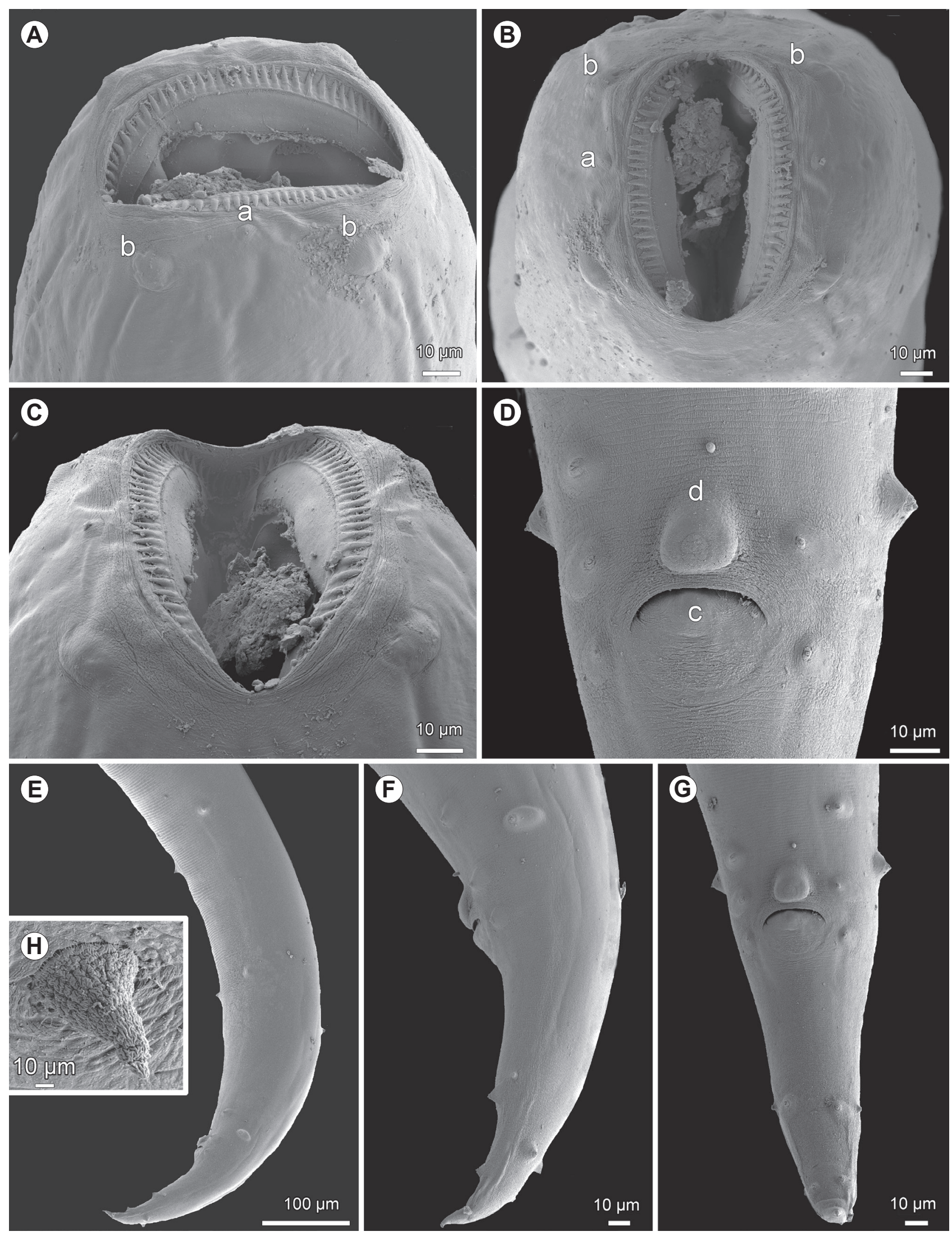

Fig. 23. Cucullanus congolensis sp. n. from Auchenoglanis occidentalis (Valenciennes), scanning electron micrographs of male. A-C - cephalic end, lateral, apical and dorsal views, respectively; D - region of cloaca, ventral view; $\mathbf{E}$ - posterior end lateral view; F, G - tail, lateral and ventral views, respectively; H - deirid. Abbreviations: a - amphid; b - cephalic papilla; c - cloacal opening; $\mathrm{d}$ - median precloacal papilla-like formation. 
not be excluded that future studies of $C$. clarotis may show its conspecificity with $C$. congolensis, for the time being we consider it more reasonable to deal with these forms as two separate species.

Ascaridoidea Railliet et Henry, 1915

Anisakidae Railliet et Henry, 1912

Dujardinascaris malapteruri (Baylis, 1923) Baylis, 1947 Figs. 24, 25

Syns.: Dujardinia malapteruri Baylis, 1923; Dujardinascaris graberi Troncy, 1969

Description. Female (based on 2 gravid specimens). Length of body 35.7-45.9 mm, maximum width 816-952. Cuticle finely transversely striated (Fig. 25F). Lips and interlabia 129-150 and 75 long, respectively (Figs. 24B,C, 25A-E). Length of oesophagus 3.4-3.7 mm, maximum width $136-150$, representing $8-10 \%$ of body length; ventriculus 163-204 long, 122-163 wide; intestinal caecum 2.0-2.2 mm long, 190-218 wide (Fig. 24A). Nerve ring and excretory pore 625-707 and 653-694 from anterior extremity, respectively. Vulva 14.6-15.6 mm from anterior end, situated at $43-44 \%$ of body length; anterior vulval lip slightly elevated. Vagina directed posteriorly from vulva. Eggs almost spherical, thin-walled, with smooth surface, 45-54 in diameter; content of eggs uncleaved (Fig. 24E). Tail conical, 585-612 long, with sharply pointed tip; phasmids indistinct (Figs. 24D, 25G).

Host: Malapterurus monsembeensis Roberts (Malapteruridae, Siluriformes).

Site of infection: Stomach.

Locality: Lower Congo River, left bank near Pioka, 0454'25"N;

$14^{\circ} 23^{\prime} 53^{\prime \prime E}$, Democratic Republic of the Congo (collected 7 July 2008).

Prevalence and intensity: 1 fish infected/15 fish examined; 2 nematodes.

Deposition of voucher specimens: IPCAS N-1135.

Remarks. Because no males were available, the species identification is mainly based on the absence of rows of denticles on lips, small size of eggs and the fact that the fish host belongs to the same genus as that from which this species was originally described.

Baylis (1923b) was the first to describe D. malapteruri from Malapterurus electricus (Gmelin) in Khartoum, Sudan; this species was also reported from the same host species and locality by Khalil (1969). Later Sprent (1990) redescribed D. malapteruri based on Baylis' type specimens and those collected from M. electricus in Gabon. According to him, Dujardinascaris graberi, described from M. electricus in Chad (Troncy 1969), is a junior synonym of D. malapteruri.

Vassiliadès and Troncy (1974) reported D. graberi (= D. malapteruri) also from Heterotis niloticus (Cuvier) (Osteoglossiformes: Arapaimidae) and Mormyrops engystoma Boulenger (Osteoglossiformes: Mormyridae)
A

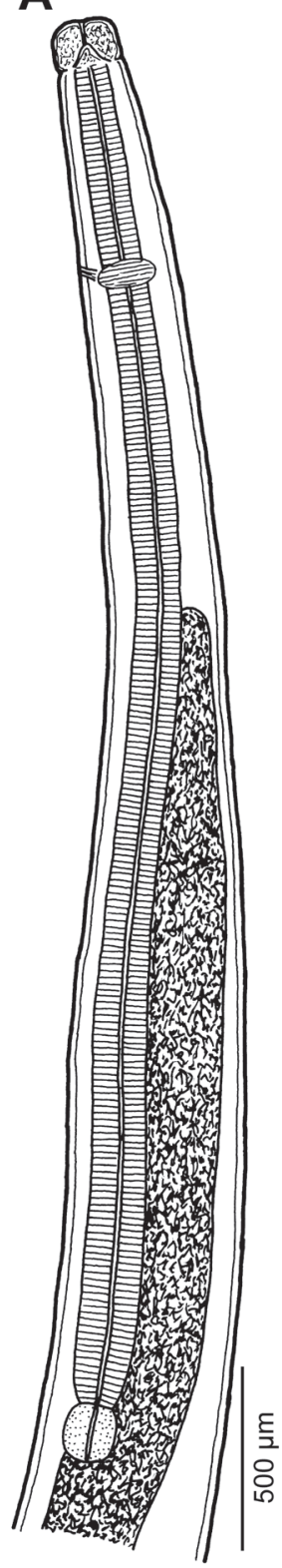

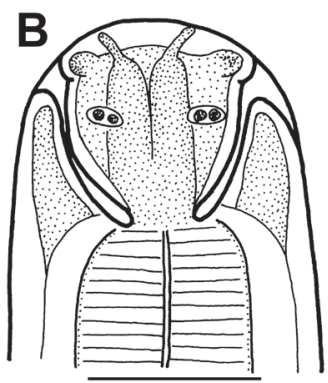

$100 \mu \mathrm{m}$

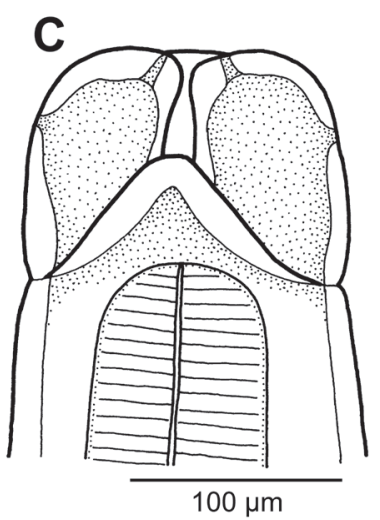

D

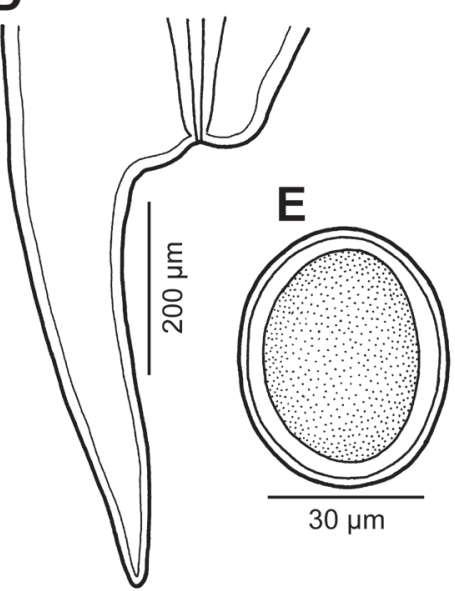

Fig. 24. Dujardinascaris malapteruri (Baylis, 1923) from Malapterurus monsembeensis Roberts, female. A - anterior end of body, lateral view; B, C - cephalic end, dorsal and subventral views, respectively; D - tail, lateral view; $\mathbf{E}$ - egg.

in Chad, but Sprent (1990) has mentioned that the identity of these nematodes with $D$. malapteruri is uncertain. Probably these nematodes belonged to Multicaecum heterotis Petter, Vassiliadès et Marchande, 1979 and Dujardinascaris mormyropsis Moravec et Jirků, 2014, respectively (Moravec and Jirků 2014a).

Dujardinascaris malapteruri has not previously been examined by SEM. The present SEM study shows that, in contrast to the recently described $D$. mormyropsis or some other congeneric species parasitising crocodiles, e.g. D. helicina (Molin, 1860) (see Moravec 2001), dentigerous ridges on lips of $D$. malapteruri are actually absent (Fig. 25B).

Most species of Dujardinascaris are parasites of crocodilians (Mozgovoy 1953, Sprent 1977, Hartwich 2009), 

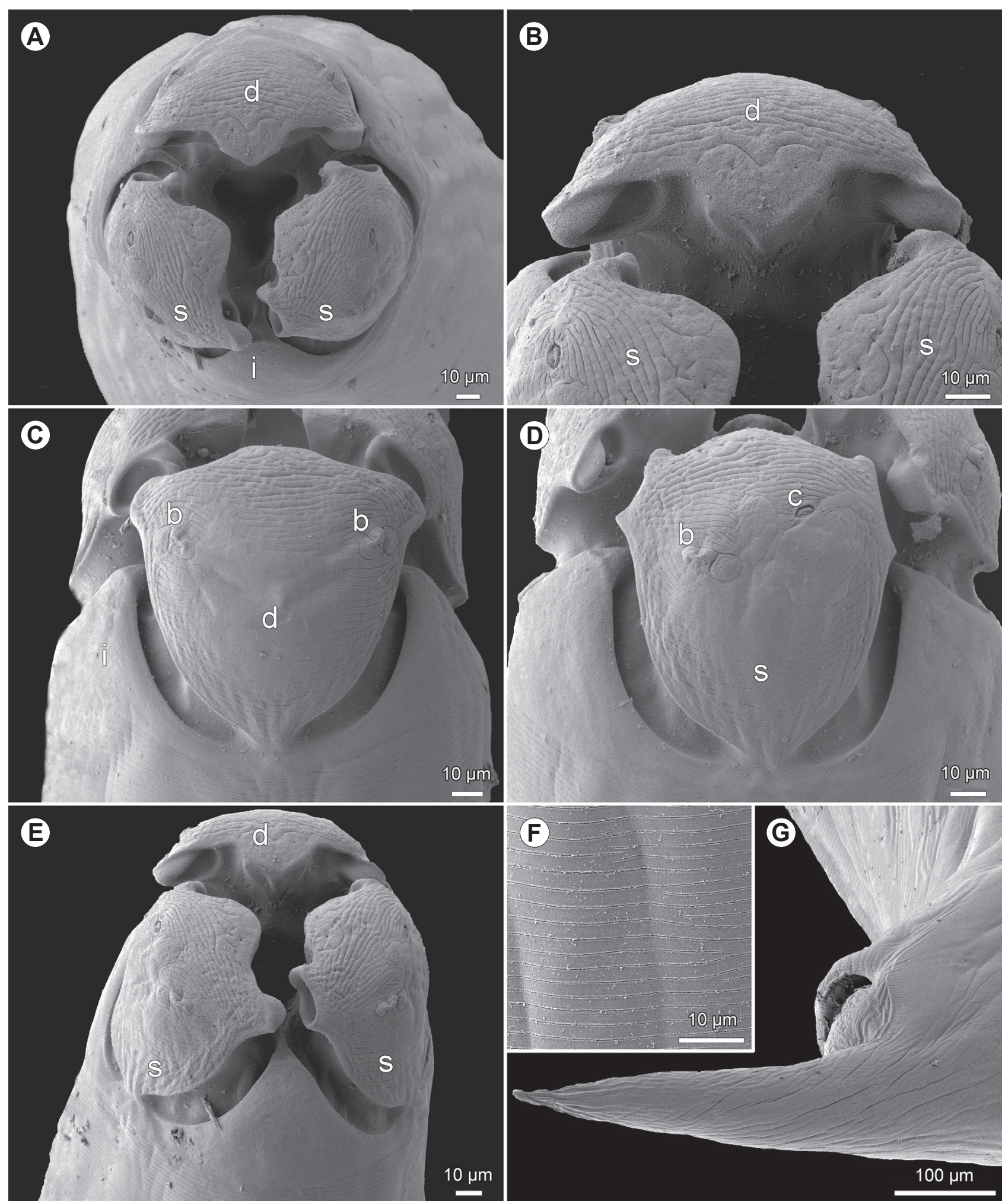

Fig. 25. Dujardinascaris malapteruri (Baylis, 1923) from Malapterurus monsembeensis Roberts, scanning electron micrographs of female. A - cephalic end, apical view; B - inner side of dorsal lip, subterminal view; C - dorsal lip, dorsal view; D - subventral lip, subventral view; $\mathbf{E}$ - cephalic end, ventral view; F - detail of body cuticle; $\mathbf{G}$ - tail, sublateral view. Abbreviations: b - double labial papilla; c - single labial papilla; d - dorsal lip; i - interlabium; s - subventral lip.

whereas adults of only two species, D. malapteruri and D. mormyropsis, are known from freshwater fishes in Africa (Moravec and Jirků 2014a). The latter species, a parasite of mormyrids, differs from $D$. malapteruri mainly in the presence of dentigerous ridges on lips, absence of caudal alae in the cloacal region, morphology of the gubernaculum and larger eggs $(60-90 \mu \mathrm{m} \times 52-78 \mu \mathrm{m})$. As mentioned above, D. malapteruri was previously reported from 
the Sudan, Gabon and Chad; the finding of this species from M. monsembeensis in the Democratic Republic of the Congo represents new host and geographical records.

Dujardinascaris sp. third-stage larva

Fig. 26

Description (one specimen). Body fusiform, whitish, with finely transversely striated cuticle; length of body $10.1 \mathrm{~mm}$, maximum width 381. Cephalic end rounded, anlagen of lips or larval tooth indistinct in lateral view (Fig. 26A). Lateral alae absent. Oesophagus narrow, $1.2 \mathrm{~mm}$ long, 57 wide. Ventriculus oval, 87 long and 54 wide. Nerve ring 258 from anterior extremity. Intestine narrow, brown-coloured; intestinal caecum long, extending anteriorly approximately along posterior three fifths of length of oesophagus; length of caecum 748, maximum width 60 (Fig. 26A). Genital primordium indistinct. Tail conical, 78 long, sharply pointed (Fig. 26B).

Host: Coptodon tholloni (Sauvage) (Perciformes: Cichlidae). Site of infection: Encapsulated on intestinal serosa.

Locality: Bas Congo (Congo basin), Democratic Republic of the Congo, no precise location available (collected 29 June 2008).

Prevalence and intensity: 1 nematode found in the only specimen of $C$. tholloni examined.

Deposition of voucher specimen: IPCAS N-1138.

Remarks. Adults of most species of Dujardinascaris are parasites of crocodilians, only two species, D. malapteruri and D. mormyropsis, are parasitic in African freshwater fishes (see above). The life cycles of species of Dujardinascaris remain unknown, but it can be assumed that freshwater fishes play a role of the intermediate or paratenic hosts, in which nematode third-stage larvae may occur. To date, the only record of Dujardinascaris larvae in fishes is that of Baylis (1928), who collected the larvae presumed to be Dujardinia (= Dujardinascaris) helicina from the gut of Lates microlepis Boulenger (Latidae) in Lake Tanganyika, Tanzania. However, this is an evident species misidentification, because $D$. helicina as adult is a parasite of crocodiles in the Neotropical Region (Sprent 1977, Moravec 2001); moreover, larval morphology does not allow identification to the species level. Therefore, the larvae recorded by Baylis (1928) from L. microlepis should be reported as Dujardinascaris sp. (see Moravec and Jirků 2014a). Hence, the present finding represents the second record of Dujardinascaris larva from fishes in Africa.

Anisakidae gen. sp. larvae

Host: Phenacogrammus aurantiacus (Pellegrin) (Characiformes: Alestidae).

Site of infection: Swimbladder.

Locality: Forest stream near Mongambe research camp, 0255'26"N; 16²3'24"E (Congo basin), DSPA, Central African Republic (collected 22 September 2012).

Prevalence and intensity: 2 fish infected/5 fish examined; 6 and 13 nematodes.

Deposition of voucher specimens: Not deposited.

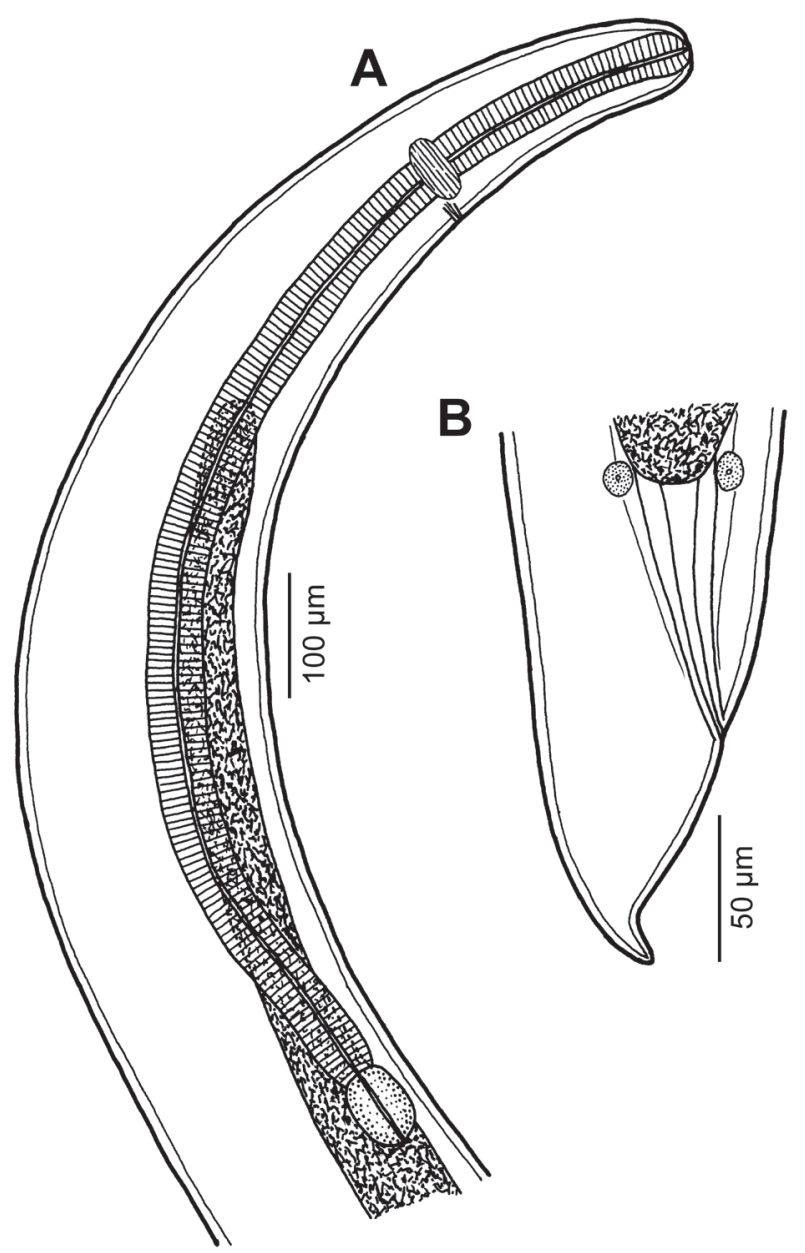

Fig. 26. A, B - Dujardinascaris sp. third-stage larva from Coptodon tholloni (Sauvage) (anterior and posterior body ends, lateral views).

Remarks. Closer identification of these small, little developed and poorly preserved nematode larvae was not possible. The shape of the ventriculum in one specimen indicates that the larva might belong to Multicaecum Baylis, 1923.

Camallanoidea Railliet et Henry, 1915

Camallanidae Railliet et Henry, 1915

\section{Procamallanus (Procamallanus) laeviconchus (Wedl,} 1861)

\section{Syn.: Cucullanus laeviconchus Wedl, 1861}

Hosts: Synodontis greshoffi, Congo squeaker S. pleurops (both Siluriformes: Mochokidae), Chrysichthys sp. (Siluriformes: Claroteidae) and longsnout distichodus Distichodus lusosso (Characiformes: Distichodontidae).

Site of infection: Stomach.

Locality: Sangha River adjacent to Sangha Lodge, $02^{\circ} 59^{\prime} 06^{\prime \prime N}$; $16^{\circ} 13^{\prime} 59^{\prime \prime} \mathrm{E}$ (Congo basin), DSPA, Central African Republic (collected 11-15 September 2012). 
Prevalence and intensity: $S$. greshoffi: 5 fish infected/7 fish examined; 2-13 (mean 5) nematodes. S. pleurops: 3/3; 1-2. Chrysichthys sp.: $1 / 1 ; 1$. D. lusosso: $1 / 1 ; 10$.

Deposition of voucher specimens: IPCAS N-13.

Remarks. This species has already been redescribed in detail by Moravec and Van As (2004, 2015c). According to Moravec and Scholz (2017), Procamallanus (P.) laeviconchus has so far been recorded from ten different Synodontis spp., which may be considered its main definitive hosts, and from Schilbe intermedius (Schilbeidae) in Egypt, Sudan, Chad, Ghana, Nigeria, Benin, Botswana, Uganda and the Democratic Republic of the Congo. Previously this species has been reported from about 30 fish species belonging to seven families in many African countries, but apparently other species have been misidentified under this name (see Campana-Rouget 1961, Moravec and Van As 2004). Distichodus spp. have already been reported as hosts of P. (P.) laeviconchus (see Khalil and Polling 1997, Mašová et al. 2011). The present finding of this nematode in the claroteid catfish Chrysichthys sp. represents a new host record. This nematode species is reported from the Central African Republic for the first time.

\section{Procamallanus (Spirocamallanus) pseudospiralis}

Moravec et Scholz, 2017

Hosts: Synodontis decorus, Synodontis greshoffi (Siluriformes: Mochokidae) and Mesoborus crocodilus Pellegrin (Characiformes: Distichodontidae).

Site of infection: Intestine.

Localities: Sangha River adjacent to Sangha Lodge, 0259'06"N; 16¹3'59"E, DSPA (S. decorus, S. greshoffi, collected 11-15 September 2012) and Mongambe, forest stream, 02 55'26"N; 16 23'24"E (M. crocodilus, collected 21 September 2012), both localities DSPA, Central African Republic, Congo basin.

Prevalence and intensity: $S$. decorus: 1 fish infected/3 fish examined; 1 nematode. S. greshoffi: 4/9; 1-3. M. crocodilus: $1 / 1 ; 1$.

Deposition of voucher specimens: IPCAS N-1124.

Remarks. The morphology of present specimens corresponds to that of Procamallanus (S.) pseudospiralis Moravec et Scholz, 2017, a species recently described from three Synodontis spp. in the Sudan and occurring also in the Democratic Republic of the Congo (Moravec and Scholz 2017). Since only one female was collected from $M$. crocodilus, occurrence of $P$. (S.) pseudospiralis in this host should be confirmed by subsequent studies.

\section{Paracamallanus cyathopharynx (Baylis, 1923) Yorke et} Maplestone, 1926

\section{Syn.: Paracamallanus senegalensis Vassiliadès, 1970}

Hosts: Eel catfish Channallabes apus (Günther), Clariallabes teugelsi Ferraris, Clarias buthupogon Sauvage and North African catfish C. gariepinus (Burchell) (all Siluriformes: Clariidae).

Site of infection: Intestine (distal part).
Localities: A small swamp (bai) north of Bayanga $03^{\circ} 00^{\prime} 54^{\prime \prime N}$; $16^{\circ} 16^{\prime} 12^{\prime \prime E}$ (Congo basin), DSPA, Central African Republic (C. apus, collected 16 September 2012); unspecified locality in Bas Congo (Congo basin, C. gariepinus, collected 10 July

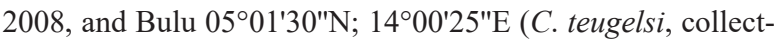
ed 11 July 2008); Lower Congo River, Democratic Republic

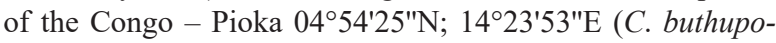
gon, C. gariepinus, collected 7 July 2008); and.

Prevalence and intensity: C. apus: 2 fish infected/7 fish examined; 1 nematode in each fish. C. teugelsi: $1 / 1 ; 4$. C. buthupogon: $2 / 2 ; 2-3$. C. gariepinus: $2 / 2 ; 2-3$.

Deposition of voucher specimens: IPCAS N-12.

Remarks. Paracamallanus cyathopharynx was recently redescribed in detail by Moravec and Van As (2015b). Since the morphology of present specimens is in agreement with this redescription, we refrain from describing these nematodes again. According to the above-mentioned authors, P. cyathopharynx has been reported from six species of African clariid catfishes, serving apparently as its definitive hosts, whereas some fishes of other families harbouring this parasite probably represent paradefinitive or postcyclic hosts. The present findings of $P$. cyathopharynx in Channallabes apus, Clariallabes teugelsi and Clarias buthupogon represent new host records.

This nematode species seems to be a common and widespread parasite in Africa, being reported from Egypt, Sudan, Ethiopia, Democratic Republic of the Congo, Tanzania, Nigeria, Senegal, Zimbabwe, Botswana and South Africa (see Moravec and Van As 2015b, Moravec and Scholz 2017). Central African Republic represents a new geographical record for this nematode. The development of this nematode in the copepod intermediate host was experimentally studied by Moravec (1974b).

Habronematoidea Chitwood et Wehr, 1932

Cystidicolidae Skryabin, 1946

Spinitectus polli Campana-Rouget, $1961 \quad$ Figs. 27-29

\section{Syn.: Spinitectus zambezensis Boomker, 1993}

Description. Small, whitish nematodes. Body elongate; cephalic end blunt, posterior end conical. Surface of body with transverse rings of spines; rings interrupted at both sides of body by lateral lines (Figs. 27C, 28A,B,D); some more posterior rings incomplete. First 2 rings of spines closer to each other than subsequent rings. First ring with 40-61 spines (Figs. 27C, 28B,D). Largest spines present in anterior second-fourth ring; first 4-6 anterior rings of spines usually elevated; spines gradually diminishing posteriorly. Female body with spines up to posterior extremity (Figs. 27F,G, 29C); spination of male visible only at oesophageal region. Oral aperture oval, dorsoventrally elongated, surrounded by 2 low, large labia, 1 dorsal and 1 ventral, with broad base (Figs. 27C,D, 28A-E), forming dorsal and ventral margins of oral opening. One simple, narrow, bent sclerotised structure (sublabium), with a somewhat thickened free margin, attached by its base to inner surface 

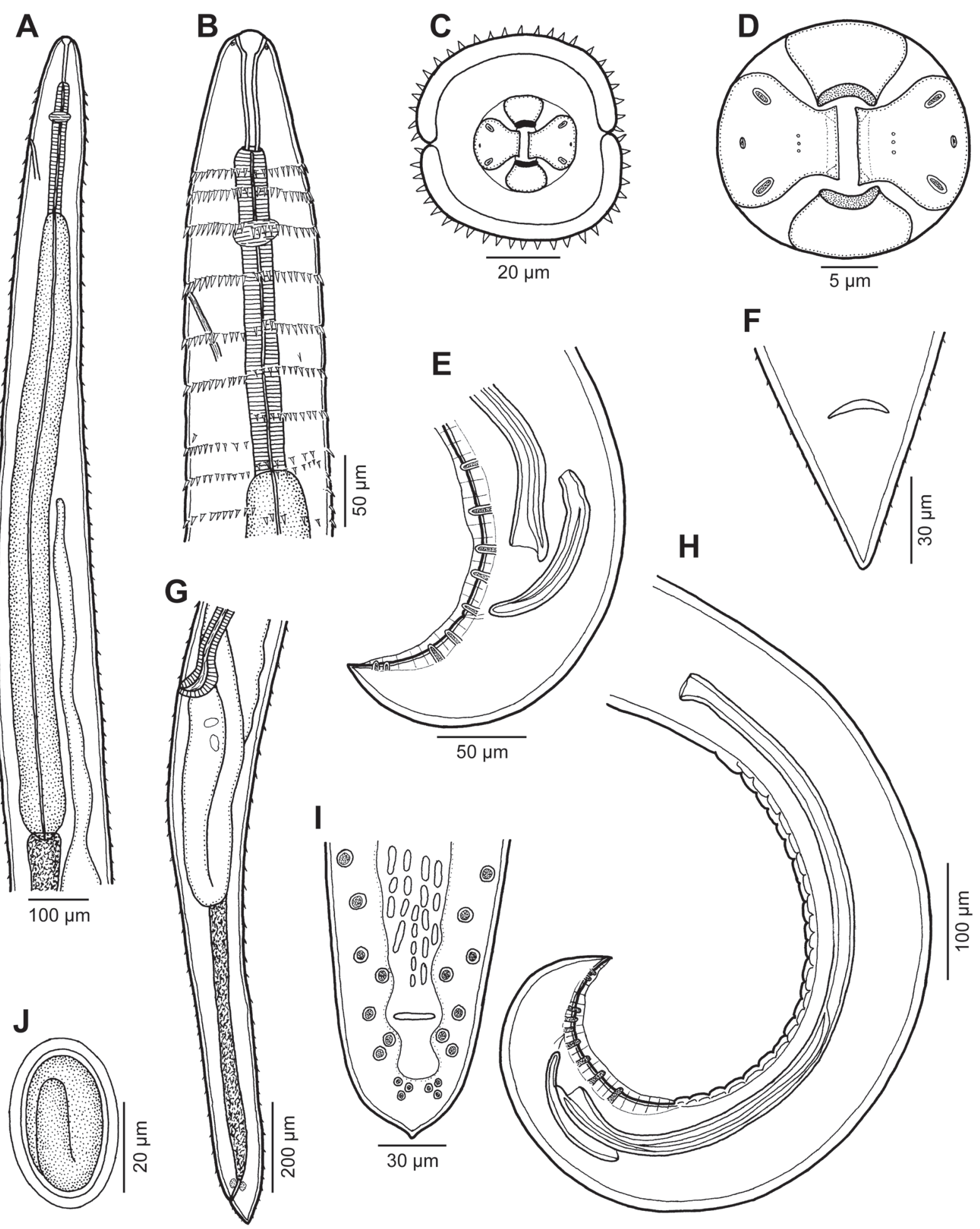

Fig. 27. Spinitectus polli Campana-Rouget, 1961 from Synodontis decorus Boulenger. A - anterior end of gravid female, lateral view; $\mathbf{B}$ - same, higher magnification; $\mathbf{C}$ - cephalic end of male, apical view; $\mathbf{D}$ - mouth, apical view; $\mathbf{E}$ - tail of male, lateral view; $\mathbf{F}$ - tail of female, ventral view; $\mathbf{G}$ - posterior end of female, lateral view; $\mathbf{H}$ - posterior end of male, lateral view; $\mathbf{I}$ - caudal end of male, ventral view; $\mathbf{J}$ - egg.

of each labium. Lateral pseudolabia rather large, projecting anteriorly beyond labia. In apical view, flat inner parts of pseudolabia covering partly oral opening somewhat dorsoventrally expanded to form small dorsolateral and ventrolateral extensions. Inner margins of both pseudolabia dorsoventrally straight, parallel to each other (Figs. 27C,D, $28 \mathrm{~A}-\mathrm{C}$ ). Narrow, inner part of each pseudolabium contin- ues posteriorly into thickened pulp bearing 2 elongate submedian cephalic papillae, small lateral amphid and 3 small, dorsoventrally arranged pores (Figs. 27C,D, 28C). Vestibule fairly long, thin-walled, with distinct anterior prostom in lateral view (Fig. 27A,B). Deirids not found. Oesophagus clearly divided into anterior muscular and much longer and somewhat wider posterior portion; length ratio of both 

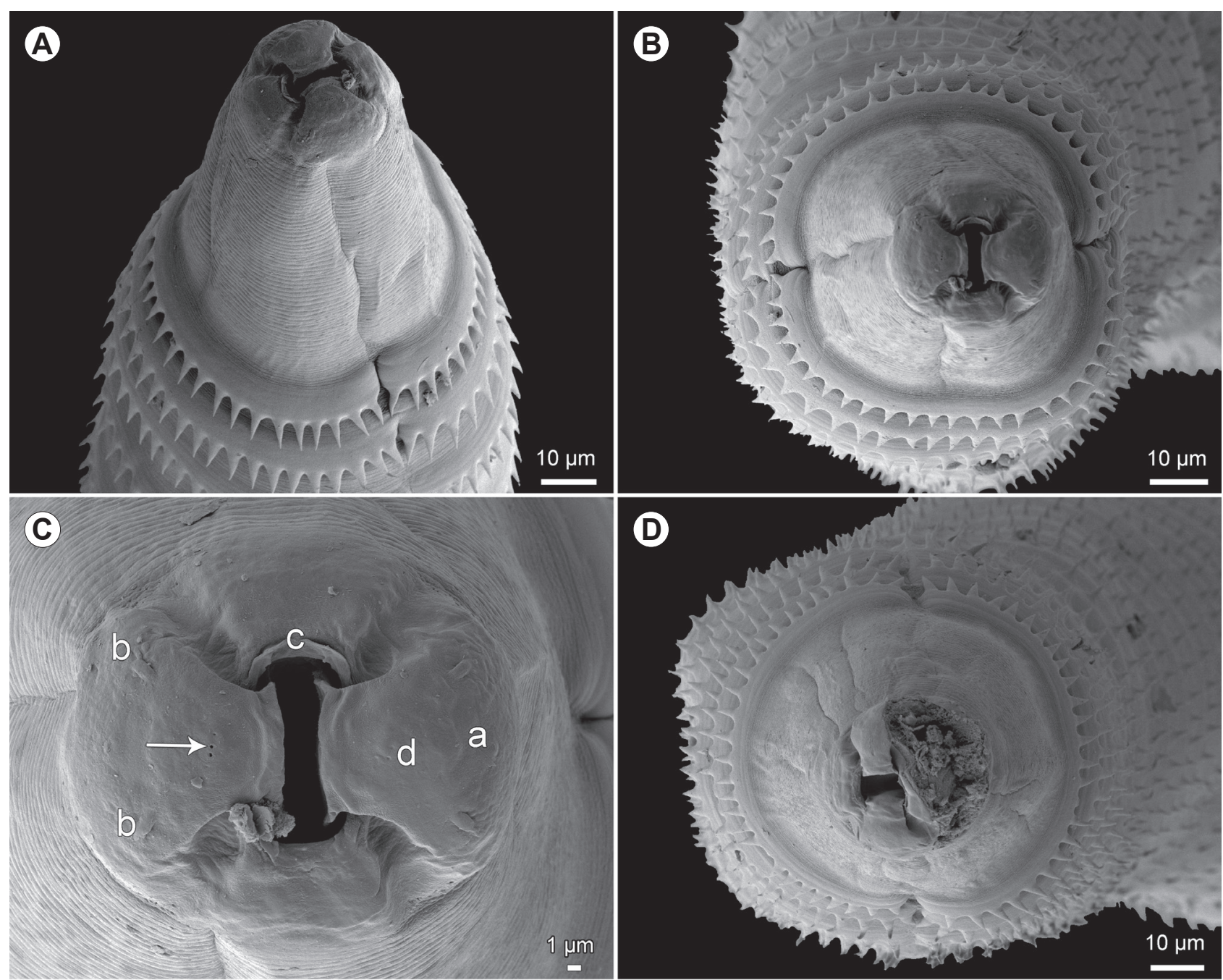

(D)
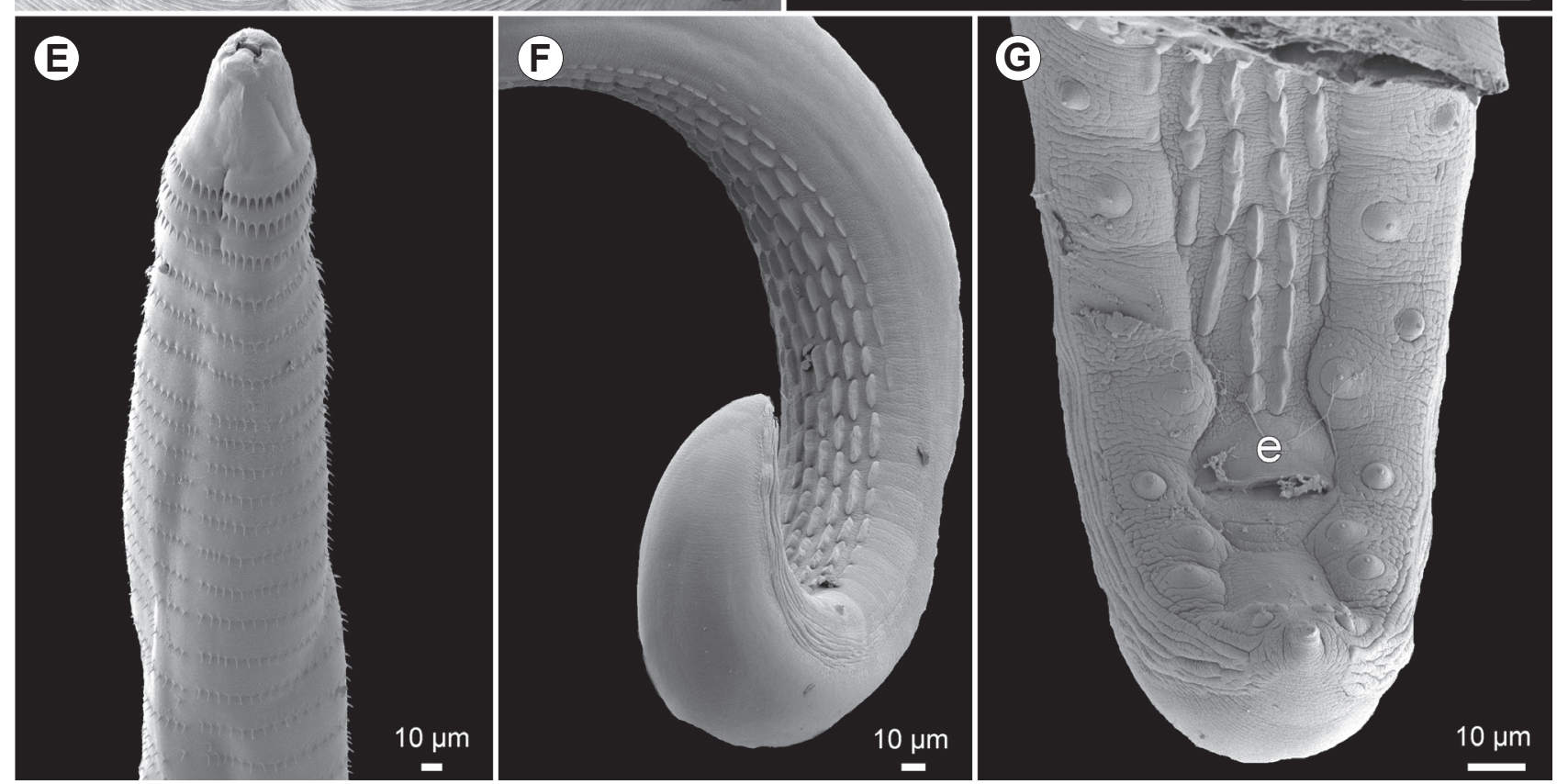

Fig. 28. Spinitectus polli Campana-Rouget, 1961 from Synodontis decorus Boulenger, scanning electron micrographs. A - anterior end of male, sublateral view; B - cephalic end of male, apical view; C - mouth, apical view (arrow indicates three pores); D - cephalic end of female, apical view (pseudolabia destroyed); $\mathbf{E}$ - anterior end of body, sublateral view; $\mathbf{F}$ - posterior end of male with distinct ventral precloacal cuticular ridges; G - caudal end of male, ventral view. Abbreviations: a - amphid; b - cephalic papilla; c - sublabium; $\mathrm{d}$ - pseudolabium; e - cloaca. 

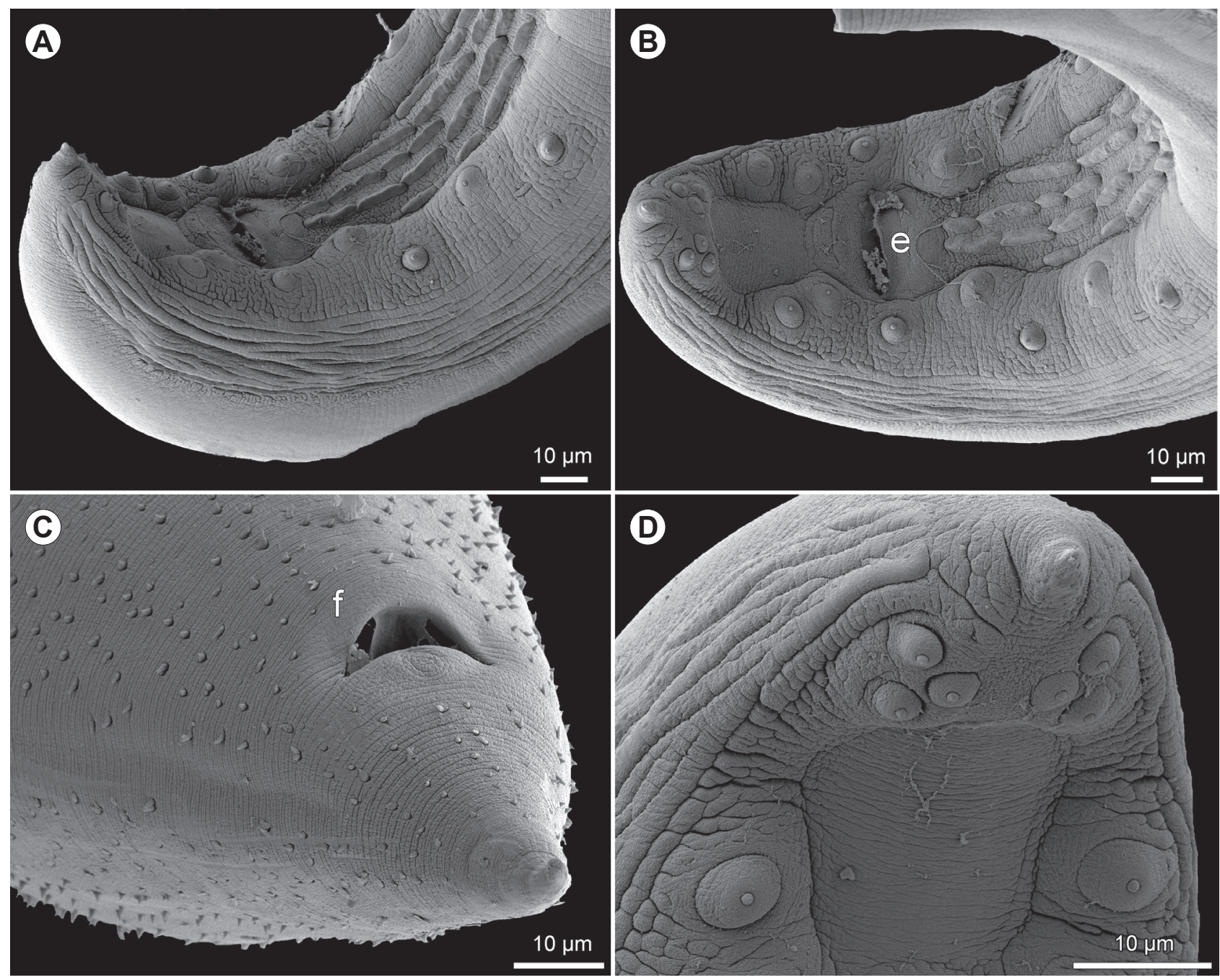

Fig. 29. Spinitectus polli Campana-Rouget, 1961 from Synodontis decorus Boulenger, scanning electron micrographs. A, B - caudal end of male, sublateral and subventral views, respectively; $\mathbf{C}$ - tail of female, ventrolateral view; $\mathbf{D}$ - distal end of male tail, ventral view. Abbreviations: e - cloaca; $\mathrm{f}$ - anus.

portions $1: 4.3-4.8$ (Fig. 27A,B). Nerve ring encircles muscular oesophagus at level between second and fourth rings of spines. Excretory pore situated at level of fourth ring of spines (Fig. 27A,B). Tails of both sexes conical.

Male (one specimen). Length of body $5.0 \mathrm{~mm}$, maximum width 177. Maximum length of spines 6 . First ring of spines situated 105 from anterior extremity. Number of spines in first ring 49. Length of vestibule including prostom 78. Muscular oesophagus 213 long, 24 wide; glandular oesophagus 911 long, 75 wide; length ratio of both parts of oesophagus $1: 4.3$. Length of entire oesophagus and vestibule represent $24 \%$ of body length. Nerve ring and excretory pore 147 and 195 from anterior extremity, respectively. Posterior end of body ventrally curved, provided with well-developed subventral alae. Ventral precloacal ridges (area rugosa) well developed, formed by several (up to 6) longitudinal rows of elevated longitudinal cuticular outgrowths (Figs. 27H,I, 28F,G, 29A,B). Preanal papillae: 4 pairs of subventral pedunculate, equally spaced papillae. Adanal papillae: 1 pair. Postanal papillae: 4 pairs of subventral papillae and 1 pair of small ventral papillae (Figs. 27E,H,I, 28G, 29A,B,D). Large (left) spicule nar- row, 705 long, with slightly distended tip provided with small cuticular membrane; length of its shaft 381 (54\% of whole spicule length). Small (right) spicule narrow, 99 long (Fig. 27E,H). Length ratio of spicules 1 : 7.1. Tail 84 long, with small digital mucron at tip.

Female (3 gravid specimens). Length of body 5.5$6.1 \mathrm{~mm}$, maximum width 190-218. Maximum length of spines 6-9. First ring of spines 96-105 from anterior extremity; postoesophageal region of body including tail with minute, sparsely distributed cuticular spines. Number of spines in first ring 55 in one specimen. Length of vestibule including prostom 75-84; prostom 15-21 long and 21-30 wide. Length of entire oesophagus and vestibule represent $24 \%$ of body length. Muscular oesophagus $225-$ 243 long, 24-27 wide; glandular oesophagus $1.0-1.1 \mathrm{~mm}$ long, 66-90 wide; length ratio of both parts of oesophagus $1: 4.5-4.8$. Nerve ring and excretory pore 108-129 and 186-204 from anterior extremity, respectively. Vulva not protruding, situated in posterior part of body at 4.194.77 from anterior extremity (at $74-80 \%$ of body length), 1.0-1.4 $\mathrm{mm}$ anterior to anus (Fig. 27G). Vagina muscular, directed anteriorly from vulva. Amphidelphic. Fully devel- 
oped eggs in uterus oval, thick-walled, smooth, larvated; size $(\mathrm{n}=10)$ 39-45 × 24-30 (Fig. 27J). Tail conical, 54-69 long, covered by irregularly distributed minute cuticular spines (Figs. 27F, 29C).

Host: Clown squeaker Synodontis decorus (Siluriformes: Mochokidae).

Site of infection: Stomach.

Locality: Sangha River adjacent to Sangha Lodge, 0259'06"N; $16^{\circ} 13^{\prime} 59^{\prime \prime E}$ (Congo basin), DSPA, Central African Republic (collected 11 September 2012).

Prevalence and intensity: 1 fish infected/3 fish examined; 5 nematodes.

Deposition of voucher specimens: IPCAS N-1081.

Remarks. The general morphology of the present specimens is, more or less, in agreement with available descriptions of S. polli, a parasite of squeakers (Synodontis spp.) (see Campana-Rouget 1961, Boomker 1993, Moravec and Van As 2015b). The only difference is a somewhat longer left spicule $(705 \mu \mathrm{m} v s$ 366-500 $\mu \mathrm{m})$, which may be considered to be within intraspecific variability. According to Moravec (1979), the length of the left spicule (663$1,068 \mu \mathrm{m}$ ) in Spinitectus inermis (Zeder, 1800), a parasite of European eels, depends on the body size of the male, so that the maximum length of this spicule represents more than $160 \%$ of the minimum length.

Based on SEM examination, Moravec and Van As (2015b) reported six pairs of postanal papillae in $S$. polli from $S$. nigromaculatus in Botswana, of which the first pair was situated very closely posterior to the posterior edge of the cloacal aperture. The same pair of papillae in the only available male of the present material is located at the level of the cloaca, so it is reported as the adanal pair. Based on LM studies, Campana-Rouget (1961) illustrated these papillae in S. polli at the level of the cloaca and Boomker (1993) as slightly posterior to the cloaca in conspecific nematodes (reported as S. zambezensis) from South Africa. However, these differences are negligible, within intraspecific variability, and may be associated, with the body size of the nematode or the way of fixation. Usually, six pairs of postanal papillae are reported for Spinitectus spp., even though the first pair may be in an adanal position in some species (e.g. S. inermis).

Spinitectus polli has so far been reported from the Democratic Republic of the Congo, Botswana and South Africa (Campana-Rouget 1961, Boomker 1993, 1994, Boomker and Puylaert 1994, Moravec and Van As 2004, 2015b). The finding of this species in S. decorus in the Central African Republic represents new host and geographical records.

Thelazioidea Skryabin, 1915

Rhabdochonidae Travassos, Artigas et Pereira, 1928

Rhabdochona paski Baylis, 1928

Syns.: Rhabdochona congolensis Campana-Rouget, 1961; R. aegyptiaca El-Naffaret Saoud, 1974; R. versterae Boomker et Petter, 1993
Host: Banded jewel cichlid Hemichromis elongatus (Guichenot) (Perciformes: Cichlidae).

Site of infection: Intestine.

Locality: Unspecified locality in Bas Congo (Congo basin, collected 29 June 2008).

Prevalence and intensity: 1 fish infected/1 fish examined; 1 nematode.

Deposition of voucher specimen: IPCAS N-997.

Remarks. The general morphology of the only available male specimen (body length $13.2 \mathrm{~mm}$, length of spicules $219 \mu \mathrm{m}$ and $66 \mu \mathrm{m}$ ), particularly the structure of the prostom, simple deirids, characteristic ventral cuticular ornamentations and the conical tail without spike-like caudal projections, is typical of $R$. paski, as redescribed by Moravec et al. (2013). Although this widespread African nematode is mainly a parasite of characiform fishes, it is frequently recorded from fishes belonging to other fish orders, which may apparently play a role of paratenic, paradefinitive or postcyclic hosts (Moravec et al. 2013, Moravec and Van As 2015b). The present finding of $R$. paski in H. elongatus represents a new host record.

Dioctophymatoidea Castellani et Chalmers, 1910

Dioctophymatidae Castellani et Chalmers, 1910

\section{Eustrongylides sp. fourth-stage larva}

Host: Aphyosemion cf. decorsei (Pellegrin) (Cyprinodontiformes: Nothobranchiidae).

Site of infection: Body cavity.

Locality: Forest stream near Mongambe research camp, $02^{\circ} 55^{\prime} 26^{\prime \prime N}$; $16^{\circ} 23^{\prime} 24^{\prime \prime} \mathrm{E}$ (Congo basin), DSPA, Central African Republic (collected 20 September 2010).

Prevalence and intensity: 1 fish infected/1 fish examined; 1 nematode.

Deposition of voucher specimen: IPCAS N-76.

Remarks. Only a body fragment of one larva was found. Larvae of Eustrongylides Jägerskiöld, 1909 from fishes and some other aquatic vertebrates, serving as paratenic hosts, are unidentifiable to species by morphological features. Adults of this genus are parasites of the proventriculus of fish-eating birds. Eustrongylides larvae have already been reported from a variety of fish species in Africa (e.g. Paperna 1974).

\section{DISCUSSION}

Considering that freshwater bodies in Africa contain almost $25 \%$ of the world's 13,000 freshwater fish species, with a high degree of endemism at species and family levels (Lévêque et al. 2008), the fauna of nematodes parasitising fishes in Africa is still little known. As already mentioned by Moravec and Scholz (2017), during the first two decades of the 21 st century, many papers on fish nematodes by researchers from some African countries were published, mostly regarding the recognition of the local helminth fauna of fishes, with emphasis to some groups of fish hosts. However, most of the reported nematodes were 
unidentified at specific level and, in some cases, their identification is questionable. Apparently, these problems are associated with an insufficient elaboration of the nematode taxonomy and hitherto fragmented data on the distribution of these parasites in fishes of Africa.

To date, 92 valid species of adult nematodes, belonging to 31 genera, have been reported parasitising freshwater and brackish-water fishes in continental Africa and in Madagascar (unpublished). Of them, 17 species (18\%) were described within a short period since 2000 , documenting again that the composition of the nematode fauna of fishews in Africa is till little known (see Moravec and Scholz 2017). Consequently, the present survey of fish nematodes in the Congo River basin on the territory of the Democratic Republic of the Congo and the Central African Republic, containing data on 20 species (including four new for science), represents an important contribution to the recognition of these parasites in Africa (in the Congolean ichthyological province).

In the present study, in addition to the descriptions of four new species in the genera Cucullanus (1), Gendria (2) and Labeonema (1), many previously known nematode species were recorded from new fish hosts, extending thus their host range: Cithariniella khalili from Synodontis acanthomias and S. greshoffi; Dujardinascaris malapteruri from Malapterurus monsembeensis; Falcaustra piscicola from Distichodus lusosso; Falcaustra similis from Synodontis acanthomias; Paracamallanus cyathopharynx from Channallabes apus, Clariallabes teugelsi and Clarias buthupogon; Procamallanus (P.) laeviconchus from Chrysichthys sp., Synodontis greshhoffi and S. pleurops; Procamallanus (S.) pseudospiralis from Synodontis decorus and Mesoborus crocodilus; Rhabdochona paski from Hemichromis elongatus; Spinitectus polli from Synodontis decorus; and Synodontisia thelastomoides from Synodontis acanthomias, $S$. decorus, $S$. greshhoffi, $S$. nigriventris, S. pleurops and Xenocharax spilurus.

Most of these nematode species exhibit their specificity at the generic or family level of their fish definitive hosts and were previously reported from water bodies belonging to other African ichthyological provinces, mainly the Nilo-Sudanense province (e.g. Khalil 1969, Moravec 1974a, El Naffar et al. 1983, Moravec and Scholz 2017). However, it is well known that the same nematode species with a broader host specificity may have different hosts in different parts of its distribution area (Mayr 1963, Moravec 2013). The present records of Procamallanus (S.) pseudospiralis and Synodontisia thelastomoides (both parasites of Synodontis spp.) in atypical hosts Mesoborus crocodilus and Xenocharax spilurus, respectively, both representatives of the different fish family Distichodontidae, indicate that these might serve as postcyclic hosts for these nematodes (Odening 1976).

In addition to adult nematodes, there are many nematode parasites occurring in fishes only as larvae, not attaining sexual maturity in these hosts. These represent infective larvae which are the source of infection for definitive hosts, i.e. various species of fish-eating vertebrates, such as piscivorous fishes, reptiles, birds and mammals including man. Fishes harbouring these larvae function as intermediate or paratenic hosts in the life cycles of these parasites. To date, only unidentifiable larvae of Eustrongylides (Dioctophymatidae), Contracaecum Railliet et Henry, 1912, Dujardinascaris, Galeiceps Railliet, 1916 and Hysterothylacium (all Anisakidae), Amplicaecum Baylis, 1912 and Porrocaecum Railliet et Henry, 1912 (both Ascarididae), Physalopteridae gen. sp. 1 and 2 of Moravec and Van As (2015b), Chordocephalus Alegret, 1941 (Acuariidae) and some closer unidentified Nematoda gen. sp. larvae have been reported from freshwater fishes in Africa.

Only three types of such larvae, Anisakidae gen. sp., Dujardinascaris sp. and Eustrongylides sp., were found within this study from characiform, perciform and cyprinidontiform fishes, respectively, of which the Dujardinascaris sp. larva was again recorded from an African fish 89 years after the first report of the congeneric larva from a cichlid in Lake Tanganyika by Baylis (1928). However, larvae of nematode genera such as Trichinella Railliet, 1895, Dioctophyme Collet-Meygret, 1802, Hystrichis Dujardin, 1845, Multicaecum, Dracunculus Stiles, 1907 and many acuarioid and spiruroid genera have not yet been reported from fishes in Africa, although congeneric adults are known to occur in African crocodiles, fish-eating birds and mammals. Some of the nematodes occurring in fishes only as larvae, either already recorded or pressumed to occur in these hosts in Africa, may be of medical or veterinary importance, e.g, species of Contracaecum, Dioctophyme, Dracunculus, Eustrongylides and Trichinella, or Paracapillaria philippinensis (Chitwood, Velasquez et Salazar, 1968), a serious parasite of humans reported several times in Egypt (e.g. Youssef et al. 1989) and developing via freshwater and brackish-water fishes as intermediate hosts, which are the source of infection for man (Cross et al. 1972).

Acknowledgements. We thank the government of the Central African Republic, namely the Ministre de l'Education Nationale, de l'Alphabetisation, de l'Enseignement Superieur, et de la Recherche for providing research permits to conduct our work in the Central African Republic; World Wildlife Fund and administration of Dzanga-Sangha Protected Areas for granting research approval and assistance with obtaining permits; and the Primate Habituation Programme for providing logistical support in the field. We are also greatly indebted to Rod Cassidy and his family for generous help in the field and for allowing junior author (M.J.) to work in facilities of the Sangha Lodge. Great thanks go to Melanie L.J. Stiassny of the Department of Ichthyology, American Museum of Natural History, New York, USA, Thomas R. Vigliotta from the Museum of Vertebrates, Cornell University, USA and Jouke van der Zee, Royal Museum for Central Africa, Tervuren, Belgium, for identification of examined fishes, as well as Raoul Monsembula, Faculty of Science, University of Kinshasa, Democratic Republic of the Congo and Victor Mamonekene, Institute of Rural Development, University of Marien Ngouabi, Brazzaville, Republic of the Congo, for their tireless support during field work on Lower Congo. Thanks are also due to the Laboratory of Electron Microscopy, Institute of Parasitology, Biology Centre CAS, institution supported by the MEYS CR (LM2015062 Czech-BioImaging) for their support with obtaining scientific data presented in this paper, and to Blanka Škoríková of the same 
Institute for help with the illustrations. This study was partly supported by the Czech Science Foundation (Grant. No. P505/12/
G112) and by institutional support (RVO: 60077344, Institute of Parasitology, BC CAS).

\section{REFERENCES}

Abdel-Ghaffar F., Bashar A.-R., Abdel-Gaber R., Morsy K., Mehlhorn H., Al Quraishy S., Mohammed S. 2014: Cucullanus egyptae sp. nov. (Nematoda, Cucullanidae) infecting the European eel Anguilla anguilla in Egypt. Morphological and molecular phylogenetic study. Parasitol. Res. 113: 3457-3465.

Anderson R.C., Chabaud A.G., Willmott S. (Eds.) 2009: Keys to the Nematode Parasites of Vertebrates. Archival Volume. CAB International, Wallingford, $463 \mathrm{pp}$.

BAKer M.R. 1987: Synopsis of the Nematoda Parasitic in Amphibians and Reptiles. Occasional Papers in Biology No. 11. Memorial University of Newfoundland, St. John's, 325 pp.

BAYLis H.A. 1923a: Some nematodes of the genus Cucullanus from fishes of the Nile. Ann. Mag. Nat. Hist., Ser. 9, 12: 233-236.

BAYLIS H.A. 1923b: On the classification of Ascaridae. III. A revision of the genus Dujardinia Gedoelst, with a description of a new genus of Anisakinae from a crocodile. Parasitology 15: 223-232.

BAYLIS H.A. 1928: Some parasitic worms, mainly from fishes, from Lake Tanganyika. Ann. Mag. Nat. Hist., Ser. 10, 1: 552-562.

BaYlis H.A. 1930: Mission Saharienne Augiéras-Draper, 19271928. Parasitic Nematodes. Bull. Mus. Nat. Hist. Nat., Sér. 2 , 2: $117-130$.

Boomker J. 1993: Parasites of South African freshwater fish. V. Description of two new species of the genus Spinitectus Fourment, 1883 (Nematoda: Cystidicolidae). Onderstepoort J. Vet. Res. 60: 139-145.

Boomker J. 1994: Parasites of South African freshwater fishes. VI. Nematode parasites of some fish species in the Kruger National Park. Onderstepoort J. Vet. Res. 61: 35-43.

Boomker J., Puylaert F.A. 1994: Eight new Afrotropical Spinitectus spp. (Nematoda: Cystidicolidae) from freshwater fishes with a key to the members of the genus in the region. Onderstepoort J. Vet. Res. 61: 127-142.

Campana-Rouget Y. 1961: Nématodes de poissons. Exploration Hydrobiologique des lacs Kivu, Édouard et Albert (1952-1954). Résultats Scientifiques, Bruxelles, 3: 1-61.

Chabaud A.G. 1956: Structure céphalique de Gendria tilapiae Baylis, 1930. Ann. Parasitol. Hum. Comp. 31: 310-311.

Cross J.H., Banzon T., Clarke M.D., Basaca-Servilla V., Watten R.H., Dizon J.J. 1972: Studies on the experimental transmission of Capillaria philippinensis in monkeys. Trans. Roy. Soc. Trop. Med. Hyg. 66: 819-827.

Dougnon J., Montchowui E., Daga F.D., Houessionon J., LALÉYÉ P., SAKITI N. 2012: Cutaneous and gastrointestinal helminth parasites of the fish Synodontis schall and Synodontis nigrita (Siluriformes: Mochokidae) from the lower Ouémé Valley in South Benin. Res. J. Biol. Sci. 7: 320-326.

El-Naffar M.K., Saoud M.F., Hassan I.M. 1983: A general survey of helminth parasites of some fishes of Lake Nasser at Aswan, A. R. Egypt. Assiut Vet. Med. J. 11: 141-183.

Fahmy M.A.M., Mandour A.M., El-Naffar M.K. 1976: On some nematodes parasites from the freshwater fishes in Assiut Province, Egypt. Vet. Med. J., Egypt, 24: 263-276.

Froese R., Pauly D. (Eds.) 2017: FishBase. World Wide Web electronic publication, http://www.fishbase.org, 07/2017.

Gendre E. 1926: Sur un nématode nouveau, parasite des poissons. Bull. Soc. Pathol. Exot. 19: 798-802.

Hartwich G. 2009: Ascaridida. In: R.C. Anderson, A.G. Chabaud and S. Willmott (Eds.), Key to the Nematode Parasites of Vertebrates. Archival Volume. CABI, Wallingford, pp. 309-323.

Imam E.A., El-Askalany M.A., Rashad S.M. 1991: The helminth parasites of Synodontis schall and Bagrus bayad from Beni-Suef water resources. Assiut Vet. Med. J. 24: 137-152.
INGLIS W.G. 1959: The systematic position of Nematoxys piscicola Linstow, 1907 (Nematoda). Z. Parasitenkd. 19: 100.

INGLIS W.G. 1967: The relationships of the nematode superfamily Seuratoidea. J. Helminthol. 41: 115-136.

IngLis W.G., Ogden C.G. 1965: Chabaudus chabaudi gen. et sp. nov. from a fresh-water fish in Sierra Leone (Nematoda: Seuratoidea). Rev. Zool. Bot. Afr. 71: 171-176.

Ivashí V.M., Khromova L.A. 1976: [Cucullanata of Animals and Man and the Diseases Caused by Them.] Osnovy Nematodologii, Vol. 27. Nauka, Moscow, 436 pp. (In Russian.)

Jackson J.A., Tinsley R.C., Du Preez L.H., Henderson A.C. 2001: A redescription of Chabaudus leberrei (Bain \& Philippon, 1969) (Nematoda: Seuratoidea) from Xenopus spp. in Swaziland. Syst. Parasitol. 50: 81-89.

KHALIL L.F. 1969: Studies on the helminth parasites of freshwater fishes of the Sudan. J. Zool., London, 158: 143-170.

Khalil L.F., Polling L. 1997: Check List of the Helminth Parasites of African Freshwater Fishes. Second Edition. University of the North, Pietersburg, $185 \mathrm{pp}$.

Koubková B., Baruš V., Hodová I. 2010: Nematodes of Cithariniella (Pharyngodonidae) from freshwater fishes in Senegal, with a key to species. Helminthologia 47: 105-114.

Koubková B., Baruš V., Hodová I., Šimková A. 2008: Morphometric and molecular characteristics of Labeonema synodontisi n. comb. (Nematoda: Atractidae) from the West African fishes. Parasitol. Res. 102: 1013-1020.

Lévêque C., Oberdorff T., Paugy D., Stiassny M.J.L., TeDESCO P.A. 2008: Global diversity of fish (Pisces) in freshwater. Hydrobiologia 595: 545-567.

vON Linstow O. 1907: Nematoden aus dem Königlichen Zoologischen Museum zu Berlin. Mitt. Zool. Mus. Berlin 3: 251-259.

MAšové Š. 2012: Structure of the cephalic end and eggs of female Cithariniella khalili Petter, Vassiliadès et Troncy, 1972 (Nematoda: Pharyngodonidae), a parasite of African fishes. Helminthologia 49: 115-118.

Mašová Š., Baruš V., Moravec F. 2011: New morphological data on the first-stage larvae of two Procamallanus species (Nematoda: Camallanidae) based on SEM studies. Folia Parasitol. 58: 318-321.

Mayr E. 1963: Animal Species and Evolution. The Belknap Press of Harward University Press, Cambridge, Massachusetts, 797 pp.

Moravec F. 1974a: On some nematodes from Egyptian freshwater fishes. Acta Soc. Zool. Bohemoslov. 38: 32-51.

Moravec F. 1974b: The development of Paracamallanus cyathopharynx (Baylis, 1923) (Nematoda: Camallanidae). Folia Parasitol. 21: 333-343.

Moravec F. 1979: Redescription of the nematode Spinitectus inermis parasitic in eels, Anguilla anguilla, of Europe. Acta Soc. Zool. Bohemoslov. 43: 35-42.

Moravec F. 1994: Structure of the cephalic end in the genus $\mathrm{Ci}$ thariniella Khalil, 1964 (Nematoda: Pharyngodonidae) as revealed by SEM, with a key to pharyngodonid genera from fishes. Syst. Parasitol. 27: 133-137.

MoraVEC F. 2001: Some helminth parasites from Morelet's crocodile, Crocodylus moreletii, from Yucatan, Mexico. Folia Parasitol. 48: 47-62.

Moravec F. 2013: Parasitic Nematodes of Freshwater Fishes of Europe. Revised Second Edition. Academia, Prague, $601 \mathrm{pp}$.

Moravec F., Charo-Karisa H., JirkŮ M. 2013: The morphology and systematics of Rhabdochona paski Baylis, 1928 (Nematoda: Rhabdochonidae), a widespread parasite of freshwater fishes in Africa. Syst. Parasitol. 85: 55-63.

MoraVEC F., JiRK U M. 2014a: Dujardinascaris mormyropsis n. sp. (Nematoda: Anisakidae) from the osteoglossiform fish Mormy- 
rops anguilloides (Linnaeus) (Mormyridae) in Central Africa. Syst. Parasitol. 88: 55-62.

Moravec F., JiRkŮ M. 2014b: Rhabdochona spp. (Nematoda: Rhabdochonidae) from fishes in the Central African Republic, including three new species. Folia Parasitol. 88: 55-62.

Moravec F., Jirk U M. 2015: Two Procamallanus (Spirocamallanus) species (Nematoda: Camallanidae) from freshwater fishes in the Lower Congo River. Acta Parasitol. 60: 226-233.

Moravec F., Řehulka J. 1987: First record of the cosmocercoid nematode Raillietnema synodontisi Vassiliades, 1973 from the aquarium-reared upside-down catfish Synodontis eupterus Boulenger. Folia Parasitol. 34: 163-164.

Moravec F., Scholz T. 2017: Some nematodes, including two new species, from freshwater fishes in the Sudan and Ethiopia. Folia Parasitol. 64: 010.

Moravec F., VAN As J.G. 2004: Nematodes from the squeaker fishes Synodontis nigromaculatus and $S$. vanderwaali from the Okavango River, Botswana, including three new species. Syst. Parasitol. 59: 169-187.

Moravec F., Van As L.L. 2015a: Studies on ascaridid, oxyurid and enoplid nematodes (Nematoda) from fishes of the Okavango River, Botswana. Folia Parasitol. 62: 039.

Moravec F., Van As L.L. 2015b: Studies on some spirurids (Nematoda: Spirurida) from fishes of the Okavango River, Botswana. Syst. Parasitol. 91: 119-138.

Moravec F., Van As L.L. 2015c: Procamallanus (Procamallanus) spp. (Nematoda: Camallanidae) in fishes of the Okavango River, Botswana, including the description of $P$. $(P$.) pseudolaeviconchus n. sp. parasitic in Clarias spp. (Clariidae) from Botswana and Egypt. Syst. Parasitol. 90: 137-149.

MozGovoy A.A. 1953: [Ascaridata of Animals and Man and the Diseases Caused by Them.] Osnovy Nematodologii 2. Publishing House of the Academy of Sciences of the USSR, Moscow, 616 pp. (In Russian.)

Ndew D.E., Diouf M., BÂ C.T., Morand S. 2014: A new species of Cucullanus (Nematoda: Cucullaninae, Cucullanidae) from Mugil curema (Mugilidae) in Senegal (West Africa). Comp. Parasitol. 81: 15-22.

Odening K. 1976: Conception and terminology of hosts in parasitology. Adv. Parasitol. 14: 1-93.

PAPERNA I. 1974: Hosts, distribution and pathology of infections with larvae of Eustrongylides (Dioctophymidae, Nematoda) in fishes from East African lakes. J. Fish Biol. 6: 67-76.

Petter A.-J., Vassiliadès G., Troncy P.-M. 1972: Trois espèces de poissons en Afrique. Ann. Parasitol. Hum. Comp. 47: 569579.

Puylaert F.A. 1970a: Description d'Auchmeronema thysi gen n., sp. n., parasite d'Auchenoglanis punctatus Blgr. (Pisces) et d'Auchmeronema williamsi sp. n., parasite de Petropedetes natator Blgr. (Amphibia) (Subulascarididae - Nematoda - Vermes). Rev. Zool. Bot. Afr. 81: 82-94.

Puylaert F.A. 1970b: Description de Labeonema intermedia gen. n., sp. n., parasite d'un Labeo (Pisces - Cyprinidae) (Atractidae - Nematoda - Vermes). Rev. Zool. Bot. Afr. 82: 370-376.
Řehulková E., Baruš V., Gelnar M. 2005: Two remarkable nematodes from the African reedfish Erpetoichthys calabaricus (Polypteriformes: Polypteridae). Helminthologia 42: 149-153.

Rizvi A.N., Bursey C.R., Maity P. 2016: Description of a new species of Chabaudus Inglis and Ogden, 1965 (Nematoda: Seuratoidea) from the frog Euphlyctis cyanophlyctis from Dehrandun, Uttarakhand, India. Acta Parasitol. 61: 79-83.

Rodhain J., Vuylsteke C. 1934: Cystidicola minuta n. sp. ver parasite de Barbus eutaenia, au Katanga. Rev. Zool. Bot. Afr. 24: $406-409$.

Schuurmans Stekhoven J.H. 1937: Parasitic Nematoda. Exploration du Parc National Albert. Mission G.F. de Witte (19331935). Bruxelles. 4: 3-40.

Sood M.L. 1989: Fish Nematodes from South Asia. Kalyani Publishers, New Delhi-Ludhiana, 703 pp.

Sood M.L. 1990: Amphibian Nematodes from South Asia. Indira Publ. House, Michigan, 138 pp.

SpRENT J.F.A. 1977: Ascaridoid nematodes of amphibians and reptiles: Dujardinascaris. J. Helminthol. 51: 251-285.

Sprent J.F.A. 1990: Some ascaridoid nematodes of fishes: Heterocheilinae. Syst. Parasitol. 16: 149-161.

TAYLOR E.L. 1925: Notes on some nematodes in the Museum of the Liverpool School of Tropical Medicine. II. Ann. Trop. Med. Parasitol. 19: 557-569.

Troncy P.-M. 1969: Description de deux nouvelles espèces de nématodes parasites de poissons. Bull. Mus. Nat. Hist. Nat., Sér. 2, 41: 598-605.

Van Waerebeke D., Chabaud A.G., Bain O., Georges A.-J. 1988: Deux nouveaux nématodes parasites de poissons de l'Oubangui. Bull. Mus. Natn. Hist. Nat., Paris, Sér. 4, sect. A, 10: 519-527.

VASSILIADÈs G. 1971: Redescription de Quimperia lanceolata Gendre, 1926 (Nematoda, Seuratoidea). Ann. Parasitol. Hum. Comp. 46: 61-67.

VAssiliadès G. 1972: Nématodes parasites des poissons de la région de Sangalkam (Sénégal). Bull. Inst. Fond. Afr. Noire, Sér. A, 34: 529-533.

VAssilladès G. 1973: Un nouveau Raillietnema (Nematoda; Cosmocercoidea) parasite de poisson, au Sénégal. Bull. Inst. Fondam. Afr. Noire, Sér. A, 35: 815-821.

VAssiliadès G. 1976: Nématodes parasites des poissons d'eau douce de la République du Sénégal. Bull. Inst. Fond. Afr. Noire, Sér. A, 37 (Year 1975): 605-618.

Vassiliadès G., Chevalier J.L. 1973: Un nouveau Gendria (Nematoda; Seuratoidea) chez un polyptère (poisson) du Sénégal. Bull. Inst. Fond. Afr. Noire 35: 92-98.

Vassiliadès G., Troncy P.-M. 1974: Nématodes parasites des poissons du bassin tchadien. Bull. Inst. Fond. Afr. Noire, Sér. A, 36: 670-681.

Youssef F.G., Mikhail E.M., Mansour N.S. 1989: Intestinal capillariasis in Egypt: a case report. Am. J. Trop. Med. Hyg. 40: 195-196. 